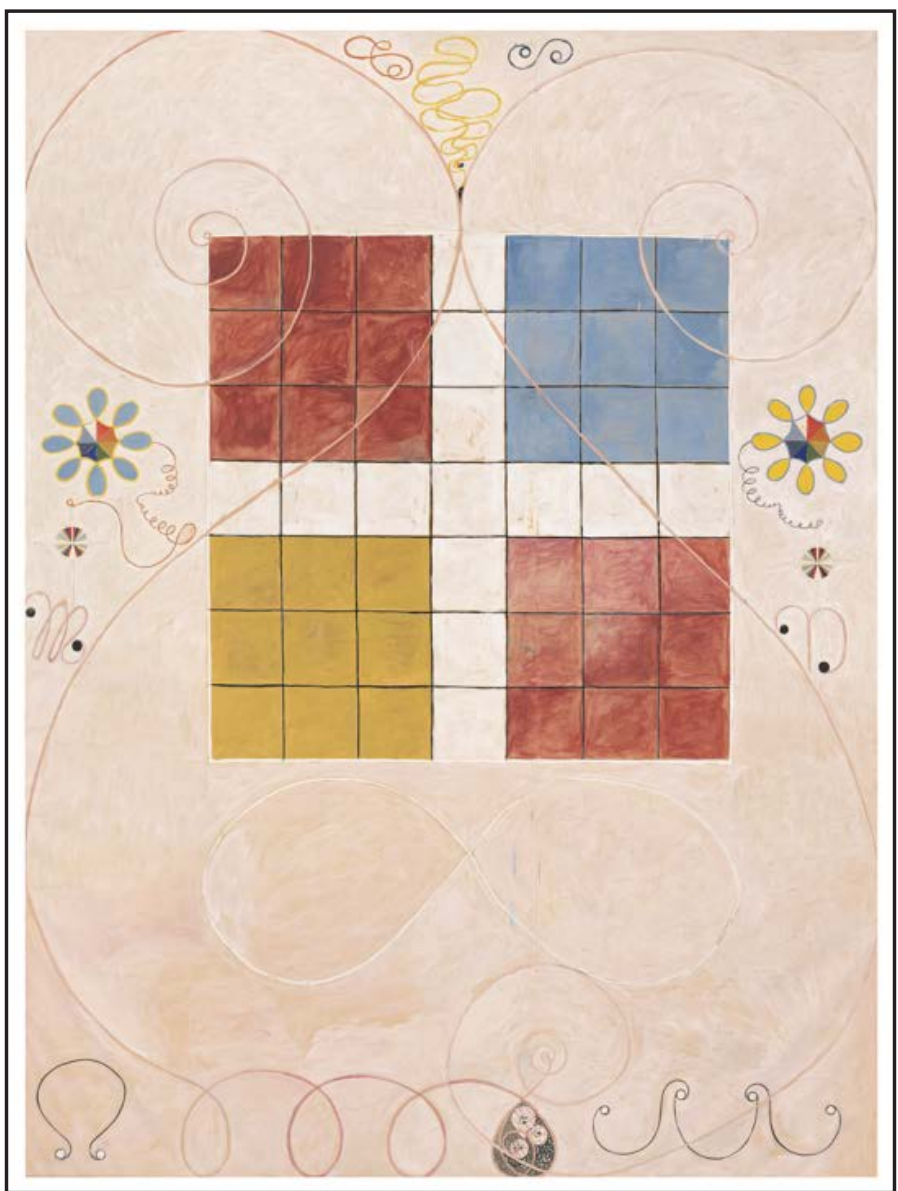

The Importance of Demographic and Geographical Factors on the Incidence and Outcome of Systemic Small Vessel Vasculitis Associated with Anti-Neutrophil Cytoplasmic Antibodies

Maria Weiner

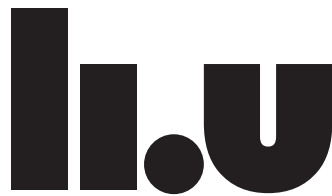

LINKÖPING

UNIVERSITY 
Linköping University Medical Dissertations No. 1701

\title{
The Importance of Demographic and Geographical Factors on the Incidence and Outcome of Systemic Small Vessel Vasculitis Associated with Anti-Neutrophil Cytoplasmic Antibodies
}

\author{
Maria Weiner
}

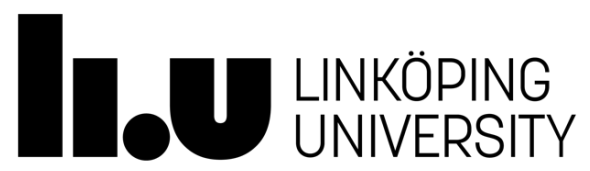

Department of Nephrology and

Department of Medical and Health Sciences

Linköping University, Sweden

Linköping 2019 
(c)Maria Weiner, 2019

Cover: Hilma af Klint, De tio största, nr 10 Ålderdomen.

Reprinted with the permission of the owner Stiftelsen Hilma af Klints Verk.

Published articles have been reprinted with the permission of the copyright holders Oxford University Press (Papers I and II), American Society of Nephrology (Paper III) and The Journal of Rheumatology Publishing Co. Ltd. (Paper IV).

Printed in Sweden by LiU-Tryck, Linköping, Sweden, 2019

ISBN 978-91-7685-000-8

ISSN $0345-0082$ 
Till Signe och Astrid

Solskensöga ser på dig, solskensfamn dig vaggar

- Ur Videvisan, Zacharias Topelius 1869 



\section{TABLE OF CONTENTS}

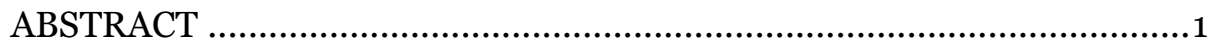

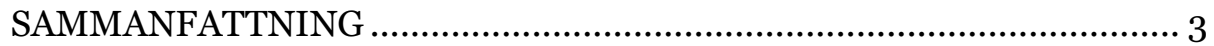

LIST OF PAPERS ………………….................................................. 5

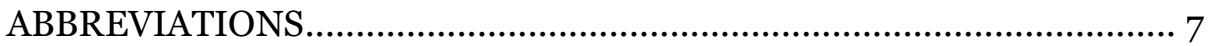

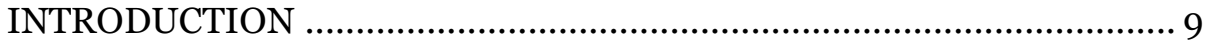

Definitions, diagnosis and classification ............................................ 10

American College of Rheumatology classification criteria ................ 10

Chapel Hill Consensus Conference nomenclature ............................... 11

European Medicines Agency algorithm ...........................................12

Future developments ......................................................................14

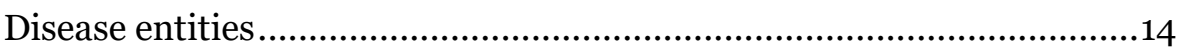

Granulomatosis with polyangiitis .....................................................14

Microscopic polyangiitis.................................................................14

Eosinophilic granulomatosis with polyangiitis..................................15

Anti-neutrophil cytoplasmic antibodies ...............................................15

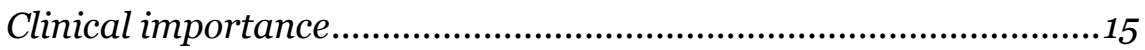

Pathogenic importance …..............................................................16

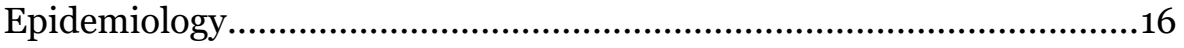

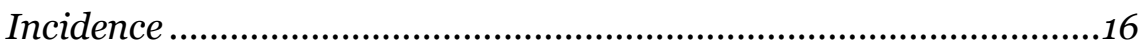

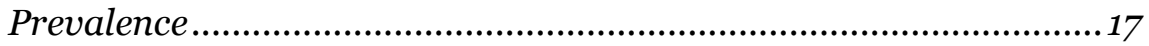

Geographical differences ..................................................................19

Seasonal differences......................................................................19

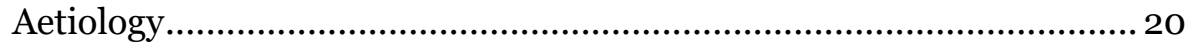

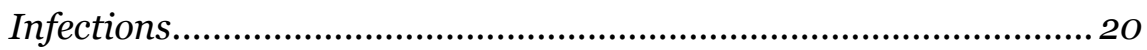

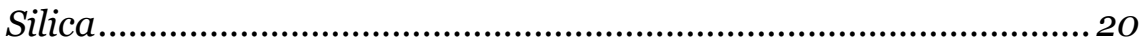

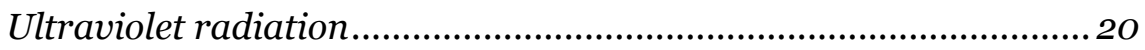

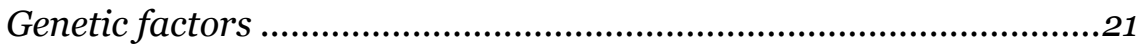

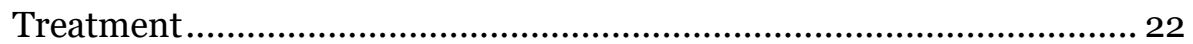

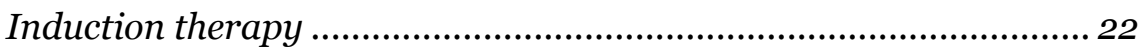

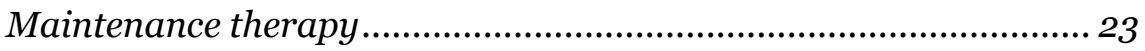

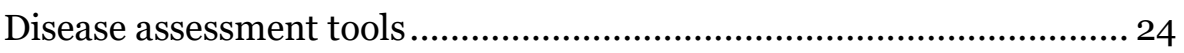

Birmingham Vasculitis Activity Score ............................................... 24

Vasculitis Damage Index ............................................................... 25 


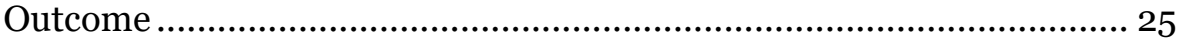

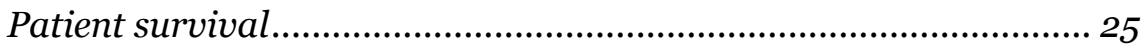

Causes of death ................................................................................ 26

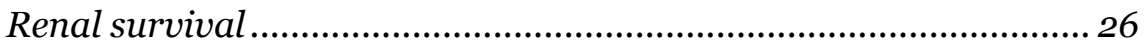

Permanent organ damage ................................................................ 27

Remission and relapse ................................................................. 27

ANCA-associated vasculitis in older patients ....................................... 28

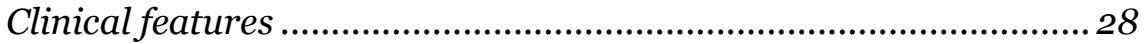

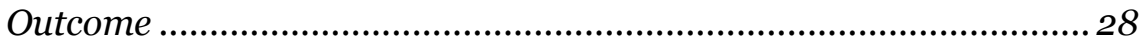

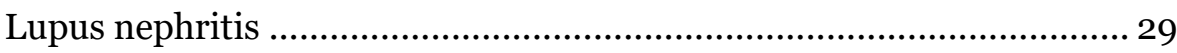

Epidemiology …............................................................................... 29

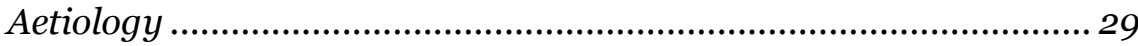

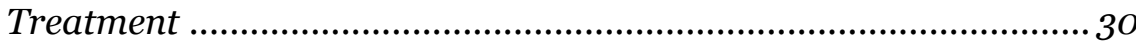

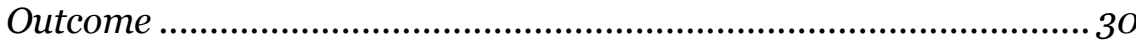

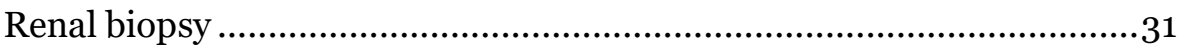

ANCA-associated glomerulonephritis .................................................31

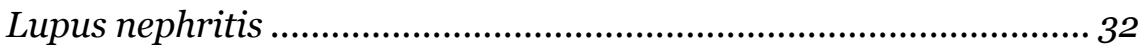

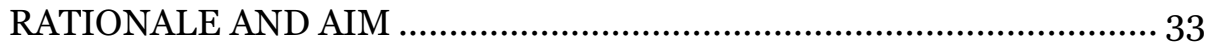

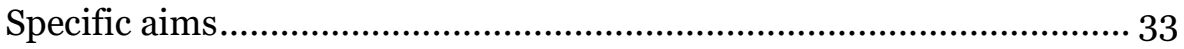

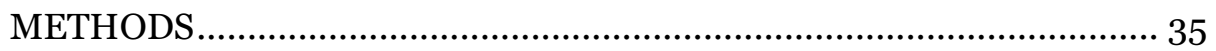

Study population and patient retrieval.................................................. 35

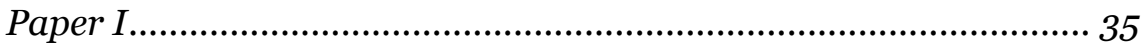

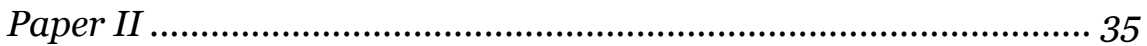

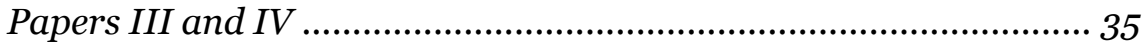

The vasculitis and SLE registries in Östergötland and Skåne........... 36

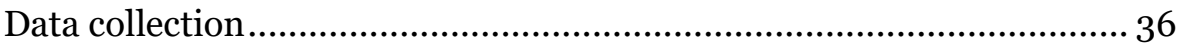

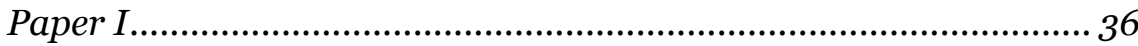

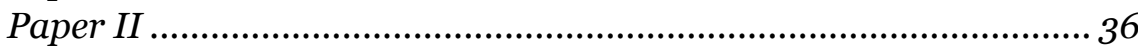

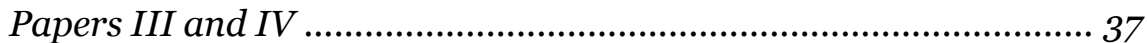

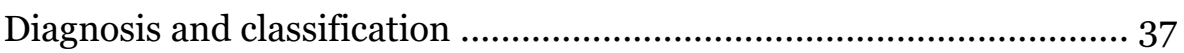

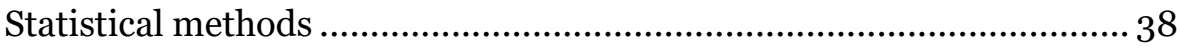

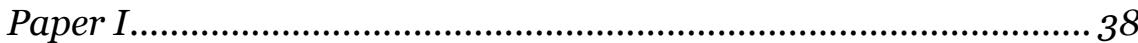

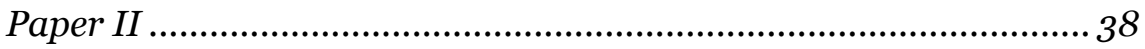

Paper III ..................................................................................... 39

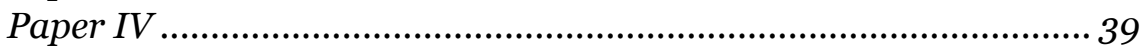

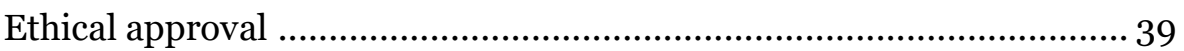


RESULTS AND DISCUSSION ….........................................................

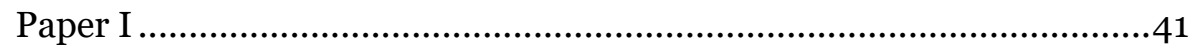

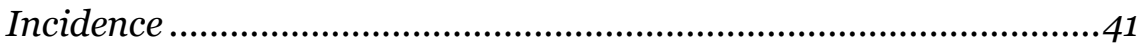

Survival ...................................................................................... 42

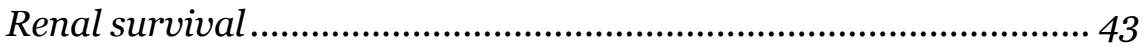

Paper II....................................................................................... 44

Geographical pattern ........................................................................ 44

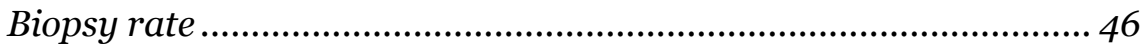

Paper III …................................................................................. 47

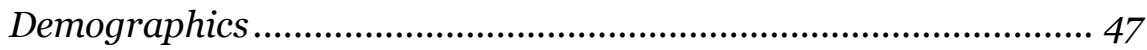

Treatment …................................................................................ 48

Survival ...................................................................................... 49

Standardized mortality ratio................................................................ 50

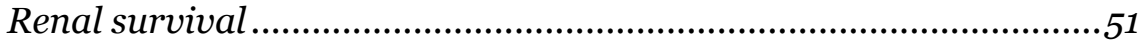

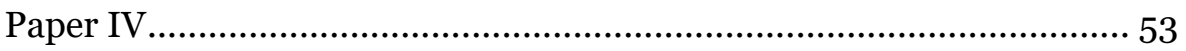

Treatment …......................................................................................... 53

Damage ..................................................................................... 53

Hospitalization .................................................................................. 55

Cause of death ...............................................................................57

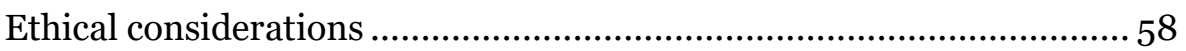

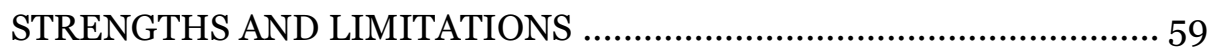

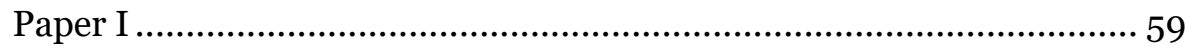

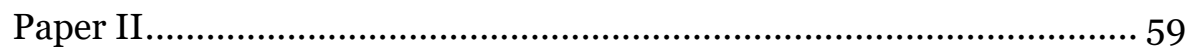

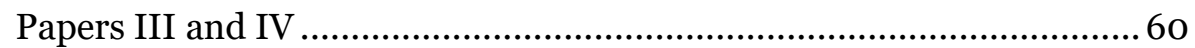

CONCLUSIONS AND FUTURE PERSPECTIVES ...................................61

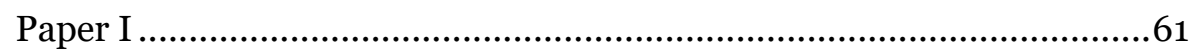

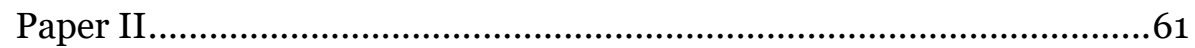

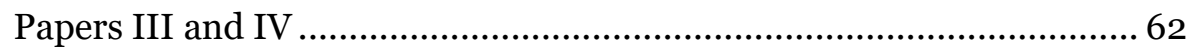

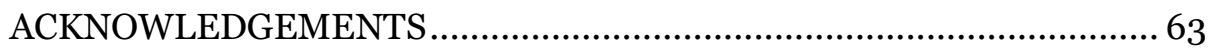

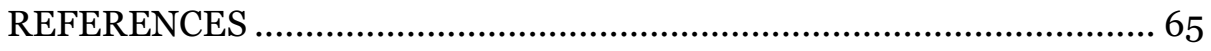


Incidence and Outcome of ANCA-Associated Vasculitis 


\section{ABSTRACT}

The anti-neutrophil cytoplasmic antibody (ANCA)-associated vasculitides (AAV) comprise microscopic polyangiitis (MPA), granulomatosis with polyangiitis (GPA) and eosinophilic granulomatosis with polyangiitis (EGPA). Two serotypes are recognized: myeloperoxidase (MPO)-ANCA and proteinase 3 (PR3)-ANCA. Renal involvement is a common and severe manifestation associated with increased mortality. The incidence varies geographically, but studies are difficult to compare due to heterogeneous methodology and inclusion criteria. AAV is commonly found in the elderly, but there are little data on outcome and optimal treatment in the highest age groups. This thesis focuses on the epidemiology of AAV: incidence, geographical distribution, and outcome.

In Paper I annual incidence rates and outcome were compared between nephritis in AAV and nephritis in systemic lupus erythematosus (SLE) in two geographically defined populations in Sweden. Even though SLE is twice as common as AAV, ANCA-associated nephritis outnumbered lupus nephritis by three to one, and was significantly more severe in terms of mortality and development of end stage renal disease.

In Paper II associations between ANCA serotype and geographical and demographic factors were investigated in a large multi-centre study of 1408 patients with renal biopsyproven AAV. PR3-ANCA was associated with male gender, younger age and higher glomerular filtration rate. PR3-ANCA was also associated with higher latitude and lower ultraviolet radiation levels, but analyses of subgroups suggested that genetic rather than environmental explanations might be more important for this geographical gradient.

In Paper III a consecutive cohort of 151 elderly patients with MPA and GPA was studied with a focus on treatment, mortality and renal survival. Patients who had received immunosuppressive treatment with cyclophosphamide or rituximab had better survival rates compared to less intensively treated or untreated patients. Severely impaired renal function at diagnosis was associated with worse outcome in terms of both patient and renal survival.

In Paper IV the elderly cohort was extended to 202 patients. In this study we found that treatment with cyclophosphamide or rituximab was associated with the development of less permanent organ damage, and not with higher utilization of in-hospital care. However, high doses of glucocorticoids were associated with fatal infections and treatment-related damage. 
Incidence and Outcome of ANCA-Associated Vasculitis 


\section{SAMMANFATTNING}

I denna avhandling har vi studerat en grupp sjukdomar som kallas för ANCA-vaskulit. 'Vaskulit' betyder inflammation i blodkärl och ANCA är en förkortning för en speciell typ av antikropp som är typisk vid dessa sjukdomar. Det finns två sorters antikroppar: PR3-ANCA och MPO-ANCA. ANCA-vaskulit är en autoimmun sjukdom där immunförsvaret riktas mot den egna kroppen; i det här fallet angrips små blodkärl vilket leder till att i stort sett alla kroppens organ kan drabbas. Njurarna är ett av de organ som innehåller flest små blodkärl och ett av de vanligaste symptomen är inflammation i njurarna.

Delarbete I: SLE och ANCA-vaskulit är två olika autoimmuna sjukdomar som kan drabba i stort sett alla organ i kroppen men där njurinflammation är en speciellt fruktad komplikation. Trots att SLE är en dubbelt så vanlig sjukdom fann vi att ANCA-vaskulit med njurinflammation var tre gånger vanligare än SLE med njurinflammation och att risken att dö eller hamna i dialys var betydligt högre. Resultaten är viktiga eftersom SLE är en mer välkänd sjukdom som ofta upptäcks i ett tidigare stadium än ANCA-vaskulit. Med denna studie hoppas vi kunna öka uppmärksamheten kring ANCA-vaskulit så att den kan upptäckas och behandlas tidigare.

Delarbete II: Det är inte klarlagt hur stor betydelse arv respektive miljö har för uppkomsten av ANCA-vaskulit. I denna studie jämförde vi förekomsten av de två ANCAtyperna på flera platser i Europa och USA och fann att PR3-ANCA var vanligare längre norrut där UV-strålningen är lägre. När vi analyserade norra och centrala Europa separat såg vi dock inget sådant samband. Detta skulle kunna tala för att genetiskt arv spelar större roll än omgivningsfaktorer för ANCA-typ eftersom skillnaderna i UV-strålning var stor mellan de platser vi analyserade, medan de genetiska skillnaderna sannolikt inte är så stora i norra och centrala Europa som mellan norra och södra Europa.

Delarbete III: ANCA-vaskulit drabbar främst äldre patienter, men trots det har få patienter över 75 år deltagit i de läkemedelsstudier som dagens behandlingsrekommendationer grundar sig på. I denna studie fann vi att dödligheten hos patienter över 75 år med ANCA-vaskulit var nästan fyra gånger högre jämfört med personer i samma ålder i Sverige. Viktigt var också att vi fann att de patienter som fått behandling med kraftigt immundämpande läkemedel enligt riktlinjer utarbetade för en yngre population hade bättre överlevnad än de som fick mindre behandling eller ingen behandling alls.

Delarbete IV: En fråga som väcktes av resultaten i delarbete III var om den högre överlevnaden hos behandlade skedde till priset av komplikationer med kroniska skador och större behov av sjukhusvård. Tvärt emot vad man kanske kunde väntat sig fann vi att de äldre patienter som fått ordentlig behandling utvecklade mindre kroniska skador och att de inte hade längre vårdtider eller fler återinläggningar på sjukhus. Vi fann dock ett samband mellan höga kortisondoser och risken för dödliga infektioner och biverkningar som benskörhet och diabetes. 
Incidence and Outcome of ANCA-Associated Vasculitis 


\section{LIST OF PAPERS}

\section{Paper I}

Incidence and disease severity of anti-neutrophil cytoplasmic antibody-associated nephritis are higher than in lupus nephritis in Sweden. Mohammad A, Weiner M, Sjöwall C, Johansson M, Bengtsson A, Ståhl-Hallengren C, Nived O, Eriksson P, Sturfelt G, Segelmark M. Nephrol Dial Transplant 2015; 30:i23-30.

\section{Paper II}

Proteinase-3 and myeloperoxidase serotype in relation to demographic factors and geographic distribution in anti-neutrophil cytoplasmic antibody-associated glomerulonephritis. Weiner $\mathrm{M}$, Bjørneklett R, Hrušková Z, Mackinnon B, Poulton CJ, Sindelar L, Mohammad AJ, Eriksson P, Gesualdo L, Geetha D, Crnogorac M, Jayne D, Hogan SL, Geddes C, Tesar V, Aasarød K, Segelmark M. Nephrol Dial Transplant 2019; 34:301-308.

\section{Paper III}

Outcome and Treatment of Elderly Patients with ANCA-Associated Vasculitis. Weiner M, Goh S, Mohammad A, Hruskova Z, Tanna A, Bruchfeld, A, Selga D, Chocova Z, Westman K, Eriksson P, Pusey C, Tesar V, Salama A, Segelmark M. Clin J Am Soc Nephrol 2015; 10:112835 .

\section{Paper IV}

Impact of treatment on damage and hospitalization in elderly patients with microscopic polyangiitis and granulomatosis with polyangiitis. Weiner M, Goh SM, Mohammad AJ, Hrušková Z, Tanna A, Sharp P, Kang A, Bruchfeld A, Selga D, Chocová Z, Westman K, Eriksson P, Harper L, Pusey CD, Tesaŕ V, Salama AD, Segelmark M. J Rheumatol 2019, doi: 10.3899/jrheum.190019. [Epub ahead of print] 
Incidence and Outcome of ANCA-Associated Vasculitis 


\title{
ABBREVIATIONS
}

\author{
AAN ANCA-associated nephritis \\ AAV ANCA-associated vasculitis \\ ACR American College of Rheumatology \\ ANA anti-nuclear antibody \\ ANCA anti-neutrophil cytoplasmic antibody \\ Anti-GBM anti-glomerular basement membrane \\ AZA azathioprine \\ BPI bactericidal/permeability-increasing protein \\ BVAS Birmingham Vasculitis Activity Score \\ C-ANCA cytoplasmic ANCA \\ CHCC Chapel Hill Consensus Conference \\ CI confidence interval \\ CRP C-reactive protein \\ CSS Churg-Strauss syndrome \\ CYC cyclophosphamide
}

DCVAS diagnostic and classification criteria in vasculitis

eGFR estimated glomerular filtration rate

EGPA eosinophilic granulomatosis with polyangiitis

ELISA enzyme-linked immunosorbent assay

EMA European Medicines Agency

ENT ear-nose-throat

ESR erythrocyte sedimentation rate

ESRD end stage renal disease

EUVAS European Vasculitis Society

GC glucocorticoids

GDCN Glomerular Disease Collaborative Network

GPA granulomatosis with polyangiitis

GWAS genome-wide association study 


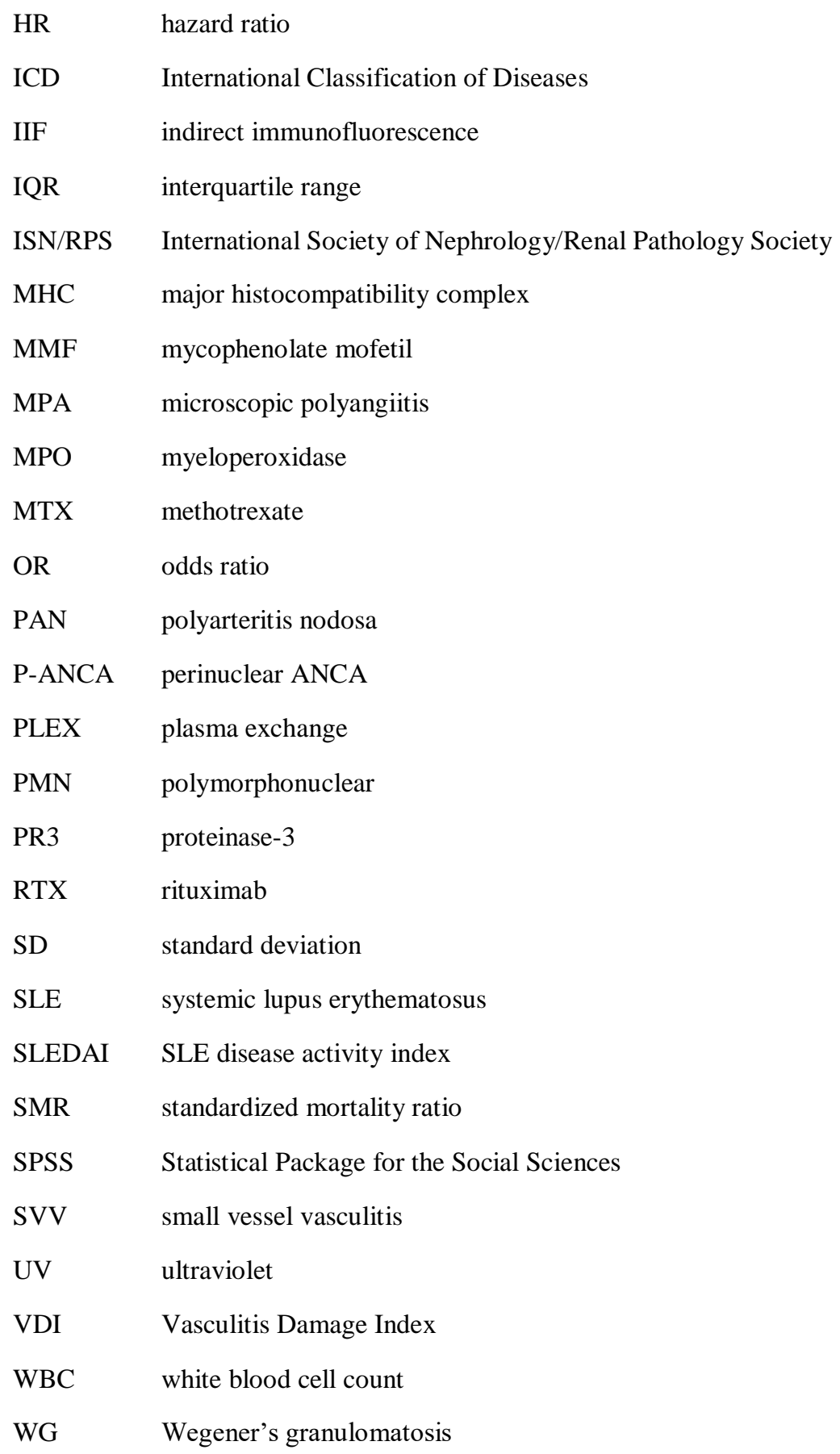




\section{INTRODUCTION}

The word 'vasculitis' means inflammation of blood vessels, but it is also the common term for a group of inflammatory diseases with vascular inflammation as a defining feature. Vasculitis can be caused by an underlying infectious, rheumatic or malignant disease, and is then referred to as secondary vasculitis. If there is no known underlying disease, the vasculitis is referred to as primary.

The primary vasculitides are categorized based on the size of the predominant vessels involved: large vessel vasculitis, medium vessel vasculitis and small vessel vasculitis [1], as shown in Figure 1. The small vessel vasculitides (SVV) are further divided into those associated with deposition of immune complexes in the vessel walls, and those without such depositions, called pauci-immune.

This thesis focuses on the pauci-immune SVV, or the preferred name anti-neutrophil cytoplasmic antibody (ANCA)-associated vasculitis (AAV). These are histologically characterized by necrotizing inflammation of vessel walls with few or no immune deposits, and associated with the presence of ANCA in the circulation. The AAV group is further divided into three different disease entities: microscopic polyangiitis (MPA), granulomatosis with polyangiitis (GPA, previously Wegener's granulomatosis) and eosinophilic granulomatosis with polyangiitis (EGPA, previously Churg-Strauss syndrome) [1].

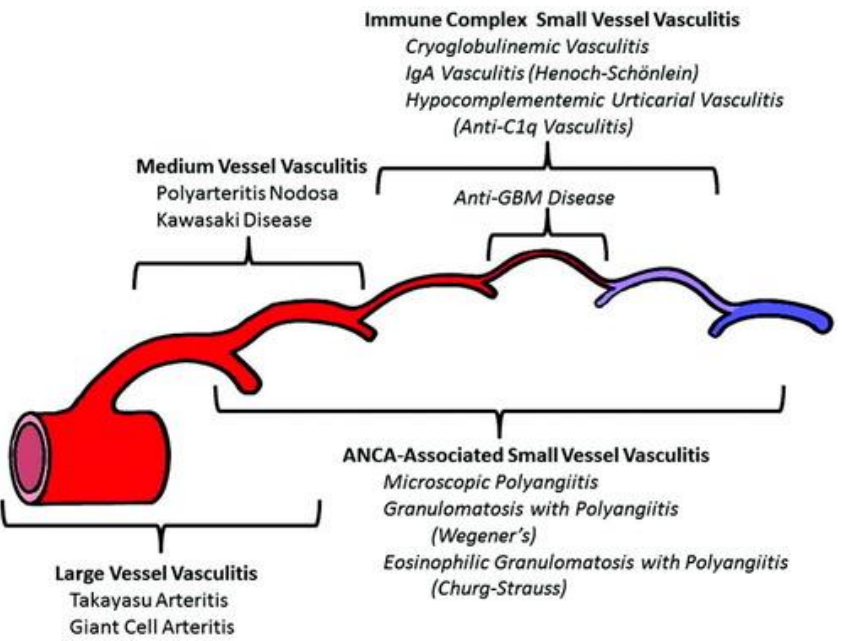

\section{Figure 1. Vessel involvement}

Reproduced from Jennette et al. [1] with permission from John Wiley \& Sons. 


\section{Definitions, diagnosis and classification}

The different vasculitides vary in underlying pathogenesis, clinical presentation and outcome. However, they also share overlapping findings and within one disease entity, presentation may vary. This makes diagnosis challenging. There is no single test that can demonstrate that a patient has vasculitis, thereby giving rise to a need for diagnostic and classification criteria. There is an important distinction between classification criteria that are used to group patients in a reproducible way for research purposes, and diagnostic criteria that are used to help clinicians to correctly diagnose individual patients and guide clinical management and treatment. Nomenclature systems are also described below. Such systems specify the name that should be used for a defined disease process, and are neither classification, nor diagnostic criteria.

\section{American College of Rheumatology classification criteria}

In 1990, the American College of Rheumatology (ACR) published classification criteria for seven vasculitis diseases: polyarteritis nodosa (PAN), Churg-Strauss syndrome (CSS), Wegener's granulomatosis (WG), hypersensitivity vasculitis, Henoch-Schönlein purpura, giant cell arteritis and Takayasu arteritis. The criteria were developed by comparing patients who had the particular vasculitis with the remaining vasculitis patients [2-9].

The ACR criteria were developed to help distinguish different vasculitis types from others for use in clinical studies, and to allow for comparisons between studies. The ACR criteria were not intended to be used for diagnosing vasculitis in individual patients, and have been shown to function poorly for this purpose [10]. The ACR criteria for WG and CSS are shown in Tables 1 and 2 , respectively.

\section{Table 1. ACR criteria for WG}

\begin{tabular}{ll}
\hline Criterion & Definition \\
\hline Nasal or oral inflammation & Development of oral ulcers or purulent/bloody nasal discharge. \\
\hline Abnormal chest radiograph & $\begin{array}{l}\text { Chest radiograph showing the presence of nodules, fixed } \\
\text { infiltrates, or cavities. }\end{array}$ \\
\hline Urinary sediment & Microhematuria or red cell casts in urine sediment. \\
\hline $\begin{array}{l}\text { Granulomatous inflammation } \\
\text { on biopsy }\end{array}$ & $\begin{array}{l}\text { Histologic changes showing granulomatous inflammation within } \\
\text { the wall of an artery or in the perivascular or extravascular area } \\
\text { (artery or arteriole). }\end{array}$ \\
\hline
\end{tabular}

At least 2 of 4 criteria need to be present to classify a patient as having WG. Adapted from Leavitt et al. [3] 


\section{Table 2. ACR criteria for CSS}

\begin{tabular}{ll}
\hline Criterion & Definition \\
\hline Asthma & History of wheezing or diffuse high-pitched rales on expiration. \\
\hline Eosinophilia & Eosinophilia $>10 \%$ on white blood cell differential count. \\
\hline $\begin{array}{l}\text { Mononeuropathy or } \\
\text { polyneuropathy }\end{array}$ & $\begin{array}{l}\text { Development of mononeuropathy, multiple mononeuropathies, or } \\
\text { polyneuropathy attributable to a systemic vasculitis. }\end{array}$ \\
\hline $\begin{array}{l}\text { Pulmonary infiltrates, } \\
\text { non-fixed }\end{array}$ & $\begin{array}{l}\text { Migratory or transitory pulmonary infiltrates on radiographs } \\
\text { attributable to a systemic vasculitis. }\end{array}$ \\
\hline $\begin{array}{l}\text { Paranasal sinus } \\
\text { abnormality }\end{array}$ & $\begin{array}{l}\text { History of acute or chronic paranasal sinus pain or tenderness or } \\
\text { radiographic opacification of the paranasal sinuses. }\end{array}$ \\
\hline $\begin{array}{l}\text { Extravascular } \\
\text { eosinophils }\end{array}$ & $\begin{array}{l}\text { Biopsy including artery, arteriole, or venule, showing accumulations of } \\
\text { eosinophils in extravascular areas. }\end{array}$ \\
\hline
\end{tabular}

At least 4 of 6 criteria need to be present to classify a patient as having CSS. Adapted from Masi et al. [8]

\section{Chapel Hill Consensus Conference nomenclature}

The first International Chapel Hill Consensus Conference (CHCC) nomenclature was published in 1994. The aim of the conference was to reach a consensus on the names and definitions of the vasculitides [11]. The CHCC is a nomenclature system, and it does not provide classification or diagnostic criteria. Importantly, even though the definitions might include histopathologic terms, this does not imply that the diagnosis can only be made if a biopsy has been carried out.

One of the most important proposals in the original document was the separation between microscopic and classical polyarteritis, which had previously been grouped together. According to the CHCC, classical PAN is a disease of medium-sized and small arteries, and glomerulonephritis is not a feature of PAN. Microscopic polyarteritis, or the preferred name microscopic polyangiitis, is on the contrary defined by necrotizing vasculitis in small vessels (capillaries, venules, arterioles) and glomerulonephritis is commonly seen.

In 2012 the nomenclature was revised with changes of names and definitions and addition of categories that were not included in the original consensus document. An important change in the revised version was that the SVV group now was divided into two categories: AAV and immune complex associated SVV. This reflected the increased recognition that ANCA are of pathogenic importance in AAV. Also, in line with advances in the understanding of the aetiology and pathogenesis of vasculitis, names of several diseases were changed in an attempt to move away from eponyms and instead towards names reflecting aetiopathogenesis. Hence, the eponyms Wegener's granulomatosis, Churg-Strauss syndrome, and Henoch-Schönlein purpura were replaced by GPA, EGPA and IgA-vasculitis, respectively [1]. Table 3 shows definitions of the AAV according to the CHCC. 


\section{Table 3. Definitions of AAV according to the CHCC}

\begin{tabular}{ll}
\hline Name & Definition \\
\hline $\begin{array}{l}\text { Granulomatosis with } \\
\text { polyangïtis (GPA) }\end{array}$ & $\begin{array}{l}\text { Necrotizing granulomatous inflammation usually involving the upper } \\
\text { and lower respiratory tract, and necrotizing vasculitis affecting } \\
\text { predominantly small to medium vessels. Necrotizing glomerulonephritis } \\
\text { is common. }\end{array}$ \\
\hline $\begin{array}{l}\text { Microscopic } \\
\text { polyangiitis (MPA) }\end{array}$ & $\begin{array}{l}\text { Necrotizing vasculitis, with few or no immune deposits, predominantly } \\
\text { affecting small vessels. Necrotizing arteritis involving small and medium } \\
\text { arteries may be present. Necrotizing glomerulonephritis is very } \\
\text { common. Pulmonary capillaritis often occurs. Granulomatous } \\
\text { inflammation is absent. }\end{array}$ \\
\hline $\begin{array}{l}\text { Eosinophilic } \\
\text { granulomatosis with } \\
\text { polyangüitis (EGPA) }\end{array}$ & $\begin{array}{l}\text { Eosinophil-rich and necrotizing granulomatous inflammation often } \\
\text { involving the respiratory tract, and necrotizing vasculitis predominantly } \\
\text { affecting small to medium vessels, and associated with asthma and } \\
\text { eosinophilia. }\end{array}$ \\
\hline
\end{tabular}

Adapted from Jennette et al. [1]

\section{European Medicines Agency algorithm}

The ACR criteria and the CHCC definitions are widely used in epidemiological research to classify patients. However, limitations in their use include that there are no ACR criteria for MPA and that the CHCC nomenclature was not intended to be used as classification criteria. In addition, neither ACR nor the original CHCC nomenclature included ANCA in their respective classification criteria and definitions.

The European Medicines Agency (EMA) algorithm was developed as a consensus on how to use the available CHCC definitions and ACR classification criteria for PAN and AAV in epidemiological studies to facilitate comparisons between different studies without confounding by classification [12]. In this algorithm, the ACR criteria for CSS [8] and WG [3], the Lanham criteria for CSS [13] and the CHCC definitions [11] are used in a stepwise, hierarchic manner, to enable each patient to be classified into one single category with a minimum of unclassified patients. Surrogate markers for GPA and renal vasculitis and ANCA are incorporated into the algorithm in addition to the existing criteria/definitions. Before applying the algorithm for classification, the patients must have a clinical diagnosis of AAV or PAN and the following criteria must be met: clinical features compatible or characteristic for AAV or PAN; objective diagnostic measures supporting diagnosis (histopathology, ANCA serology, investigations strongly suggesting vasculitis/granuloma); no other diagnosis more likely to account for the signs/symptoms. Figure 2 shows the EMA classification algorithm and surrogate markers for GPA and renal vasculitis.

The initial validation showed good agreement between the classification algorithm and the clinical diagnosis, and it has since also been evaluated in Chinese and Turkish populations [14, 15]. The changes introduced in the 2012 revised $\mathrm{CHCC}$ nomenclature was shown not to affect the performance of the algorithm [16]. 


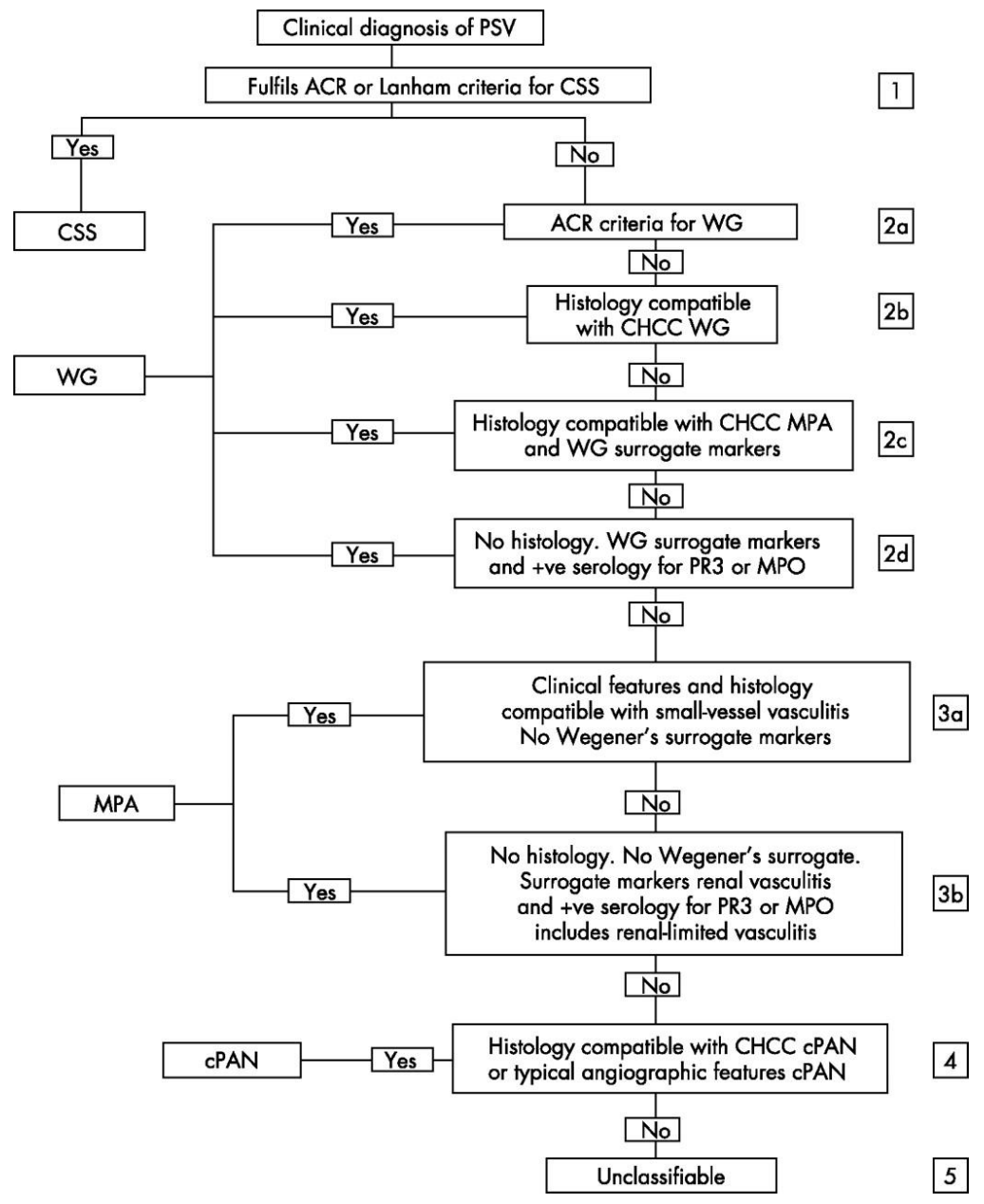

\section{Surrogate markers for GPA}

- X-ray evidence of fixed pulmonary infiltrates/nodules/cavitations present for $>1$ month

- Bloody nasal discharge and crusting for $>\mathbf{1}$ month, or nasal ulceration

- $\quad$ Chronic sinusitis, otitis media or mastoiditis for $>3$ months

- Retro-orbital mass or inflammation

- Saddle nose deformity/destructive sinonasal disease

- Bronchial stenosis

- Subglottic stenosis
Surrogate markers for renal vasculitis

- $\quad$ Red cell casts or $>10 \%$ dysmorphic erythrocytes

- $2+$ hematuria and 2+ proteinuria on urinalysis

\section{Figure 2. EMA classification algorithm and surrogate markers}

Reproduced from Watts et al. [12] with permission from BMJ Publishing Group Ltd. 


\section{Future developments}

There are no validated diagnostic criteria for vasculitis, and as described above, the currently available classification criteria are imperfect. This is the rationale behind the diagnosis and classification of vasculitis study (DCVAS), a multinational, observational study that aims to develop diagnostic criteria and update and validate classification criteria in vasculitis [17].

\section{Disease entities}

\section{Granulomatosis with polyangiitis}

Characteristic for GPA is granulomatous inflammation of the upper and lower respiratory tract in combination with necrotizing small vessel vasculitis [1]. The type of ANCA usually associated with GPA is proteinase 3 (PR3)-ANCA [18], but 10-15\% in Europe have myeloperoxidase (MPO)-ANCA [19-21].

The most typical manifestation is involvement of the ear-nose-throat (ENT) region with symptoms like epistaxis, nasal crusting, sinusitis, otitis media, and chronic changes including saddle nose deformity and subglottic stenosis. Involvement of the lower respiratory tract with lung nodules and alveolar haemorrhage is seen in 50-90\% [22]. Renal disease is also common and associated with worse prognosis [23, 24]. Gastrointestinal manifestations have been reported in $5-10 \%$ of patients and cardiac involvement such as heart failure, pericarditis and valvular heart disease in 10-20\% [24-26]. In a study by Mahr et al., patients with gastrointestinal and cardiac involvement had the worst prognosis in a cohort of patients with both MPA and GPA [27].

In the majority of cases GPA is a systemic disease, but a persistent localized disease of the respiratory tract with no signs of systemic involvement has been described in $5 \%$ of patients with GPA. In these cases ANCA positivity is seen in about half of patients, long-term survival is good, but permanent damage such as septal perforation and saddle nose deformity is common [28].

\section{Microscopic polyangiitis}

In MPA, the defining feature is necrotizing vasculitis of small vessels, while granulomatous inflammation is not present [1]. Most patients with MPA are MPO-ANCA positive at diagnosis [18], but $15-30 \%$ are PR3-ANCA positive [19-21] and a small number of patients are ANCA negative [29].

The most common manifestation is glomerulonephritis, present in about $90 \%$ and sometimes being the only manifestation of the disease [30]. Lung involvement with pulmonary capillaritis occurs, in the most severe cases in the form of massive lung bleedings. MPA is also associated with pulmonary fibrosis [31]. Skin manifestations and involvement of peripheral nerves have 
been reported in up to $60 \%$ of patients [32]. Patients with MPA are often older compared to patients with GPA, and mortality rates are higher [19, 33].

\section{Eosinophilic granulomatosis with polyangiitis}

In EGPA, asthma, eosinophilia and granulomatous inflammation are the characteristic findings [1]. Although the majority of patients are ANCA negative, EGPA is classified as an AAV and MPO-ANCA is seen in $30-40 \%$ of patients $[34,35]$.

Cardiac, skin and gastrointestinal manifestations, and involvement of the peripheral nervous system are common [36]. Due to its differing clinical presentation and outcome, EGPA is often studied separately from GPA and MPA.

\section{Anti-neutrophil cytoplasmic antibodies}

Anti-neutrophil cytoplasmic antibodies (ANCA) are autoantibodies reacting with proteins that are predominantly expressed in the cytoplasmic granules of polymorphonuclear neutrophil granulocytes (PMNs) and lysosomes of monocytes. With indirect immunofluorescence (IIF), two main patterns are recognized: perinuclear ANCA (P-ANCA) and cytoplasmic ANCA (CANCA) [37]. Today, the use of antigen-specific immunoassays such as enzyme-linked immunosorbent assay (ELISA) is preferred to increase specificity [18]. In recent years, novel automated techniques have been introduced, and assays have developed with second generation capture ELISA and third generation anchor ELISA [18, 38].

The ANCA associated with AAV have two main antigens, myeloperoxidase (MPO) [39] and proteinase-3 (PR3) [40], which are both expressed in the granules of PMNs and monocytes. Autoantibodies against MPO are referred to as MPO-ANCA and those against PR3 as PR3ANCA. The C-ANCA pattern is usually caused by PR3-ANCA, but in some cases by reactivity with MPO or bactericidal/permeability-increasing protein (BPI) [41]. The P-ANCA pattern can be caused by antibodies against MPO, but also against elastase [42], lactoferrin [43], cathepsin $\mathrm{G}$ [44] and BPI [41], and is thus less specific.

\section{Clinical importance}

Although ANCA are characteristic for AAV, they are neither required for diagnosis nor specific. Especially when detected by IIF, ANCA can also be seen in other diseases with varying frequency, such as anti-glomerular basement membrane (anti-GBM) disease [45], inflammatory bowel disease [46], rheumatoid arthritis [47], systemic lupus erythematosus (SLE) [48], infections [49-51] and haematological malignancies [52, 53].

A role for ANCA in disease development is supported by the fact that the majority of AAV patients are ANCA positive and that titres often rise in active disease [54]. Patients who become ANCA negative after induction treatment have a lower risk of relapse [55], but serial measurements of ANCA during remission are only modestly predictive of relapses and cannot 
be used alone to guide treatment decisions [56]. Several studies have shown that ANCA serotype is important in predicting outcome in terms of treatment response [57], risk of relapse, renal survival and mortality $[27,58,59]$, and it has been suggested that classification according to ANCA serotype (PR3-AAV vs MPO-AAV) is to be preferred or used in addition to the traditional dichotomization based on clinical diagnosis (GPA vs MPA).

\section{Pathogenic importance}

Further support for a pathogenic role for ANCA can be found in animal models. There are several different mouse and rat models in which an immune response to MPO is induced resulting in necrotizing pauci-immune glomerulonephritis and pulmonary capillaritis, thus mimicking MPO-AAV in humans. Similar rodent models have been developed in efforts to study PR3-ANCA related disease, but have so far failed in inducing granulomatous disease. This is likely in part attributed to differences between human and rodent PR3 [60-62].

In vitro studies have demonstrated that PR3- and MPO-ANCA can activate neutrophils, leading to the production of reactive oxygen species and proteolytic enzymes with subsequent endothelial damage and inflammation of the vessel walls [63, 64]. Additional work have demonstrated that ANCA can stimulate neutrophils to produce pro-inflammatory mediators such as IL-1 $\beta$ [65], neutrophil extracellular traps [66], and factors that activate complement via the alternative pathway $[67,68]$. The latter and other discoveries regarding the importance of the complement system in the pathogenesis of AAV have led to the development of complement-targeted therapies that are now being tested as part of the treatment arsenal in AAV $[69,70]$.

\section{Epidemiology}

\section{Incidence}

Overall incidence numbers for AAV vary between countries and regions (Table 4). In Europe, incidence rates range between 10 and 20 per million. Studies from Australia and New Zealand show similar incidence rates to those found in Europe [71], while the incidence found in Minnesota in the USA is the highest reported so far [72].

Reasons for differences in incidence estimates could be found in the methodology used: the classification criteria and case recruitment, adjustments for age and gender, and choice of population used as the denominator. Other likely contributing factors are differences in population demographics and genetics, environmental factors and health care access.

Several studies have shown an increase in the incidence of GPA and MPA since the 1980s $[73,74]$. Naturally, this observation could be the result of a true increase in the number of patients developing the diseases due to unidentified environmental factors. However, the widespread introduction of ANCA testing in routine clinical practice in the 1990s and the 
subsequent increased detection and awareness of AAV have most likely played an important role, as more recent studies on the incidence of AAV have found stable figures [72, 75].

Most studies show a fairly equal gender distribution for the AAV group as a whole. Agespecific incidence numbers show an increase with age, with peak incidence numbers reported in the age groups 55-64 years [76], 65-74 years [77] and above 75 years [21, 72].

\section{Prevalence}

Prevalence numbers also vary between studies, and have increased with time [23, 78, 79]. This reflects the increased incidence followed by the introduction of ANCA in clinical practice as discussed above, but also increased survival in AAV patients in recent decades due to earlier detection and improvements in the treatment and management of patients.

The prevalence estimates for MPA in Europe range between 25 and 94 per million and for GPA between 24 and 160 per million [23, 79-83]. In Australia and New Zealand prevalence numbers are around 95 per million for GPA and 39 per million for MPA [71, 84], and in Japan 2 per million for GPA and 14 per million for MPA [85]. The highest prevalence estimates reported are from the USA, at 218 per million for GPA and 184 per million for MPA [72].

Prevalence figures are generally lower for MPA compared to GPA. This mirrors the lower incidence found in many areas, but is also seen in areas in which incidence numbers are equal $[72,80]$, conceivably reflecting the higher mortality in patients with MPA. 


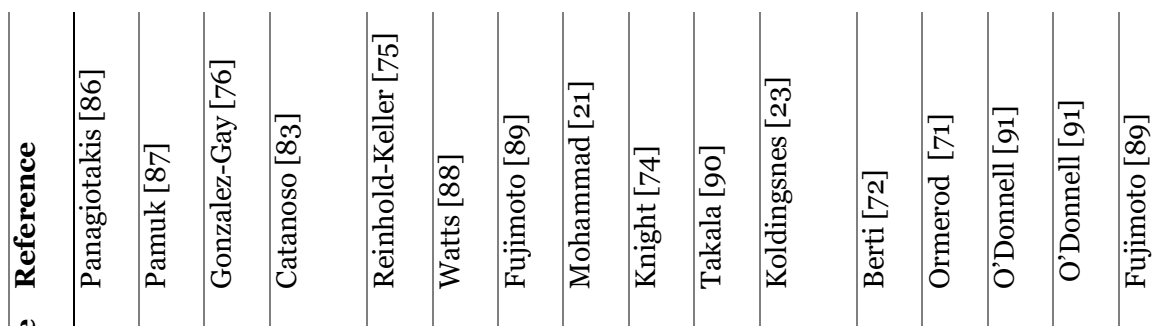

突

:

巳ֶ.

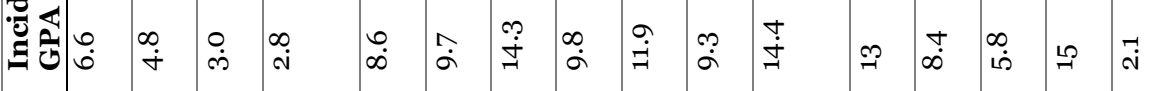

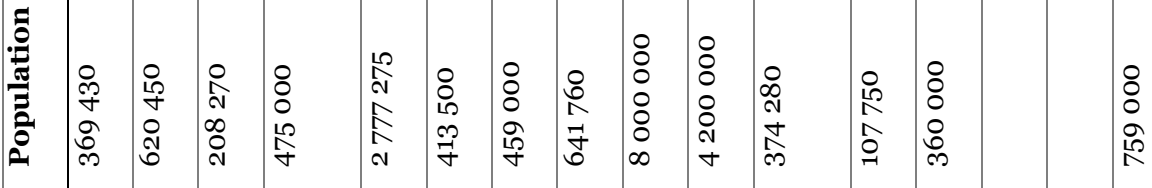

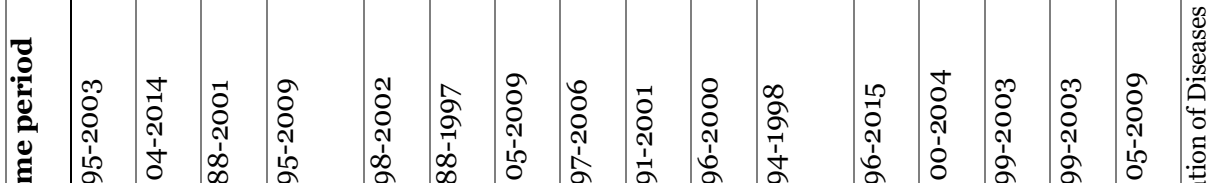

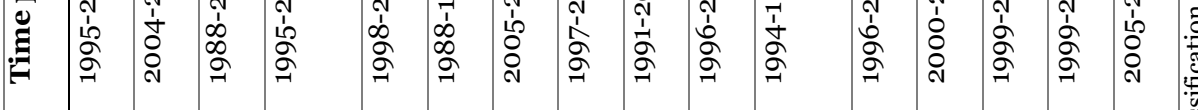

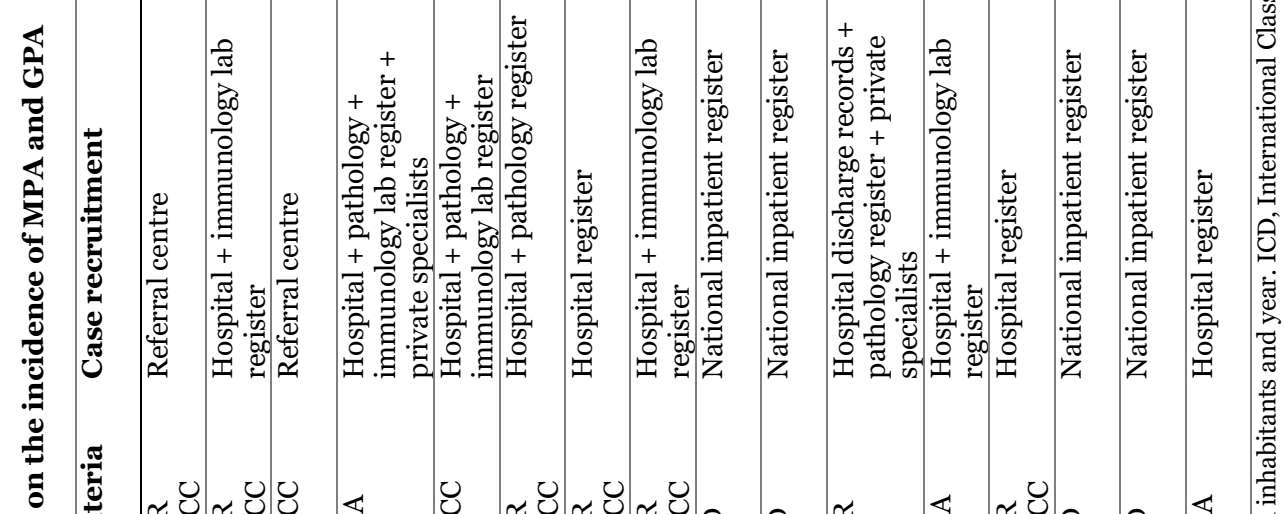

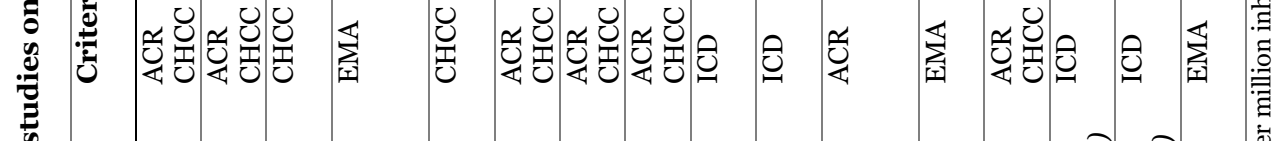

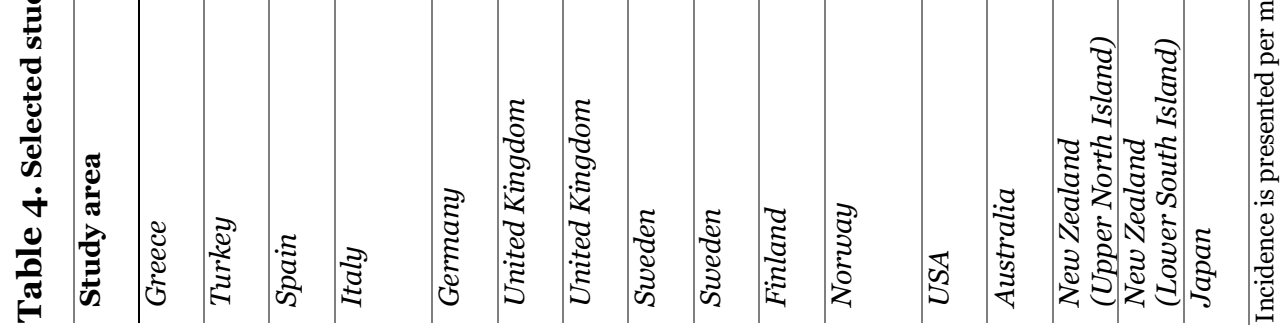




\section{Geographical differences}

A north-south gradient in the distribution of AAV has been proposed based on an observation that GPA is more common in the north of Europe compared to the south, with the opposite for MPA (Table 4). A reciprocal gradient has been reported from the southern hemisphere [91]. Nevertheless, there are studies from Sweden, the United Kingdom and the USA showing fairly equal incidence of MPA and GPA [21,72,88], and simply comparing incidence figures derived from different epidemiological studies with heterogeneous inclusion criteria and case retrieval is not easily done. In a study by Watts et al. the same methodology was therefore applied in three different areas: in Spain, the United Kingdom and Norway. The annual incidence of GPA was lower in Spain compared to the United Kingdom and Norway, while the incidence of MPA was lower in Norway compared to the United Kingdom and Spain [92]. This study has however not yet been replicated.

In addition to the proposed north-south axis, there are other differences in the geographic and ethnic distribution of AAV that could suggest both environmental and genetic factors. The overall incidence of AAV is similar in the United Kingdom, Scandinavia and Japan, but the relative distribution of the different serotypes and clinical diagnoses varies greatly [21, 89, 92]. MPO-ANCA and MPA is strongly predominant over PR3-ANCA and GPA in Asian countries $[85,93]$. In a study from a multi-ethnic population in Paris, GPA was reported to be less common in patients of non-European origin [82], and similarly PR3-ANCA positivity was more uncommon in African-Americans compared to Caucasians in a study from the USA [94]. The incidence of GPA is higher in Caucasians compared to individuals of Maori or Asian origin in New Zealand [91] and the Inuit in Greenland [95].

There are also studies investigating the influence of living in rural versus urban areas. The incidence of AAV was significantly higher in rural areas compared to urban areas in studies from Australia and Canada [71, 96], while such a pattern was not seen for MPA and GPA in a Spanish study [76].

\section{Seasonal differences}

Seasonal variations in the onset of vasculitis have been discussed and studied for many years, although such an association has not been established. There are some studies showing peak onset during winter [97, 98] and some showing peak onset during summer [99]. Other studies have not been able to confirm these findings $[23,100]$. In a study from the United Kingdom, GPA was found to follow a cyclical pattern of occurrence with a periodicity of 7.6 years. A similar cyclical pattern was not evident for MPA [81]. 


\section{Aetiology}

Epidemiological data may reveal clues to the aetiology of disease. The ethnic differences suggest that genetic factors play an important role, although geographic differences in the incidence and prevalence of AAV and the relative distribution of different serotypes and clinical phenotypes could also be due to environmental factors. Among the environmental factors that have been associated with AAV are different infectious agents, silica and ultraviolet (UV) radiation.

\section{Infections}

The observed seasonal and cyclical variations in the onset of symptoms have led to hypotheses of an infectious trigger of disease. There are several smaller studies and case reports implicating different infectious agents, but the best studied association is between chronic carriage of Staphylococcus aureus in the nose and development and relapse of GPA [101, 102]. The finding that treatment with trimethoprim-sulfamethoxazole reduced the risk of relapse in patients with GPA in remission supports a causal relationship [103]. However, this could also be due to the immunomodulatory effects of trimethoprim-sulfamethoxazole and a pathogenic mechanism behind the association has not been fully elucidated [104].

\section{Silica}

An increased frequency of ANCA positivity in individuals occupationally exposed to silica was described in the 1990s [105]. Silica has been shown to activate T-cells and cause dysregulation of the immune response [106, 107]. It has also been suggested that apoptosis induced by silica exposes antigens leading to the production of autoantibodies [108]. Silica has been implicated in several other autoimmune diseases, such as rheumatoid arthritis [109], SLE [110] and systemic sclerosis [111]. In a meta-analysis of six case-control studies, the overall odds ratio for developing AAV after exposure for silica was found to be 2.56 (95\% CI 1.51-4.36), with a latency between the exposure and diagnosis of around 25 years [112].

\section{Ultraviolet radiation}

Another environmental factor that has been implicated in AAV is exposure to UV radiation, and this has been suggested as the underlying mechanism behind the latitudinal gradient described above. In other autoimmune diseases such as type 1 diabetes and multiple sclerosis, UV radiation has been studied more extensively [113-115].

Gatenby et al. investigated this possible relationship in AAV and found an increase in the incidence of GPA with increasing latitude and decreasing UV radiation levels, while no latitudinal variation in MPA incidence was found [116]. This study was based on previously published incidence studies from different continents (Asia, South America, North America, 
Europe and Australia), and the authors acknowledge that genetic variations between the studied populations were not controlled for and might play a role.

The proposed mechanism behind the effect of UV radiation on autoimmune diseases is the effect of vitamin D on the immune system. Sun exposure of the skin is the main source of vitamin D in humans [117]. The active form of vitamin D, 1,25-dihydroxyvitamin D3, has the ability to suppress Th1 cell proliferation and cytokine production, as well as Th17 cell responses [118]. Th1/Th17 cells have been implicated in the pathogenesis of GPA and PR3-ANCA mediated disease [119].

\section{Genetic factors}

Genetic factors are thought to play a role in the development of AAV, and there are numerous studies on genetic susceptibility focusing on genes involved in immune responses and in the expression of target antigens [120]. Many of the genetic studies are small, and not all associations have been replicated. Familial cases of AAV have been described [121, 122], although the risk of disease among close relatives has been shown to be lower compared to that in several other autoimmune diseases [123].

In a large meta-analysis the pooled effects of genetic variants investigated in at least two studies were assessed. The majority of the genetic variants were in the major histocompatibility complex (MHC) region. The strongest contributors to an increased risk of AAV were the SERPINA1 Z allele and $H L A-D P B 1 * 0401$ allele, while the strongest protective effect was found for HLA-DPA1 rs9277341 [124]. Associations were also found for PTNP22 and CTLA-4, which are implicated in several other autoimmune diseases such as rheumatoid arthritis, type 1 diabetes, SLE and giant cell arteritis [124].

In a large genome-wide association study (GWAS) conducted in Europe, a genetic association between HLA-DP, SERPINA1 and PRTN3 (the gene encoding PR3) and PR3ANCA was found, while $H L A-D Q$ was associated with MPO-ANCA. In this GWAS, the strongest genetic association was seen for ANCA serotype and not for the clinical diagnosis [20]. Such a division was also supported in the meta-analysis mentioned above, in which the genetic associations differed for MPA/GPA and for MPO-ANCA/PR3-ANCA, but odds ratios were higher for ANCA serotype than for clinical diagnosis. An association between $H L A$ $D P B 1 * 0401$ and GPA was confirmed in another GWAS in patients of European descent in North America [125].

The serpin A1 gene (SERPINA1) encodes the serine protease inhibitor alpha-1-antitrypsin which has PR3 as one of its substrates. Studies of its global distribution show that it is more common in Scandinavia, Western and Central Europe and countries colonized by Europeans [126]. The $H L A-D P B 1 * 0401$ allele also varies geographically, and is more common in Europe compared to Japan, China and African Americans in the USA [127]. 


\section{Treatment}

Treatment of AAV is aimed at inducing remission, preventing relapses and avoiding permanent organ damage caused by the vasculitis disease and the treatment.

\section{Induction therapy}

Treatment with cyclophosphamide in combination with corticosteroids has dramatically improved survival and has been the first choice of treatment for AAV for decades [128]. Although effective in achieving remission, the use of cyclophosphamide is associated with adverse effects such as leukopenia, infections, infertility and malignancies [29]. The search for less toxic treatment alternatives has resulted in several trials aiming at reducing the use of cyclophosphamide. Intravenous pulse cyclophosphamide is now preferentially used over daily oral cyclophosphamide, since it results in similar rates of remission, but a lower cumulative dose of cyclophosphamide and a lower rate of leukopenia [129].

The RAVE trial showed that rituximab, a monoclonal anti-CD20 antibody resulting in Bcell depletion, was as effective as cyclophosphamide for inducing remission in AAV, and it was even more effective in relapsing disease. Rituximab was also as effective as cyclophosphamide among patients with renal disease or alveolar haemorrhage [130, 131]. In the RITUXIVAS trial, a rituximab-based regimen was found to be equally effective as cyclophosphamide in inducing remission in AAV with renal involvement [132]. After two years, relapse rates and mortality rates did not differ between the two arms [133]. Nevertheless, the rituximab-based regimens have not been associated with lower rates of adverse events compared to standard cyclophosphamide therapy in these trials [130, 132]. A combination of glucocorticoids and cyclophosphamide or rituximab is currently recommended in guidelines for induction of organ- or life-threatening disease [134, 135].

For patients with severe renal disease due to rapidly progressive glomerulonephritis and patients with diffuse alveolar haemorrhage, plasma exchange should be considered [135]. Plasma exchange was shown to decrease the risk of end stage renal disease (ESRD) and death at three months in the MEPEX trial [136], although the long-term results are unclear [19]. PEXIVAS is a randomized trial aimed at evaluating the effect of plasma exchange on mortality and ESRD and comparing a low-dose glucocorticoid regimen with standard dosing [137]. Preliminary results have shown that the use of plasma exchange did not reduce the risk of death or ESRD. Importantly, the reduced dose glucocorticoid regimen was associated with fewer serious infections without increasing the risk of adverse outcome [138].

For non-organ-threatening disease, both methotrexate and mycophenolate mofetil (MMF) have been shown to be non-inferior to cyclophosphamide in inducing remission [139, 140]. However, long-term disease control seems to be less effective [140, 141].

The use of prophylaxis against infection with Pneumocystis jiroveci with trimethoprimsulfamethoxazole is recommended during induction treatment [134, 135]. A treatment algorithm based on current guidelines is shown in Figure 3. 


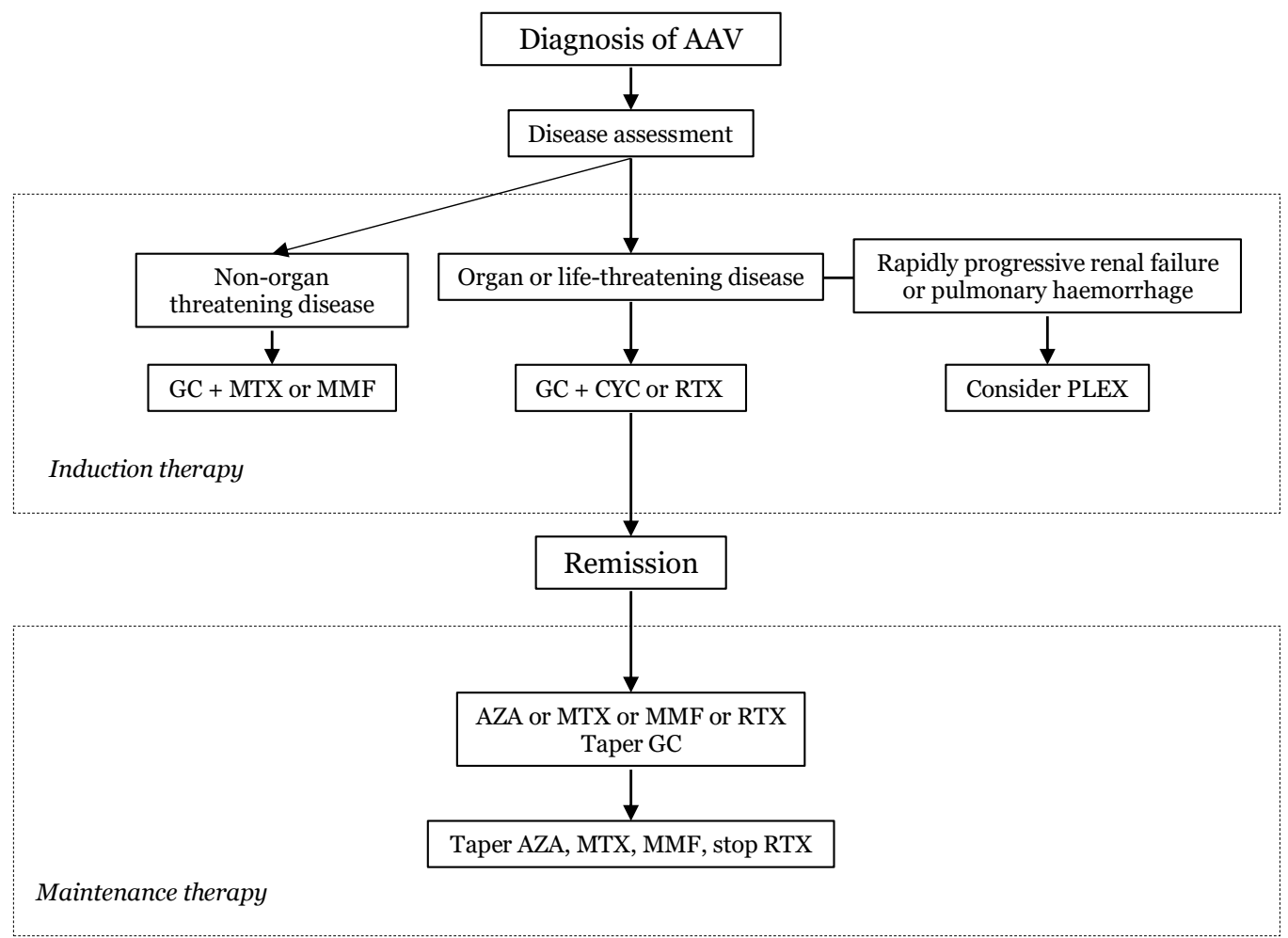

\section{Figure 3. Treatment algorithm.}

Adapted from Yates et al. [135] and Ntatsaki et al. [134]. GC, glucocorticoids; MTX, methotrexate; MMF, mycophenolate mofetil; CYC, cyclophosphamide; RTX, rituximab; PLEX, plasma exchange; AZA, azathioprine

\section{Maintenance therapy}

After induction therapy, maintenance therapy with low-dose glucocorticoids in combination with azathioprine, methotrexate, rituximab or MMF is initiated [134, 135]. Azathioprine was the first immunosuppressive agent shown to be an equal alternative to cyclophosphamide as maintenance therapy. In CYCAZAREM, it was shown that the standard therapy with 12 months of oral cyclophosphamide could be replaced by azathioprine once patients had achieved remission, without increasing the risk of relapses [142]. If azathioprine is used after cyclophosphamide induction, relapse rates are lower if treatment is continued for 48 months as opposed to 24 months [143]. Methotrexate can be used for maintenance after cyclophosphamide induction in patients without severely impaired renal function and has been shown to be equivalent to azathioprine [144]. MMF is an alternative, but azathioprine is preferred due to a higher relapse rate in patients treated with MMF [145]. 
In MAINRITSAN, low-dose rituximab given at fixed intervals was shown to be associated with lower relapse rates at 28 months compared to standard-of-care with azathioprine [146]. In a recently published phase III trial, rituximab given at similar fixed intervals was compared with an individually tailored regimen with rituximab given only at the reappearance of CD19+ B-cells or ANCA, or marked rise in ANCA titre. The relapse rate did not differ significantly between arms, even though there was a trend towards more relapses in the patients receiving the tailored regimen. Monitoring ANCA and B-cells could not predict relapses, but resulted in fewer rituximab infusions [147].

\section{Disease assessment tools}

Chronic diseases such as AAV can be described in terms of both disease activity and damage, respectively representing the reversible and irreversible aspects of the disease process [148]. For the purpose of quantifying the information collected during clinical evaluation of patients, scoring systems recording both disease activity and permanent damage have been developed, the most widely used being the Birmingham Vasculitis Activity Score (BVAS) and the Vasculitis Damage Index (VDI).

\section{Birmingham Vasculitis Activity Score}

The Birmingham Vasculitis Activity Score (BVAS) is a clinical tool for assessing disease activity in systemic vasculitis, first published in 1994 [149]. It was designed to document the presence of new or worsening active vasculitis that requires institution or intensification of immunosuppressive treatment.

The most important principle when recording disease activity is that a symptom can only be recorded if it is attributed to active vasculitis, after exclusion of other causes such as infections or permanent damage. The second principle is the intention-to-treat principle. If a symptom is scored this should give an indication to act on that item and intensify treatment [150].

The current version consists of a wide variety of clinical features grouped in nine different organ systems. Each item has a numerical value reflecting its clinical relevance and there is a maximum score for each organ system. The issue of low-grade activity not requiring intensification of treatment is addressed in the latest version of BVAS by the opportunity to record "persistent disease only" if all items scored are due to active disease that is not new or worse within the last three months. This situation would normally not require intensification of treatment. However, if a patient has a mixture of persistent and new or worse disease, all items will be scored as new or worse and warrant increased therapy according to the intention-to-treat principle [150].

The BVAS score has become the standard disease activity measure in vasculitis [148], used in a large number of clinical trials to assess disease activity at diagnosis, and during follow-up to define remission and relapse [150]. It has also been shown to have prognostic value [19, 149]. 


\section{Vasculitis Damage Index}

Damage is defined as a non-healing scar that is not responsive to immunosuppressive treatment. The distinction between activity that calls for intensification of therapy and permanent damage that does not warrant immunosuppression is not always easy, but is important in order to avoid over-treatment [148]. Generally, if a sign or symptom does not respond to treatment over time, it should be considered as damage.

The Vasculitis Damage Index (VDI) was developed to reflect damage items common in patients with vasculitis and comprises items of damage in 11 categories. If an item occurred after the onset of vasculitis and has lasted for at least three months it can be recorded as damage. Importantly, items are scored regardless of attribution, and damage items can thus reflect both the effects of the vasculitis disease and the effects of therapy. Since items are considered permanent, the VDI score can only increase or remain stable over time [151].

Treatment-related damage refers to VDI items attributable in major part to drug toxicity rather than the vasculitis process itself and includes osteoporosis, avascular necrosis, osteomyelitis, cataract, gonadal failure, marrow failure, chemical cystitis, diabetes mellitus and malignancy [152]. Critical damage (items consistent with organ failure) and major vascular damage (damage to major blood vessels) are also described in the original publication [152].

Damage is an important outcome in AAV both as a reflection of cumulative disease activity and treatment toxicity [153], and as a predictor of subsequent mortality [24, 152]. The VDI is therefore recommended as one of the key outcome measures in clinical trials in AAV [148].

\section{Outcome}

\section{Patient survival}

If not treated, mortality rates are up to $80-90 \%$ in a few months, mainly caused by renal failure and lung bleedings $[154,155]$. The introduction of immunosuppressive therapy has dramatically improved this poor survival rate. Although still accounting for significant mortality, the AAV have changed into chronic diseases with a relapsing course associated with accumulation of permanent organ damage over time.

Survival at 1, 2 and 5 years in four randomized multi-centre trials conducted by the European Vasculitis Society (EUVAS) between 1995 and 2002 was 88\%, 85\% and 78\% respectively [19]. These studies have often excluded the oldest and most severely ill patients, and descriptive cohort studies are important in describing outcome in the clinical setting. In a Swedish cohort of patients with renal AAV, survival was $85 \%$ at 1 year, $82 \%$ at 2 years, $74 \%$ at 5 years and $52 \%$ at 10 years [156], similar to survival rates found in the United Kingdom [157]. In a population-based study from the USA including all known AAV cases 2-, 5- and 10-year survival was $91 \%, 81 \%$ and $64 \%$ [72]. Compared to the general population, mortality in patients with AAV is increased two to three times [19, 21, 72].

A number of risk factors have been associated with increased mortality, the most wellestablished being higher age and worse renal function [19, 24, 29, 156, 158-161]. Other risk 
factors described include high levels of PR3-ANCA [156], high BVAS at diagnosis [19, 158], low serum albumin [33, 162], lower haemoglobin [19] and development of permanent organ damage $[24,151]$.

\section{Causes of death}

Most deaths occur during the first year, and in particular during the first three months, corresponding to the time frame when both immunosuppression and vasculitis activity is most intensive $[19,163]$. Early mortality is mainly caused by infections and active vasculitis, with infections being the leading cause of death during the first year after diagnosis [163]. Longterm risks include malignancies and increased cardiovascular risk [19, 164, 165].

Older studies showed that the cancer incidence in patients with AAV was increased about two times compared to the general population, with the highest risk observed for bladder cancer, non-melanoma skin cancer, leukaemia and lymphoma [166, 167]. A more recent EUVAS follow-up study found a lower incidence ratio, and non-melanoma skin cancer was the only cancer site with a statistically significantly increased incidence [164]. In a German study, there was no increased incidence of malignancies in vasculitis patients [168]. These recent findings might reflect advances in reducing the toxicity of treatment, with less cyclophosphamide exposure, but it is also possible that follow-up needs to be longer to detect a significant increase in cancer incidence [169].

Compared with controls, patients with AAV have a two- to threefold increased risk of cardiovascular events $[165,170]$. Long-term data have shown that $14 \%$ of patients with AAV suffered from cardiovascular events within five years from diagnosis [171]. The increased cardiovascular risk is probably multifactorial, including endothelial dysfunction, renal impairment, chronic inflammation and corticosteroid use causing accelerated development of hypertension, hyperlipidaemia and diabetes [165].

\section{Renal survival}

Development of ESRD is seen in 20 to $40 \%$ of patients during long-term follow-up [24, 156, 157, 172]. These numbers vary depending on the characteristics of the patients studied (e.g., age, renal involvement at diagnosis or not, renal function at presentation, ANCA type). Dialysis dependency at diagnosis and initial creatinine level have been associated with increased risk of subsequent ESRD in several studies [162, 173]. Increasing age is another risk factor [162]. MPO-ANCA positivity has been associated with increased risk of developing ESRD compared to PR3-ANCA positivity [58, 173], possibly due to the presence of more chronic renal lesions such as glomerulosclerosis, tubular atrophy and interstitial fibrosis [174, 175]. However, these results are not consistent, and others have found no significant differences in renal outcome with relation to ANCA specificity $[174,176]$.

Development of ESRD is associated with increased mortality, while relapse rates are lower compared to patients with preserved renal function [177]. In patients with dialysis dependency 
at diagnosis, 23\% died within 6 months, and of those surviving 29\% remained dialysis dependent [173].

\section{Permanent organ damage}

As survival has improved, other outcome measures have become more important. The majority of patients with AAV develop some degree of permanent organ damage during follow-up. Development of higher total VDI scores is associated with increased mortality [152]. Patients with severe fatal disease were more likely to have major vascular damage and critical damage, while there was no association between treatment-related damage and fatal disease in the study by Exley et al. [152].

In a cross-sectional study of vasculitis patients in Sweden, the median VDI score was 3 after a median disease duration of 9 years. Severe damage ( $\geq 5$ items) was seen in $56 \%$ of the patients included and only $9 \%$ had no items of damage. Cardiovascular and renal damage were most common, and the single most prevalent item was hypertension [178].

The type of damage developing over time differs between the two clinical diagnoses GPA and MPA. In patients with GPA, the most common damage items are found in the ENT domain, while renal damage is more frequently seen in MPA [153, 178, 179]. Interestingly, in the Swedish study there was almost complete separation between ENT damage and cardiac and renal damage in GPA patients, underscoring the differences in terms of organ involvement and prognosis that are present within this group [178].

\section{Remission and relapse}

Remission is achieved in the majority of patients, but relapses are common and up to $60 \%$ of patients relapse during long-term follow-up [29]. Remission rates in the large randomized clinical trials range from $60 \%$ to $90 \%$ depending on the definition of remission (i.e., absence of new or worse clinical disease activity but allowing minor persistent disease activity, or complete absence of disease activity at six months and adherence to the prednisolone taper scheme) [130, 139].

A clinical diagnosis of GPA and PR3-ANCA positivity is associated with a greater risk of relapse compared to patients with MPA and MPO-ANCA positivity [142, 157, 180]. Other factors associated with increased risk of relapse include chronic nasal carriage of Staphylococcus aureus [101], cardiac involvement [181], respiratory tract involvement [182] and preserved renal function [101]. 


\section{ANCA-associated vasculitis in older patients}

The AAV can affect patients of any age, but are mainly diseases of older patients with incidence rates increasing with age as described above. A large study of patients with ANCA-associated glomerulonephritis identified through the Norwegian Kidney Biopsy Registry found that 27\% of the patients were 75 years or older at the time of biopsy [183]. In the Swedish Renal Biopsy Registry, AAV was the most common diagnosis in patients aged 75 years or more, accounting for $18 \%$ of the biopsies [184], and in patients aged 80 years or more, pauci-immune glomerulonephritis accounted for about $30 \%$ in patients biopsied for acute kidney injury in the USA [185].

\section{Clinical features}

With increasing age, the proportion of MPO-ANCA positivity and a clinical diagnosis of MPA increases compared to PR3-ANCA positivity and GPA [33, 158, 161]. In line with this, the majority of older patients with AAV have renal involvement, while ENT symptoms are less common [158, 186, 187]. Some studies have also described more pulmonary involvement in the elderly [86, 161], although this is not evident in other studies [188]. Renal impairment is often severe, with dialysis dependency more frequently seen when comparing older and younger patients $[33,189]$. Nevertheless, in studies describing renal histology, no significant differences have been found with regard to the percentage of normal glomeruli and percentage of crescents in renal biopsy specimens [161, 188].

\section{Outcome}

The response to immunosuppressive treatment is described as equal in some [33, 186], but not all [161] studies comparing older and younger patients. Regarding relapses, rates are similar to or lower than those found in younger patients [33, 161, 187]. PR3-ANCA positivity is a wellestablished risk factor for relapses, and this is also evident in older patients. While PR3-ANCA positivity increases the risk of relapse, impaired renal function decreases the risk and the seemingly lower overall relapse risk in the elderly might be due to the lower frequency of PR3ANCA and the high frequency of renal involvement [190].

As described above, age is one of the best-established risk factors for death. Older patients are at a higher risk of death due to comorbidities such as cardiovascular disease [186], but are also more susceptible to infections [33, 189] and adverse events [163, 178], due to impaired renal function and possibly also to changes in the immune system [191].

Despite the fact that a large and growing proportion of patients with AAV are older, and that age has consistently been shown to be a risk factor for poor outcome, the mean age in a majority of the large vasculitis trials conducted to date is around 60 years and many of the clinical trials on which current guidelines are based have excluded patients over the age of 75 years [136, $139,142]$. 


\section{Lupus nephritis}

Often described as the prototype of a systemic autoimmune disease, SLE is characterized by the production of a number of different autoantibodies and a broad range of clinical manifestations, including muco-cutaneous, musculoskeletal, neurologic, haematological, pulmonary, cardiac, gastrointestinal and renal involvement.

Renal disease with lupus nephritis (LN) develops in 20 to $45 \%$ of Caucasian SLE populations [192-195] and in up to 70\% of African American, Asian and Hispanic populations $[194,196]$. Some patients present with renal involvement, but it occurs most commonly after the diagnosis of SLE has been made [197].

\section{Epidemiology}

Incidence rates for SLE vary around the world, ranging from 10 to 49 per million in Europe to 10 to 76 per million in North America, 46 to 63 per million in Central America, 48 to 87 per million in South America, 110 per million in Australia, and 12 to 84 per million in Asia [198]. As in AAV, there may be true differences in the incidence of SLE around the world. However, the large differences found between studies from the same geographical area suggest that factors such as case retrieval strategy and classification are also of importance.

Peak incidence is seen in middle-aged adults and SLE is more common in women than in men, with a ratio ranging from 2:1 to 15:1 [198]. This is seen across all age groups, but particularly during childbearing age [199]. SLE more frequently affects African-Americans, Hispanics and Asians than Caucasians in the USA, suggesting that genetic factors play a role [200]. Renal involvement with $\mathrm{LN}$ is also more common in patients of African-American and Hispanic ethnicity compared to Caucasians [201].

Incidence numbers for LN in Caucasian populations range from 4 to 7 per million [202-206]. There are conflicting data on trends in the incidence of LN over the years. In Norway, the incidence decreased from 7 per million in the years 1978-1995 to 4.5 per million in 1996-2006 [204]. Contrary to these findings, the incidence in Germany increased from 2 per million in 1990-1997 to 4 per million in 2006-2013 [207]. Reported incidence figures from the USA were stable over a period of 30 years [203].

\section{Aetiology}

In SLE, inadequate removal of apoptotic cells exposing immune cells to nuclear and cell membrane components and loss of self-tolerance ultimately lead to the production of autoantibodies. Autoantibodies binding to circulating antigens or antigens deposited in the glomeruli form immune complexes. Subsequent inflammation and cytotoxicity mediated by complement and $\mathrm{Fc}$ receptor binding causes damage to the glomeruli [197].

The best-studied autoantibodies associated with LN are anti-dsDNA antibodies and antiC1q-antibodies. Both are seen more frequently in SLE patients with renal involvement 
compared to those without [197]. A number of different genes have been associated with SLE and $\mathrm{LN}$, and as in several other autoimmune diseases many of the genetic variants are found in the MHC region [208].

Environmental risk factors associated with SLE include exposure to silica, solvents, pesticides [209], oral contraceptives and hormone replacement therapy [210, 211]. Current, but not past, cigarette smoking increases the risk [212, 213], while there is an inverse relationship between moderate alcohol intake and risk of SLE [214]. Exposure to UV radiation can exacerbate symptoms, but it remains to be determined if UV radiation is also a risk factor for developing disease [215].

\section{Treatment}

Treatment of $\mathrm{LN}$, as with AAV, is divided into an induction phase to achieve remission, and a maintenance phase to prevent relapses. The ultimate goal of treatment is to prevent chronic kidney disease and ESRD. For induction, glucocorticoids in combination with intravenous cyclophosphamide or MMF are recommended, and for maintenance MMF or azathioprine are first-line choices. In severe nephrotic syndrome or incomplete renal response, MMF may be combined with a calcineurin inhibitor [216]. Hydroxychloroquine is recommended for all patients with SLE [216] due to its effect on disease activity, organ damage and survival [217].

In a randomized trial comparing MMF with standard-dose intravenous cyclophosphamide, renal response rates at 6 months were similar in the two treatment arms [218]. Low-dose cyclophosphamide has been shown to be equivalent to standard-dose cyclophosphamide, for both induction of remission and long-term kidney preservation [219, 220]. For maintenance, MMF has been shown to be superior to azathioprine in maintaining renal remission and preventing flares [221].

A combination of MMF and a calcineurin inhibitor has been studied in LN as induction therapy [222], as maintenance therapy [223] and in patients not responding to standard therapy [224, 225]. The great majority of these studies have been performed in Asian populations, but recently a phase II trial in 20 countries in America, Europe and Asia evaluated addition of the calcineurin inhibitor voclosporin to background MMF and corticosteroids for induction treatment of LN. Renal response was higher in the voclosporin group, but also adverse events including deaths [226]. Rituximab can be considered following failure of the first-line treatment or in relapsing disease [216, 227].

\section{Outcome}

Survival rates at 5, 10, 15 and 20 years are $95 \%, 91 \%, 85 \%$ and $78 \%$ respectively in a mixed North American SLE population [228]. The most common causes of death are infections and cardiovascular disease [229]. Outcome is generally worse in African-American and Hispanic patients, with regard to both development of ESRD and death [230, 231]. 
Development of $\mathrm{LN}$ is associated with worse outcome in terms of both morbidity and mortality. The standardized mortality ratio (SMR) in patients with SLE is 1.5-3.0 [195, 232234], and in patients with $\mathrm{LN}$ it is 5.9-6.6 [235, 236]. In a population-based Norwegian SLE cohort, the SMR was 3.8 in LN patients compared with 1.7 in non-LN patients. ESRD developed in $6 \%$ of the entire cohort and in $20 \%$ of LN patients [195]. Overall, $22 \%$ of patients with LN in developed countries reached ESRD within 15 years, and in patients with class IV LN the corresponding figure was $44 \%$ of patients [237].

\section{Renal biopsy}

Renal biopsies are performed in order to establish a histological diagnosis in various renal diseases, and are recommended in current guidelines for both AAV and SLE $[135,216]$.

\section{ANCA-associated glomerulonephritis}

Pauci-immune necrotizing and crescentic glomerulonephritis is the characteristic histologic finding in AAV with renal involvement [1]. A renal biopsy is useful not only for confirming a new diagnosis or relapse of AAV, but also for histopathological classification and predicting prognosis. Lesions are classified as focal (predominance of normal glomeruli), crescentic (predominance of crescentic glomeruli), sclerotic (predominance of sclerotic glomeruli) or mixed (none of the aforementioned features is predominant). This classification has prognostic value on renal outcome, with the best renal survival seen in the focal class and the worst seen in the sclerotic class [238, 239].

When extra-renal involvement is present, a histological diagnosis can also be made with biopsies from other organs such as nasal mucosa, skin, lung tissue, muscle and nerves [240242]. Reasons for not performing a renal biopsy in AAV include the presence of absolute or relative contraindications such as increased bleeding risk, uncontrolled hypertension and solitary kidney [243], or that a histological diagnosis has already been obtained by biopsy of another organ.

In a report from the Spanish Registry of Glomerulonephritis, vasculitis accounted for $4.5 \%$ of all biopsies, but in the elderly it accounted for 18.3\% [205]. In the Czech Republic, necrotizing vasculitis accounted for $5.7 \%$ of renal biopsies [206]. Pauci-immune glomerulonephritis accounted for $4.9 \%$ and $9.4 \%$ of the biopsies performed in patients <65 years and $\geq 65$ years respectively in Poland [244]. 


\section{Lupus nephritis}

If there is clinical evidence of renal involvement in SLE, a renal biopsy should be performed to establish a histological diagnosis in order to guide treatment and for prognostic information. Immune-complex-mediated glomerulonephritis is the most common cause of renal disease in SLE, but tubulointerstitial disease, podocytopathy and thrombotic microangiopathy also occur [245]. The lesions found are classified according to the International Society of Nephrology/Renal Pathology Society (ISN/RPS) 2003 classification of LN [246] (Table 5).

\section{Table 5. ISN/RPS 2003 classification of LN}

\begin{tabular}{ll}
\hline Class I & $\begin{array}{l}\text { Minimal mesangial lupus nephritis } \\
\text { Normal glomeruli by light microscopy, mesangial immune deposits by } \\
\text { immunofluorescence. }\end{array}$ \\
\hline Class II & $\begin{array}{l}\text { Mesangial proliferative lupus nephritis } \\
\text { Mesangial hypercellularity or mesangial matrix expansion, with mesangial immune } \\
\text { deposits. }\end{array}$ \\
\hline Class III & $\begin{array}{l}\text { Focal lupus nephritis } \\
\text { Focal, segmental or global endocapillary or extracapillary glomerulonephritis involving } \\
<50 \% \text { of glomeruli. Active (A) or chronic (C) lesions. }\end{array}$ \\
\hline Class IV & $\begin{array}{l}\text { Diffuse segmental (IV-S) or global (IV-G) lupus nephritis } \\
\text { Diffuse, segmental or global endocapillary or extracapillary glomerulonephritis } \\
\text { involving } \geq 50 \% \text { of glomeruli. Active (A) or chronic (C) lesions. }\end{array}$ \\
\hline Class V & $\begin{array}{l}\text { Membranous lupus nephritis } \\
\text { Global or segmental subepithelial immune deposits or their morphologic sequelae. }\end{array}$ \\
\hline Class VI & $\begin{array}{l}\text { Advanced sclerosing lupus nephritis } \\
\geq 90 \% \text { of glomeruli globally sclerosed. }\end{array}$ \\
\hline
\end{tabular}

Adapted from Weening et al. [246]

Immunosuppressive treatment for renal disease is used in proliferative LN (classes III and IV), and in membranous LN (class V) with nephrotic range proteinuria. During the course of disease, patients with LN can change ISN/RPS class, and repeat biopsy in the setting of worsening renal function or persistence/worsening of proteinuria can thus be indicated and support changes in treatment strategy [245].

When reporting on the frequency and incidence of $\mathrm{LN}$, it is crucial to exclude re-biopsies in order to obtain correct estimates. Data from renal biopsy registries in Europe report that LN constitutes $5-10 \%$ of all biopsy diagnoses [205-207, 244]. 


\section{RATIONALE AND AIM}

Although great progress has been made in the understanding, diagnosis and treatment of AAV, much remains to be elucidated regarding aetiology and further improvement is needed in the management and treatment of patients. Epidemiologic studies are important in this sense, allowing for both descriptive and analytic studies in large populations and in a real-world setting.

The descriptive epidemiology of both AAV and SLE has been studied for many years, but the incidence and outcome of renal disease in the two conditions has not previously been studied simultaneously in the same geographic area with similar inclusion criteria allowing for headto-head comparison.

There are geographical differences in the occurrence of AAV. Data available from different studies can however not be readily compared, and there is need for larger studies in a more homogeneous population. UV radiation is one environmental factor associated with geographical location that has been studied extensively in other autoimmune diseases, but the data in AAV are scarce.

The elderly constitute a large and growing proportion of patients with AAV. Despite this, most studies on the elderly define this as an age above 60-65 years and data on clinical presentation and outcome in patients above 75 years are insufficient. In addition, many of the large randomized trials on treatment of AAV have excluded this patient population, and there is uncertainty regarding treatment of elderly patients.

The overall aim of the work presented in this thesis was to learn more about the epidemiology of AAV: incidence and distribution, factors potentially underlying the development of disease and factors influencing outcome. In the four studies we have used different epidemiological approaches, making comparisons with another inflammatory disease, between geographic regions and with a focus on a specific age group.

\section{Specific aims}

1. To compare annual incidence rates of biopsy-proven lupus nephritis and ANCAassociated nephritis in two geographically defined populations in Sweden and to compare renal and patient survival between these two groups.

2. To investigate associations between ANCA serotype and geographical latitude and ultraviolet radiation levels in a population of patients with biopsy-proven ANCAassociated glomerulonephritis in Europe and North America.

3. To study associations between demographic factors, treatment and outcome in terms of patient survival and renal survival in patients aged 75 years or more with MPA and GPA.

4. To investigate whether immunosuppressive treatment in elderly patients aged 75 years or more with MPA and GPA is associated with development of permanent organ damage and increased need for in-hospital care, and to study causes of death. 
Incidence and Outcome of ANCA-Associated Vasculitis 


\section{METHODS}

\section{Study population and patient retrieval}

\section{Paper I}

Two geographically defined areas in Sweden were studied: a health care district in the county of Skåne and one in the county of Östergötland. Patients were identified from local registries based at Skåne University Hospital in Lund and the University Hospital in Linköping.

Inclusion criteria were residence within the study area, a clinical diagnosis of AAV or SLE and a first flare of biopsy-proven nephritis during the period 1997 to 2008. Only biopsy-verified nephritis cases were included to ensure that all were incident during the study period and that no prevalent nephritis cases before the study period were included.

\section{Paper II}

Patients with renal biopsy-proven AAV were identified from national and regional renal biopsy registries and vasculitis registries in seven countries in Europe and the USA: the Norwegian renal biopsy registry, the Scottish renal biopsy registry, the Italian Registry of Renal Biopsies, the renal biopsy registry at Dubrava University Hospital in Croatia, the Vasculitis registry in the Czech Republic, the vasculitis registries in Östergötland and Skåne, the vasculitis registry in Cambridge, the Glomerular Disease Collaborative Network (GDCN) registry in North Carolina and the Johns Hopkins Vasculitis database in Maryland.

Only registries including consecutive patients from a defined geographic area were included. Inclusion criteria were a clinical diagnosis of AAV verified by renal biopsy during the period 2000 to 2013, ANCA positivity verified by ELISA and age 18 years or above.

\section{Papers III and IV}

Consecutive patients were included from Linköping University Hospital, Skåne University Hospital and Karolinska University Hospital in Sweden; Imperial College London and Royal Free Hospital in the United Kingdom; and General University Hospital in the Czech Republic. In Paper IV, a centre at Queen Elizabeth Hospital in Birmingham was also involved.

Patients were included if they were aged 75 years or more at diagnosis and had a clinical diagnosis of MPA and GPA. The study periods were 1997 to 2009 for Paper III and 1997 to 2013 for Paper IV. 


\section{The vasculitis and SLE registries in Östergötland and Skåne}

All patients diagnosed with systemic vasculitis and SLE in the county of Östergötland are referred to the Nephrology and Rheumatology departments at Linköping University Hospital. Since 1997, all patients with AAV are registered in a local vasculitis registry. The database includes all incident cases since 1997 and all prevalent cases at the time of the start of the registry. A clinical SLE registry was started at the Department of Rheumatology in Linköping in 2008 and includes both incident and prevalent cases.

A local vasculitis registry was started in the county of Skåne in 2002, including all cases of AAV since 1997 and covering the health care district surrounding Skåne University Hospital in Lund and Malmö. Using a capture-recapture technique, the completeness of the database has been shown to be $>95 \%$ [80]. All diagnosed cases of SLE at the Department of Rheumatology in Lund have been included in a longitudinal cohort since 1981. The retrieval of patients has been analysed by capture-recapture methodology [247].

\section{Data collection}

Data were collected from registries/databases and patients' medical records. Baseline demographic data and clinical and laboratory data were collected from the time of diagnosis or renal biopsy as described below.

\section{Paper I}

Baseline data were collected on age, gender, creatinine, haemoglobin, white blood cell count (WBC), platelet count, C-reactive protein (CRP), erythrocyte sedimentation rate (ESR) and organ involvement at the time of biopsy. For LN data were also collected on anti-nuclear antibodies (ANA), anti-dsDNA and complement consumption. Data on outcome included death, ESRD and creatinine at last follow-up.

Biopsy rate was calculated by dividing the number of patients with biopsy-proven nephritis with the number of patients who were judged to have active nephritis by clinical assessment. For AAV this corresponded to a score $\geq 1$ in the BVAS renal domain and for SLE the presence of haematuria and proteinuria according to SLE disease activity index (SLEDAI) [248].

\section{Paper II}

Data were only collected from the time of biopsy and included age, gender, ANCA serotype (according to antigen-specific ELISA) and estimated glomerular filtration rate (eGFR) according to the Modification of Diet in Renal Disease equation [249]. Biopsy rate was calculated as described for Paper I. 
Data on mean monthly erythemally weighted UV radiation levels in Europe were extracted from the STRÅNG database provided by the Swedish Meteorological and Hydrological Institute [250]. Historical data can be extracted from the database with yearly, monthly, daily or hourly radiation data by defining the latitude and longitude for the location of interest and the dates defining the time period of interest. The World Geodetic System 84 coordinate reference system was used for the latitude and longitude coordinates of the participating centres (in the USA the capital city of participating states).

\section{Papers III and IV}

Demographic and clinical data at the time of diagnosis included: date of diagnosis, age, gender, diagnosis type (MPA/GPA), ANCA specificity (according to IIF or ELISA), CRP, creatinine, dialysis dependency, BVAS and major comorbidities. Data on outcome up to two years from diagnosis included: date of death, cause of death, date of ESRD, accumulated organ damage according to VDI at one and two years, and hospitalization during the first year. Treatment data included: cumulative dose of intravenous pulsed methylprednisolone, oral prednisolone and intravenous/oral cyclophosphamide; treatment with rituximab, MMF, azathioprine or methotrexate; and use of plasma exchange.

A comorbidity score was calculated as described by Davies et al. [251] with one point awarded each for malignancy, ischemic heart disease, peripheral vascular disease, heart failure, diabetes, systemic inflammatory disease (excluding AAV), pulmonary disease and cirrhosis.

\section{Diagnosis and classification}

Patients with a clinical diagnosis of AAV were eligible for inclusion in all four studies in this thesis. Classification of patients as having GPA, MPA or EGPA was made according to the EMA algorithm. Only primary AAV was included, excluding PAN, anti-GBM disease, secondary vasculitis and drug-induced vasculitis.

All SLE patients fulfilled the 1982 ACR classification criteria [252]. Histopathology classifications were performed according to the ISN/RPS 2003 classification of LN.

In Paper I, patients with EGPA were included in the estimation of annual incidence. In the remaining papers, patients with EGPA were excluded based on the differing clinical picture and outcome. In Papers I and II, only patients with renal involvement were included and the diagnosis was confirmed by renal biopsy in all cases. 


\section{Statistical methods}

All statistical analyses were performed using Statistical Package for the Social Sciences (SPSS) Statistics for Windows versions 21-24 (IBM, Armonk, NY, USA). P values $<0.05$ were considered significant and all analyses were two-sided. For hazard ratios (HR), odds ratios (OR), $\beta$-coefficients, SMR and incidence rates, 95\% confidence intervals (CI) were calculated.

Continuous variables were described as mean with standard deviation (SD) when normally distributed and as median with interquartile range (IQR) when non-normally distributed. Categorical variables were described as frequencies. Differences between groups were analysed using the Mann-Whitney or Kruskal-Wallis test for non-normally distributed or nonparametric data, the Student's t-test for normally distributed data and the chi-square test or Fisher's exact test for categorical data. An overview of the statistical methods used is shown in Table 6.

\section{Table 6. Overview of statistical methods}

\begin{tabular}{lllll}
\hline Statistical method & Paper I & Paper II & Paper III & Paper IV \\
\hline Descriptive statistics & & & & \\
\hline Mean with standard deviation (SD) & $\mathrm{X}$ & & & \\
\hline Median with interquartile range (IQR) & $\mathrm{X}$ & $\mathrm{X}$ & $\mathrm{X}$ & $\mathrm{X}$ \\
\hline Frequency & $\mathrm{X}$ & $\mathrm{X}$ & $\mathrm{X}$ & $\mathrm{X}$ \\
\hline Annual incidence rates & $\mathrm{X}$ & & & \\
\hline Analytic statistics & & & & \\
\hline Student's t-test & $\mathrm{X}$ & & & \\
\hline Mann-Whitney/Kruskal-Wallis test & $\mathrm{X}$ & $\mathrm{X}$ & $\mathrm{X}$ & $\mathrm{X}$ \\
\hline Chi-square/Fisher's exact test & $\mathrm{X}$ & $\mathrm{X}$ & $\mathrm{X}$ & $\mathrm{X}$ \\
\hline Regression analysis & & & & \\
\hline Binary logistic regression with odds ratios (OR) & & $\mathrm{X}$ & & $\mathrm{X}$ \\
\hline Linear regression with $\beta$-coefficient & & & & $\mathrm{X}$ \\
\hline Survival analysis & & & & \\
\hline Kaplan-Meier analysis with log-rank rest & $\mathrm{X}$ & & $\mathrm{X}$ & \\
\hline Cox regression with hazard ratios $(H R)$ & & & $\mathrm{X}$ & $\mathrm{X}$ \\
\hline
\end{tabular}

\section{Paper I}

Annual incidence rates were calculated using the number of cases as the numerator and the mean population between 1997 and 2008 in the two geographical areas as the denominator. The Kaplan-Meier method was used to estimate patient and renal survival and the log-rank test to evaluate differences in survival between ANCA-associated nephritis (AAN) and LN.

\section{Paper II}

Univariable and multivariable logistic regression analysis was used to assess associations between ANCA serotype (PR3-ANCA) and the variables gender, age, eGFR, latitude, longitude 
and UV radiation levels. Latitude and UV radiation were not entered in multivariable analysis simultaneously due to strong correlation.

\section{Paper III}

The Kaplan-Meier method was used to estimate overall and renal survival and the log-rank test to evaluate differences in survival between groups. Cox proportional hazards models were used to analyse time-dependent variables (time to death and time to ESRD). The proportional hazards assumption was checked using visual examination of the Kaplan-Meier curves and by investigating interaction terms. Censoring was performed at the day of loss to follow-up or completion of follow-up. Estimates of renal survival were censored for death. In analysis of treatment, patients who died within 30 days of diagnosis were excluded.

Both univariable and multivariable analyses were performed. The variables entered were chosen to reflect patient characteristics (age, gender and comorbidity score), disease severity (BVAS, CRP and creatinine), disease type (ANCA serotype) and treatment (cyclophosphamide or rituximab) based on previous studies and theoretical reasoning.

The SMR was calculated by dividing the observed death rates in the Swedish cohort with expected death rates in the general Swedish population matched for age and calendar year using life tables provided by Statistics Sweden.

\section{Paper IV}

Binary logistic regression analysis was used to analyse binary variables (readmission, treatment-related damage), linear regression analysis to analyse continuous variables (VDI score, total hospital time) and Cox regression analysis to analyse time-dependent variables (time to death caused by infection). Scatter plots and residual plots were examined to determine whether the assumption for linear regression was met. In addition to the variables described above for Paper III, cumulative oral and intravenous glucocorticoid dose were included.

\section{Ethical approval}

The collection of data on vasculitis patients in Skåne and Östergötland was approved by the Regional Ethical Review Board in Lund (numbers 2010/517, 2012/252). For Paper I, the collection of data on SLE patients was approved by the Regional Ethical Review Boards in Lund (number 2010/668) and Linköping (number M75-08/2008). For the remaining centres, the applicable ethical permits have been obtained according to national regulations. 
Incidence and Outcome of ANCA-Associated Vasculitis 


\section{RESULTS AND DISCUSSION}

\section{Paper I}

\section{Incidence}

The major finding in Paper I was that the incidence of biopsy-verified AAN was three times higher than the incidence of LN. The annual incidence rate per million adults in the two areas combined was estimated to be 13.2 (95\% CI 10.4-16.1) for AAN and 4.3 (95\% CI 2.7-6.0) for LN $(\mathrm{P}<0.001)$ (Table 7). The biopsy rate was $88 \%$ for $\mathrm{LN}$ and $67.9 \%$ for AAN, showing that the higher incidence of AAN cannot be explained by differences in the biopsy rate.

The incidence of AAN differed significantly between the two areas $(\mathrm{P}=0.001)$, mainly driven by a difference in MPA incidence. The reason for this discrepancy could be a true lower incidence in Östergötland, or lower completeness in the case retrieval. Capture-recapture analysis has been carried out on the case retrieval strategy in the Skåne area, but not in Östergötland. There is an established collaboration between the vasculitis registry in Linköping and the nephrology unit at a referring hospital, but it is possible that diagnosis of renal limited MPA cases in this part of the county was lower during the first part of the study period. It should also be noted that the incidence of MPA was lower in the Malmö area compared with the Lund area in a previous publication by our group [21].

\section{Table 7. Annual incidence rate of biopsy-proven AAN and LN}

\begin{tabular}{llllll}
\hline & AAN & MPA & GPA & EGPA & LN \\
\hline All & $13.2(10.4-16.1)$ & $9.7(7.2-12.1)$ & $3.4(1.9-4.8)$ & $0.2(0-0.5)$ & $4.3(2.7-6.0)$ \\
\hline Skåne area & $19.5(13.7-25.2)$ & $15.0(10.0-20.1)$ & $4.0(1.4-6.6)$ & $0.4(0-1.3)$ & $5.7(2.6-8.9)$ \\
\hline Östergötland area & $9.6(6.6-12.7)$ & $6.6(4.1-9.1)$ & $3.0(1.3-4.8)$ & o (0-0) & $3.5(1.7-5.4)$ \\
\hline
\end{tabular}

Incidence is presented per million inhabitants and year. Values between parentheses are $95 \%$ confidence intervals.

The incidence figures for renal AAV found in this study are similar to the incidence of 14.8 per million found in Japan [85] and 12.2 per million found in the United Kingdom [253]. Incidence numbers for $\mathrm{LN}$ described previously range from 4 per million in the United Kingdom and the Czech Republic [202, 206] to 4.5 per million in Norway [204], 5.6 per million in Spain [205] and 7 per million in the USA [203]. Since the incidence figures in this study are similar to previously published data, it is likely that AAN is also more common than LN in other Caucasian populations. As described in the introduction, LN is less common in Caucasians compared to other ethnic groups, and therefore our findings cannot readily be generalized to other parts of the world. 
Previous studies from the same area in Sweden found an annual incidence of SLE of 48 per million [254], while the incidence of AAV was 21 per million [21]. The higher incidence of AAN compared to LN is thus most likely due to a lower occurrence of nephritis in SLE patients compared to AAV patients in this and other Caucasian populations.

\section{Survival}

Mortality rates were significantly higher for the patients with AAN compared to $\mathrm{LN}(\mathrm{P}=0.001)$. The 1-, 5- and 10-year survival for patients with AAN was 85.4\%, 71.8\% and 48.3\% respectively. The corresponding figures for $\mathrm{LN}$ were $100 \%, 96.3 \%$ and $96.3 \%$ (Figure 4 ).
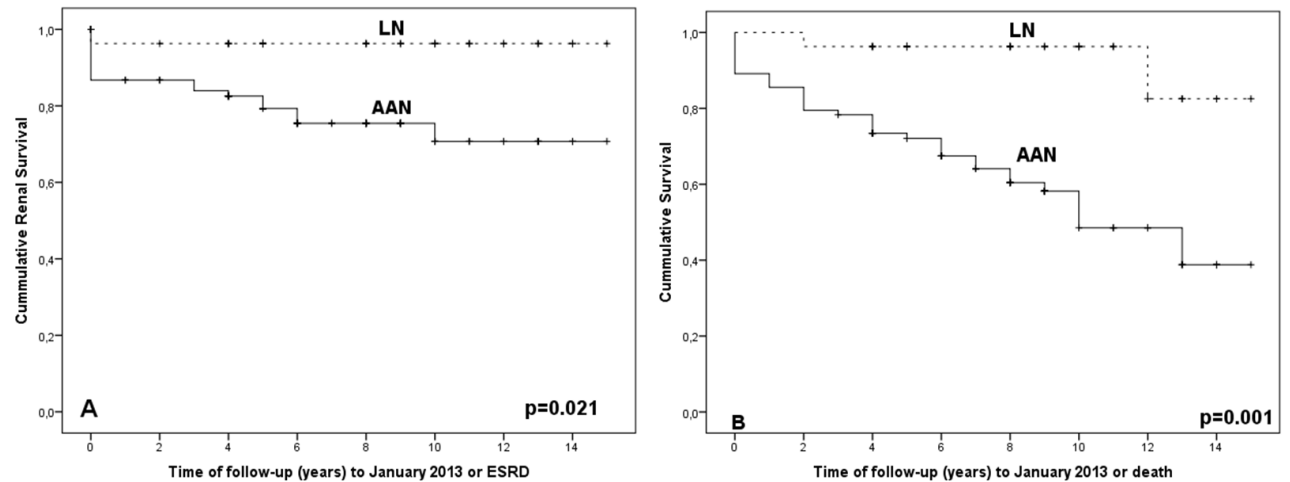

\section{Figure 4. Renal and patient survival}

Kaplan-Meier curves showing renal (A) and patient (B) survival in AAN and LN. $P$ values derived from the log-rank test.

Survival rates for AAN are comparable to previously described cohorts in the United Kingdom and Sweden $[156,157]$. The survival rates in the LN group are comparable to or better than other published data from SLE populations in Sweden and the USA [228, 254], and thus show a good prognosis despite renal involvement.

The worse survival seen in AAN was not surprising given the fact that age and severity of renal disease are associated with worse prognosis in both SLE and AAV [19, 230, 255]. Mean age at diagnosis was 65.5 years $(\mathrm{SD} \pm 13.9)$ in patients with AAN and 38.6 years $(\mathrm{SD} \pm 15.1)$ in patients with LN. Renal function at the time of biopsy was more severely impaired in AAN with a median creatinine at diagnosis of $249 \mu \mathrm{mol} / \mathrm{L}$ (IQR 161-392) compared to $77 \mu \mathrm{mol} / \mathrm{L}$ (IQR 64-100) in LN.

Due to the low number of deaths in the LN group, it was not possible to perform any analyses of predictors of mortality or further determine the relative contribution of age and renal function 
to the survival difference observed. Nor did we have very long-term data on the survival of LN patients. Whether or not mortality rates will be similar in the LN patients when they reach above 60-70 years to those observed in the AAN patients remains to be determined.

\section{Renal survival}

Renal survival was significantly worse for patients with AAN compared to patients with LN, and 19 of 20 patients who developed ESRD had AAN ( $\mathrm{P}=0.02)$ (Figure 4). The proportion of patients who developed ESRD was $23.2 \%$ for AAN and 3.7\% for LN during a mean follow-up period of 6.4 years. The frequency of AAV patients developing ESRD is similar to previously published numbers ranging from $20 \%$ to $40 \%$ [157, 162, 183, 256, 257].

The favourable renal outcome in LN described in this cohort is in line with the results from the long-term follow-up of the Euro-Lupus Nephritis Trial, in which 7\% developed ESRD [220]. In a Norwegian population-based study of LN conducted during a similar time period to Paper I, the frequency of ESRD was 20\% during a mean follow-up of 18 years [195]. In another Norwegian study renal outcome improved over time, with $11 \%$ developing ESRD in the early cohort (1978-1995) during a 10-year follow-up period, while there were no cases of ESRD in the more recent cohort (1996-2006). The use of hydroxychloroquine, pulse methylprednisolone, anticoagulants and anti-hypertensive treatment increased significantly in the more recent cohort, and the authors speculate that the lower incidence and more favourable renal outcome might be due to earlier institution of immunosuppressive, anticoagulant and antihypertensive therapies [204]. Among the patients with LN in our study, 63\% had a diagnosis of SLE established before the onset of nephritis, with a median time from diagnosis of SLE to diagnosis of nephritis of 50 months (IQR 16.5-186.5). All the AAN patients had renal involvement at the time of diagnosis. The latency between diagnosis of SLE and onset of nephritis allows for the initiation of therapy as described above, and this could affect renal outcome in a positive direction. This view is further supported by a meta-analysis of both prospective and retrospective studies as well as clinical trials in LN, showing a decreased risk of ESRD paralleled by an increased use of immunosuppressive treatment [237].

Success in terms of increased awareness, earlier diagnosis and treatment are probably key reasons behind the favourable prognosis observed in LN in Paper I. Since impaired renal function at diagnosis has consistently been shown to be associated with poor prognosis in AAV, these factors are most likely key elements in improving results in AAN as well. A recently published study on renal AAV showed better renal survival in a cohort of patients diagnosed in 2000-2010 compared to an older cohort diagnosed in 1988-1999 and significantly lower creatinine levels at diagnosis in the recent cohort, supporting this assumption [258]. Similar findings with improved renal survival paralleled by better renal function at diagnosis, indicating shorter diagnostic delay, have been reported also in other studies in ANCA-associated glomerulonephritis [183, 259]. 


\section{Paper II}

\section{Geographical pattern}

The latitude of the participating centres spanned a large distance, between $35.8^{\circ} \mathrm{N}$ and $69.6^{\circ} \mathrm{N}$ and the UV radiation levels varied between $5246 \mathrm{mWh} / \mathrm{m}^{2}$ in the northernmost centre and $14565 \mathrm{mWh} / \mathrm{m}^{2}$ in the southernmost centre in Europe. Table 8 shows demographic and geographical factors at the time of biopsy.

\section{Table 8. Demographic and geographical factors}

\begin{tabular}{|c|c|c|c|c|c|c|c|}
\hline Centre & $\mathbf{N}$ & $\begin{array}{l}\text { ANCA \% } \\
\text { PR3/MPO }\end{array}$ & $\begin{array}{l}\text { Gender \% } \\
\text { M/F }\end{array}$ & Age & eGFR ${ }^{1}$ & Latitude & UVR \\
\hline Tromsø & 21 & $57.1 / 42.9$ & $52.4 / 47.6$ & $60(51-69)$ & $17(7-25)$ & $69.6^{\circ} \mathrm{N}$ & 5246 \\
\hline Trondheim & 62 & $53.2 / 46.8$ & $45 \cdot 2 / 54.8$ & $68(58-76)$ & $20(8-38)$ & $63.4^{\circ} \mathrm{N}$ & 6616 \\
\hline Bergen & 88 & $44 \cdot 3 / 55 \cdot 7$ & $52.3 / 47.7$ & $62(49-75)$ & $27(15-54)$ & $60.4^{\circ} \mathrm{N}$ & 7082 \\
\hline Oslo & 140 & $48.6 / 51.4$ & $54 \cdot 3 / 45 \cdot 7$ & $65(53-74)$ & $19(10-40)$ & $59.9^{\circ} \mathrm{N}$ & 7623 \\
\hline Linköping & 49 & $30.6 / 69.4$ & $61.2 / 38.8$ & $70(61-75)$ & $26(18-37)$ & $58.4^{\circ} \mathrm{N}$ & 9398 \\
\hline Glasgow & 238 & $43.7 / 56.3$ & $45.8 / 54.2$ & $67(59-75)$ & $15(9-27)$ & $55 \cdot 9^{\circ} \mathrm{N}$ & 8086 \\
\hline Lund & 72 & $48.6 / 51.4$ & $51.4 / 48.6$ & 66 (54-75) & $24(13-44)$ & $55 \cdot 7^{\circ} \mathrm{N}$ & 10087 \\
\hline Cambridge & 54 & $40.7 / 59.3$ & $57.4 / 42.6$ & $64(58-73)$ & $20(10-43)$ & $52.2^{\circ} \mathrm{N}$ & 9851 \\
\hline Prague & 305 & $52.5 / 47.5$ & $53.4 / 46.6$ & $59(52-67)$ & $23(13-47)$ & $50.1^{\circ} \mathrm{N}$ & 12262 \\
\hline Zagreb & 42 & $28.6 / 71.4$ & $45.2 / 54.8$ & $64(47-70)$ & $12(7-20)$ & $45.8^{\circ} \mathrm{N}$ & 14395 \\
\hline Milan & 71 & $39.4 / 60.6$ & $46.5 / 53.5$ & $68(61-74)$ & $15(8-25)$ & $45 \cdot 5^{\circ} \mathrm{N}$ & 13874 \\
\hline Rome & 25 & $36.0 / 64.0$ & $60.0 / 40.0$ & $65(56-70)$ & $8(6-21)$ & $41.9^{\circ} \mathrm{N}$ & 14565 \\
\hline Maryland & 71 & $42.3 / 57.7$ & $43.7 / 56.3$ & $63\left(55^{-72}\right)$ & $18(10-29)$ & $39.0^{\circ} \mathrm{N}$ & \\
\hline North Carolina & 170 & $40.6 / 59.4$ & $55 \cdot 3 / 44 \cdot 7$ & $59(49-72)$ & $18(10-36)$ & $35.8^{\circ} \mathrm{N}$ & \\
\hline
\end{tabular}

Data are expressed as \% or median (IQR). ${ }^{1}$ Data missing in 84 patients. UV radiation (UVR) levels in $\mathrm{mWh} / \mathrm{m}^{2}$; eGFR in $\mathrm{ml} / \mathrm{min} / 1,73 \mathrm{~m}^{2}$.

Increasing age was associated with lower odds of PR3-ANCA positivity, while increasing eGFR and male gender were associated with higher odds of PR3-ANCA positivity (Table 9). The association was seen in both univariable and multivariable analysis, and both when analysing the entire study population and when restricting the analysis to the European patients. Our results support the view that patients with PR3-ANCA positivity are in general younger and have better renal function at diagnosis compared to patients with MPO-ANCA positivity [27, 173]. Higher proportion of PR3-ANCA positivity in men has also been reported in previous studies [19, 173]. In multivariable analysis, higher latitude was associated with higher odds of PR3-ANCA positivity (Table 9). When analysing the European patients separately, the results remained essentially the same. For UV radiation levels an opposite association was found with 
lower odds of PR3-ANCA positivity with increasing UV radiation levels (OR per $\mathrm{Wh} / \mathrm{m}^{2}$ 0.94; 95\% CI 0.89-0.99; $\mathrm{P}=0.038$ ).

\section{Table 9. Analysis of ANCA serotype}

\begin{tabular}{lllll}
\hline \multirow{2}{*}{ Variables } & \multicolumn{2}{l}{ Univariable analysis } & \multicolumn{2}{l}{ Multivariable analysis } \\
OR $(95 \% \mathrm{CI})$ & P value & OR $(95 \% \mathrm{CI})$ & P value \\
\hline Age (per year) & $0.97(0.96-0.98)$ & $<0.001$ & $0.97(0.97-0.98)$ & $<0.001$ \\
\hline Gender (male) & $2.12(1.71-2.62)$ & $<0.001$ & $1.98(1.58-2.49)$ & $<0.001$ \\
\hline eGFR (per ml/min/1.73 m²) & $1.01(1.01-1.02)$ & $<0.001$ & $1.01(1.00-1.01)$ & 0.012 \\
\hline Latitude (per 10 units) & $1.12(0.99-1.27)$ & 0.071 & $1.29(1.05-1.58)$ & 0.016 \\
\hline Longitude (per 10 units) & $1.03(0.99-1.06)$ & 0.11 & $0.98(0.93-1.03)$ & 0.34 \\
\hline
\end{tabular}

The OR refers to the probability of being PR3-ANCA positive.

Previous studies on the geographical distribution of AAV have mainly been focused on the clinical entities MPA and GPA, while associations between latitude and ANCA serotype have not previously been explored. Our selection of patients is in line with the suggested clustering of AAV patients into non-renal AAV and renal AAV and further into PR3-ANCA positive and PR3-ANCA negative renal AAV [27].

The association between PR3-ANCA and latitude observed is consistent with the hypothesis that GPA/PR3-ANCA is more common at northern latitudes and lower UV radiation levels [92, 116]. However, it was only significant in multivariable analysis when adjusting for age, gender and renal function. Previous epidemiological studies have shown large differences in the incidence of GPA in different regions in Europe, from 2.8 per million inhabitants in Italy [83] to 14.4 per million in Norway [23].

In renal AAV, the proportion of MPO-ANCA and PR3-ANCA positivity is more equal compared to non-renal AAV in which PR3-ANCA and GPA predominate [27, 173]. ANCA negativity is more common in limited and localized forms of GPA [28, 260], and it has been suggested that the underlying pathogenesis is different with localized forms being caused by granulomatous inflammation and a more predominant Th1 response [22]. Since we only included patients with renal biopsy-proven glomerulonephritis, patients with GPA limited to the upper airways were excluded and whether this disease type is more common at northern latitudes and contribute to the described north-south gradient in the occurrence of GPA remains to be determined.

There are genetic differences between populations in the north and south of Europe [261], and most likely also in the populations in North Carolina and Maryland given their mixed origins from Latin America, Africa and Europe. When limiting the analysis to northern and central Europe, our aim was to analyse a more genetically homogeneous population. Interestingly, the association between ANCA serotype and latitude and UV radiation level was lost in this sub-analysis (Table 10). 
Given the large difference in UV radiation levels between the centres included, the paucity of a significant association between serotype and UV radiation could speak in favour of genetic differences along a latitudinal gradient rather than environmental factors such as UV radiation. This is supported by a study from Europe showing that the association between GPA incidence and latitude was due to the distribution of $H L A-D P B * 0401$ allele frequency [127], a gene variant associated with PR3-ANCA positivity. Further support for this hypothesis comes from a recent analysis of data from several rheumatology units, in which an increased chance of MPO-ANCA positivity (compared with PR3-ANCA) was found in Caucasian Americans and southern Europeans compared with northern Europeans, although the latter did not reach statistical significance [262].

\section{Table 10. Analysis of ANCA serotype in northern and central Europe}

\begin{tabular}{lll}
\hline Variables & OR (95\% CI) & Pvalue \\
\hline Age $($ per year) & $0.98(0.97-0.99)$ & $<0.001$ \\
\hline Gender (male) & $2.01(1.54-2.63)$ & $<0.001$ \\
\hline eGFR $\left(\right.$ per $\left.\mathrm{ml} / \mathrm{min} / 1.73 \mathrm{~m}^{2}\right)$ & $1.01(1.00-1.01)$ & 0.021 \\
\hline Latitude $($ per 1o units) & $1.14(0.85-1.52)$ & 0.38 \\
\hline Longitude (per 10 units) & $1.00(0.84-1.19)$ & 0.99 \\
\hline
\end{tabular}

The OR refers to the probability of being PR3-ANCA positive. Showing results from multivariable analysis.

\section{Biopsy rate}

Since the study only included biopsy-proven cases of nephritis, a comparison was made between biopsied and non-biopsied cases with AAV and renal involvement at the Linköping, Lund and Cambridge centres. The overall biopsy rate was $68.9 \%$. In Linköping the figure was $71 \%$, which can be compared to the biopsy rate of $67.9 \%$ found in Paper I. Biopsied patients were significantly younger (67 years vs 74 years; $\mathrm{P}=0.002)$ and more often MPO-ANCA positive $(58.9 \%$ vs $43.0 \%$; $\mathrm{P}=0.019)$ compared to non-biopsied patients, which would underestimate the number of PR3-ANCA positive patients in the study. The reasons for this difference could be that PR3-ANCA positive patients have more extra-renal manifestations and that diagnosis is confirmed by biopsy of another organ, or that MPO-ANCA positive patients have more severe renal disease strengthening the indication for renal biopsy.

It is not possible to rule out the possibility that there are differences in biopsy policies between the centres, and this is important to consider when interpreting the results. However, it is not likely that minor differences in the tendency to perform renal biopsy in patients with a clinical diagnosis of AAV and renal involvement would have altered the main findings of the study. 


\section{Paper III}

\section{Demographics}

Renal involvement was seen in $92 \%$ of the patients, while ENT involvement was only present in $15 \%$ at diagnosis. This is in line with the observation that older patients with AAV have more renal and less ENT involvement [263]. The majority of the patients had MPA and were MPO/PANCA positive, which is consistent with the findings in other studies of older patients [158, 161]. Demographic and clinical factors at the time of diagnosis are shown in Table 11.

\section{Table 11. Demographic and clinical factors}

\begin{tabular}{|c|c|c|c|c|}
\hline Variables & All $(n=151)$ & $\operatorname{MPA}(n=105)$ & $\operatorname{GPA}(n=46)$ & P value \\
\hline Female gender & $50 \%(75)$ & $53 \%(56)$ & $41 \%(19)$ & 0.17 \\
\hline Age & $79(77-82)$ & $79(77-82)$ & $78(76-81)$ & 0.16 \\
\hline \multicolumn{5}{|l|}{$A N C A^{1}$} \\
\hline MPO/P-ANCA & $60 \%(89)$ & $75 \%(78)$ & $24 \%(11)$ & $<0.001$ \\
\hline $\mathrm{PR}_{3} / \mathrm{C}-\mathrm{ANCA}$ & $36 \%(53)$ & $18 \%(19)$ & $76 \%(34)$ & $<0.001$ \\
\hline Double-positive & $1 \%(2)$ & $2 \%(2)$ & $0 \%(0)$ & $>0.99$ \\
\hline Negative & $3 \%(5)$ & $5 \%(5)$ & o\% (o) & 0.32 \\
\hline Creatinine $\mu \mathrm{mol} / L^{2}$ & $283(152-458)$ & $332(201-503)$ & $180(86-287)$ & $<0.001$ \\
\hline$C R P \mathrm{mg} / \mathrm{L}^{3}$ & $75(18-134)$ & $62(15-123)$ & $119(50-156)$ & $<0.001$ \\
\hline$B V A S^{4}$ & $15(12-19)$ & $14(12-18)$ & $17(13-21)$ & 0.02 \\
\hline \multicolumn{5}{|l|}{ Organ involvement 5} \\
\hline General & $63 \%(82)$ & $62 \%(56)$ & $65 \%(26)$ & 0.71 \\
\hline Cutaneous & $9 \%(12)$ & $10 \%(9)$ & $8 \%(3)$ & 0.76 \\
\hline Mucous/eyes & $5 \%(7)$ & o\% (o) & $18 \%(7)$ & $<0.001$ \\
\hline ENT & $15 \%(20)$ & $3 \%(3)$ & $43 \%(17)$ & $<0.001$ \\
\hline Chest & $34 \%(44)$ & $25 \%(23)$ & $53 \%(21)$ & 0.002 \\
\hline Cardiovascular & $5 \%(7)$ & $4 \%(4)$ & $8 \%(3)$ & 0.44 \\
\hline Abdominal & $3 \%(4)$ & $3 \%(3)$ & $3 \%(1)$ & $>0.99$ \\
\hline Renal & $92 \%(121)$ & $98 \%(89)$ & $80 \%(32)$ & $<0.001$ \\
\hline Nervous system & $16 \%(21)$ & $15 \%(14)$ & $18 \%(7)$ & 0.76 \\
\hline Dialysis dependency 6 & $31 \%(45)$ & $34 \%(35)$ & $22 \%(10)$ & 0.14 \\
\hline \multicolumn{5}{|l|}{ Comorbidity score } \\
\hline o & $40 \%(61)$ & $36 \%(38)$ & $50 \%(23)$ & 0.11 \\
\hline 1 & $35 \%(53)$ & $35 \%(37)$ & $35 \%(16)$ & 0.96 \\
\hline 2 & $19 \%(29)$ & $22 \%(23)$ & $13 \%(6)$ & 0.20 \\
\hline $3-4$ & $5 \%(8)$ & $7 \%(7)$ & $2 \%(1)$ & 0.44 \\
\hline \multicolumn{5}{|l|}{ Comorbidities } \\
\hline Hypertension & $46 \%(70)$ & $49 \%(51)$ & $41 \%(19)$ & 0.41 \\
\hline Heart failure & $8 \%(12)$ & $10 \%(11)$ & $2 \%(1)$ & 0.11 \\
\hline Diabetes & $15 \%(22)$ & $14 \%(15)$ & $15 \%(7)$ & 0.88 \\
\hline Ischemic heart disease & $19 \%(28)$ & $23 \%(24)$ & $9 \%(4)$ & 0.04 \\
\hline Stroke & $13 \%(20)$ & $14 \%(15)$ & $11 \%(5)$ & 0.57 \\
\hline Malignancy & $15 \%(22)$ & $12 \%(13)$ & $20 \%(9)$ & 0.25 \\
\hline Pulmonary disease & $12 \%(18)$ & $16 \%(17)$ & $2 \%(1)$ & 0.01 \\
\hline
\end{tabular}

Values are presented as \% (n) or median (interquartile range) and exclude missing data. ${ }^{1}$ Data missing for two patients; ${ }^{2}$ data missing for nine patients; ${ }^{3}$ data missing for six patients; ${ }^{4}$ data missing for four patients; 5 data missing for 20 patients; ${ }^{6}$ data missing for four patients. 
Comorbidities were common, with $60 \%$ of the patients having some degree of comorbidity according to the modified version of the Davies score. In addition to this, $46 \%$ had hypertension prior to the diagnosis of AAV.

\section{Treatment}

Complete treatment data for patients alive 30 days after diagnosis were available for 130 patients. These were divided into six groups as shown in Table 12. In total, 78.5\% had received cyclophosphamide or rituximab. The cut-off for cyclophosphamide dose was chosen to reflect the minimum dose that would have been administered if there was an intention to treat the patient, reasoning that three intravenous pulses or 30 days of continuous oral cyclophosphamide would have been given to patients surviving the first month.

\section{Table 12. Treatment groups}

\begin{tabular}{lll}
\hline Treatment group & Description & N (\%) \\
\hline Oral cyclophosphamide & $\geq 2000$ mg during first three months & $46(35.4 \%)$ \\
\hline Intravenous cyclophosphamide & $\geq 1500$ mg during first three months & $40(30.8 \%)$ \\
\hline Rituximab & Any dose of rituximab & $16(12.3 \%)$ \\
\hline Steroids & $\geq 30$ mg prednisolone/day & $2(1.5 \%)$ \\
\hline Other & $\begin{array}{l}\text { Azathioprine, methotrexate, MMF, } \\
\text { low dose cyclophosphamide }\end{array}$ & $19(14.6 \%)$ \\
\hline Untreated & $\begin{array}{l}<30 \text { mg prednisolone/day, no other } \\
\text { immunosuppressive therapy }\end{array}$ & $7(5.4 \%)$ \\
\hline
\end{tabular}

When comparing the patients who had received cyclophosphamide or rituximab with those who had not received such therapy (other, steroids and untreated groups), there were no significant differences with regard to creatinine level, BVAS, dialysis dependency or comorbidities at diagnosis, showing that at the group level they were comparable in terms of disease severity and comorbidity. As a group, the patients in Paper III did not present with mild disease that could motivate less intensive treatment than what is recommended in current guidelines for organ- or life-threatening disease [135]. Rather, renal involvement was seen in a great majority of the patients, median creatinine at diagnosis was $283 \mu \mathrm{mol} / \mathrm{L}$ (IQR 152-458) and median BVAS was 15 (IQR 12-19). 


\section{Survival}

The overall 1- and 2-year survival in patients aged 75 years or more was $71.5 \%$ and $64.6 \%$. These survival figures are, not surprisingly, lower than previously reported in younger patients $[19,157]$, but largely similar to other cohorts of older patients in which the reported 1-year mortality has varied between $20 \%$ and $40 \%$ [33, 186, 190, 239]. Older age, higher creatinine and lower BVAS were all associated with mortality when analysing the entire cohort (Figure $5)$.

A

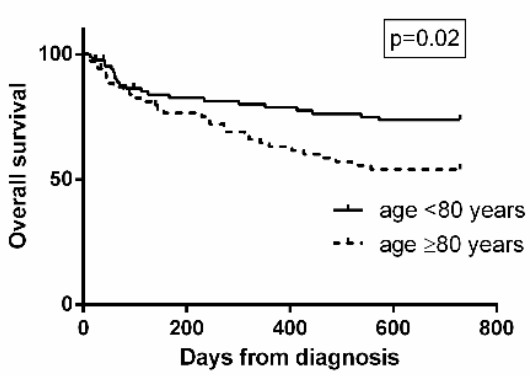

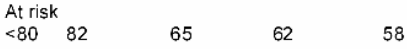

$\begin{array}{lllll}80 & 69 & 51 & 42 & 36\end{array}$

C

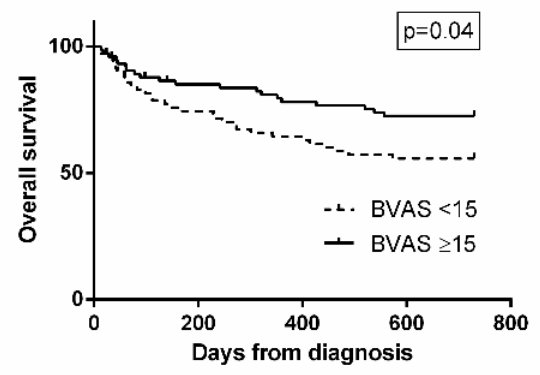

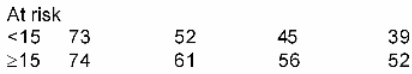

B

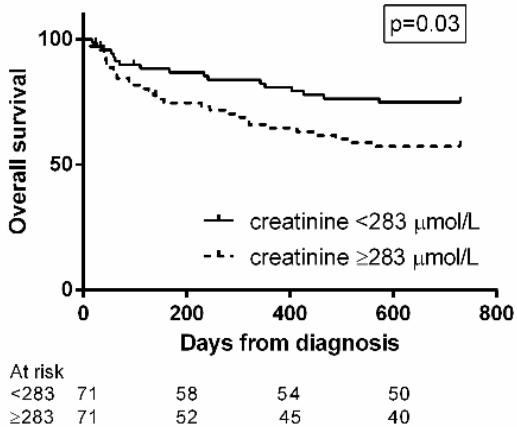

D

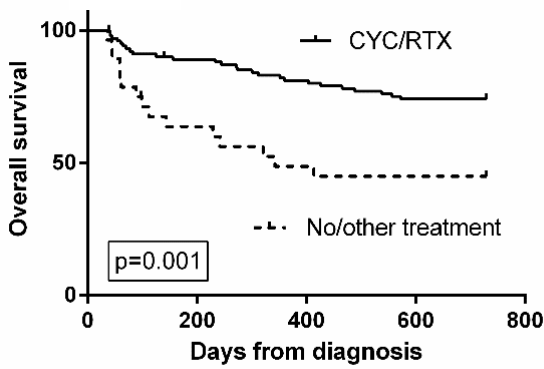

At risk

CYC/RTX $102 \quad 89 \quad 81 \quad 14$

\section{Figure 5. Patient survival}

Kaplan-Meier curves showing patient survival according to age (A), creatinine (B), BVAS (C) and treatment (D). P values derived from the log-rank test.

Higher age and worse renal function have been shown to predict mortality in a number of studies, in both older and younger patients [19, 29, 158], while previous studies have found an association between higher BVAS and higher mortality $[19,158]$, contrary to our results. We speculate that the reverse association between BVAS and mortality could be due to patients 
with few extra-renal symptoms being diagnosed at a later stage with more irreversible renal damage and higher mortality. Median BVAS in patients with renal-limited disease was 12 (IQR 9-12) compared to 16 (IQR 13-19) in patients with more than one organ system involved $(\mathrm{P}<0.001)$.

In analysis of treatment, patients in the intravenous/oral cyclophosphamide and rituximab groups were compared with the remaining patients. Mortality was significantly higher in those patients who had not been treated with cyclophosphamide or rituximab (Table 13, Figure 5). When treatment was included in the multivariable analysis, age and creatinine level remained significant predictors of mortality, while BVAS lost its significance. Two-year survival was $72.9 \%$ for patients treated with oral cyclophosphamide, $72.5 \%$ for intravenous cyclophosphamide, $81.3 \%$ for rituximab and $45.0 \%$ for no/other treatment. Also when considering all cyclophosphamide doses as standard therapy, there was a clear survival benefit in the treatment group. Our findings are in line with the study by Bomback et al. showing better survival for elderly patients above 80 years of age treated with immunosuppressive therapy [264].

\section{Table 13. Analysis of mortality at two years}

\begin{tabular}{lllll}
\hline & \multicolumn{2}{l}{ Univariable analysis } & \multicolumn{2}{l}{ Multivariable analysis } \\
Variables & $\mathrm{HR}(95 \% \mathrm{CI})$ & $\mathrm{P}$ value & $\mathrm{HR}(95 \% \mathrm{CI})$ & P value \\
\hline Age (per year) & $1.15(1.07-1.25)$ & $<0.001$ & $1.13(1.04-1.23)$ & 0.003 \\
\hline Male gender & $1.17(0.63-2.15)$ & 0.62 & $1.37(0.69-2.73)$ & 0.37 \\
\hline BVAS (per point) ${ }^{1}$ & $0.94(0.89-0.99)$ & 0.05 & $0.94(0.88-1.01)$ & 0.09 \\
\hline MPO/P-ANCA ${ }^{1}$ & $0.88(0.47-1.67)$ & 0.71 & $0.74(0.36-1.51)$ & 0.41 \\
\hline CRP (per quartile) ${ }^{2}$ & $1.01(0.77-1.33)$ & 0.94 & $1.01(0.72-1.42)$ & 0.95 \\
\hline Creatinine (per quartile) ${ }^{3}$ & $1.47(1.08-2.00)$ & 0.01 & $1.40(1.02-1.92)$ & 0.04 \\
\hline Comorbidity score (per point) & $1.32(0.90-1.93)$ & 0.16 & $1.48(0.97-2.26)$ & 0.07 \\
\hline Cyclophosphamide/rituximab & $0.35(0.18-0.66)$ & 0.001 & $0.40(0.19-0.87)$ & 0.02 \\
\hline
\end{tabular}

Analysis of 130 patients with complete treatment data. Multivariable analysis performed on 119 patients. ${ }^{1}$ Data missing for one patient; ${ }^{2}$ data missing for four patients; ${ }^{3}$ data missing for six patients.

\section{Standardized mortality ratio}

There are several studies comparing the mortality rate in AAV patients with that in the normal population. In a meta-analysis including a total number of 3338 patients with AAV included in observational studies between 1966 and 2009, the meta-SMR was 2.71 (95\% CI 2.26-3.24), with a non-significant trend towards lower SMR in the more recent cohorts [265].

The SMR for the Swedish cohort aged 75-84 years in Paper III was 3.69 (95\% CI 2.45-5.55). In the first year it was 5.04 (95\% CI 3.13-8.11), while it was not significantly increased in the second year (SMR 1.86; 95\% CI 0.77-4.47). In comparison, the SMR in a cohort of patients 
with ANCA-associated glomerulonephritis retrieved from the Norwegian Kidney Biopsy Registry was 2.8 (95\% CI 2.4-3.3), and during the first year after diagnosis it was 10.8 (95\% CI 8.6-13.5). Similar to our findings, the mortality rate in patients surviving the first year without ESRD was not increased compared to the general population [183].

In a recent study based on the Norwegian systemic connective tissue disease and vasculitis registry (NOSVAR) based at the Rheumatology Department in Oslo, the SMR for AAV was found to be 1.5 (95\% CI 1.0-2.1) [234]. The reason for the discrepancy between this result and the results in Paper III and the study from the Norwegian Kidney Biopsy Registry is probably that fewer of the patients in NOSVAR had severe renal involvement. This is supported by a previous study by our group showing an SMR of 3.22 (95\% CI 2.21-4.23) in patients with primary systemic vasculitis and renal involvement compared to 1.46 (95\% CI 0.29-2.62) in patients without renal involvement [21].

\section{Renal survival}

Dialysis dependency at presentation was seen in $30.6 \%$ of the patients. By the end of the first year, 37 patients $(24.5 \%$ ) had developed ESRD (need for dialysis $>90$ days), which is similar to previous studies on elderly patients [86, 186, 187, 190, 239]. Renal survival censored for death at two years was $74.8 \%$.

Creatinine level at diagnosis was the only significant predictor of ESRD (HR 4.10 per quartile; 95\% CI 2.25-7.49; $\mathrm{P}<0.001$ ) (Figure 6), indicating that early recognition before severe renal impairment has developed is important for improving renal survival in elderly patients.

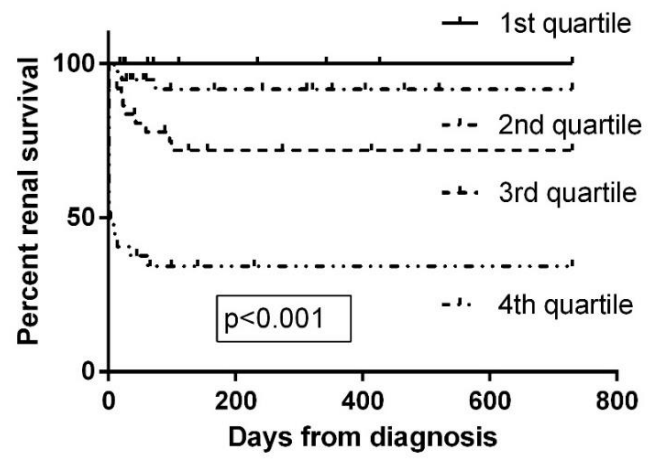

\section{Figure 6. Renal survival}

Kaplan-Meier curve depicting renal survival censored for death divided according to serum creatinine at diagnosis ( $1^{\text {st }}$ quartile $61-153 \mu \mathrm{mol} / \mathrm{L}$, $2^{\text {nd }}$ quartile $154-295 \mu \mathrm{mol} / \mathrm{L}, 3^{\text {rd }}$ quartile $296-501 \mu \mathrm{mol} / \mathrm{L}, 4^{\text {th }}$ quartile $502 \mu \mathrm{mol} / \mathrm{L}$-dialysis dependency). P value derived from the log-rank test. 
Censoring the analysis for death decreases the number of individuals at risk of ESRD and overestimates the probability of the event compared to analyses in which death is treated as a competing risk. However, we were indeed interested in the risk of ESRD in those patients who did not die, and found a fairly favourable outcome in patients surviving the first year with no new cases of ESRD occurring during the second year after diagnosis.

Treatment with cyclophosphamide or rituximab was not associated with the risk of ESRD (HR 1.88; 95\% CI 0.61-5.77; $\mathrm{P}=0.27$ ). This differs from the results of Bomback et al., who showed that renal survival was better in patients treated with immunosuppressive therapy [264]. Many of the patients reaching ESRD in Paper III were dialysis dependent at the time of diagnosis, and presumably already had renal damage that was not reversible despite immunosuppressive therapy. Still, $26.7 \%$ of the patients who presented with dialysisdependency recovered independent renal function. Among these, a larger proportion had received plasma exchange $(81.8 \%)$ compared to those who did not recover renal function (53.8\%), although this was not statistically significant $(\mathrm{P}=0.15)$. Interestingly, Lee et al. have presented a model in which the likelihood of treatment response (defined as dialysis independency and no signs of active vasculitis) was seen in $>14 \%$ of patients even with severely impaired renal function at diagnosis and a high chronicity score on renal biopsy, arguing that there is no threshold below which there is no chance for renal recovery [266]. In a study of patients with AAV requiring dialysis at presentation $43 \%$ had ESRD three months after diagnosis, with a statistically similar proportion in the older cohort aged above 60 years compared to the younger cohort (50\% vs $33 \%$; $\mathrm{P}=0.37)$ [188]. 


\section{Paper IV}

\section{Treatment}

Complete data on treatment in patients alive after 30 days from diagnosis were available for 167 patients. These were divided up as described for Paper III, and further into three groups: CYC (intravenous or oral cyclophosphamide; $n=112$ ), RTX (any dose of rituximab; $n=24$ ) and no/other treatment (low dose cyclophosphamide, azathioprine, MMF, methotrexate, steroids only, no treatment; $n=31$ ). Intravenous methylprednisolone was given in $45.5 \%$ of the patients.

\section{Damage}

Two years after diagnosis, the median VDI score was 2 (IQR 1-3) in patients surviving to that point. Almost all patients developed some degree of permanent damage during follow-up. Only $3.7 \%$ had no damage item at two years, even though five or more items was only seen in $6.5 \%$ of the patients. This can be compared to the data from long-term follow-up of several randomized trials in Europe conducted by the EUVAS and a population-based study from Sweden in which $8 \%$ and $9 \%$ of patients had no items of damage and $34 \%$ and $56 \%$ had five or more items $[153,178]$. It is important to remember that the damage items in Paper IV were recorded in patients alive at one and two years, and that severe damage might have been overrepresented in those who died, as shown by Exley et al. [152].

The pattern of damage is largely dependent on the organ involvement at diagnosis, and differs depending on the studied population. In studies of damage in GPA patients, ENT damage is far more common $[24,179]$ compared to the frequency found in this elderly population with predominance of MPA. Instead, renal damage predominated (Figure 7). Renal and cardiovascular damage were most common in the follow-up of the EUVAS trials, although ENT damage was also seen more frequently [153]. In the Swedish study, cardiovascular damage was most common, followed by renal damage. In patients aged above 65 years renal damage was most frequent, similar to our results [178].

When comparing damage items with those found in younger cohorts, it is important to bear in mind that items can only be scored if they occurred after the onset of vasculitis. Comorbidities present at diagnosis can thus not be recorded in the VDI. Since almost half the patients had hypertension at presentation, cardiovascular damage is underestimated in the elderly patients in Paper IV. This inherent restriction of the damage score would however not affect the comparison between treated and untreated patients since the presence of comorbidities did not differ. 


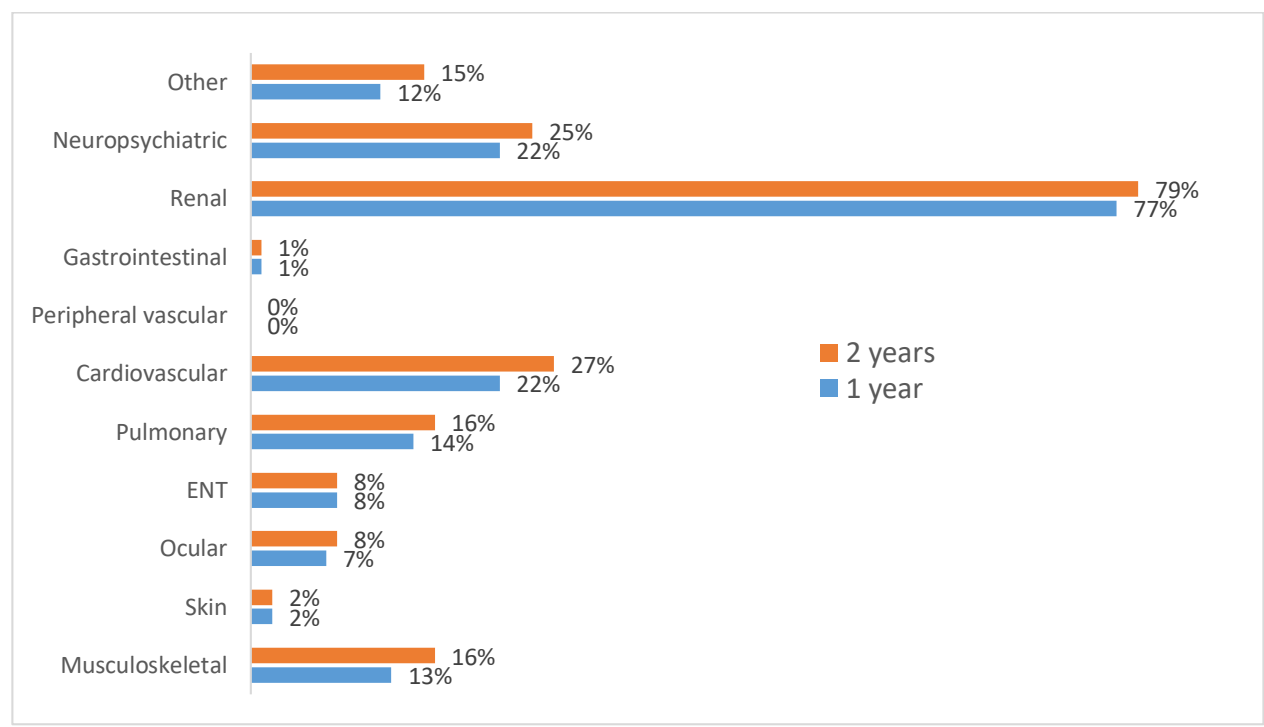

\section{Figure 7. Vasculitis Damage Index items}

Frequency of damage items at one and two years in patients surviving two years $(\mathrm{N}=108)$.

In multivariable analysis, BVAS was positively associated with VDI score at two years, while there was a negative association with treatment with cyclophosphamide or rituximab (Table 14). Patients treated with cyclophosphamide or rituximab had a median VDI of 2 (IQR 1-3) at two years, which can be compared to a median VDI of 3 (IQR 2-4) in patients not given such treatment $(\mathrm{P}=0.09)$.

The starting point for the study was the question of whether the increased survival seen in treated patients in Paper III was accompanied by an increase in permanent organ damage. Instead, the opposite was found, suggesting that treatment can halt the disease process leading to development of permanent organ damage. In a previous study on damage development in GPA patients, the cumulative dose of cyclophosphamide was associated with increasing VDI score during follow-up. However, treatment with cyclophosphamide during the first six months and pulsed intravenous compared to daily oral cyclophosphamide were associated with reduced VDI score. The authors suggested that this is because cyclophosphamide has an effect on initial disease activity, while long-term high cumulative doses increase the risk of damage development [24]. This hypothesis is supported by our results of an inverse association between induction treatment with cyclophosphamide/rituximab and permanent damage. 


\section{Table 14. Vasculitis Damage Index at two years}

\begin{tabular}{|c|c|c|c|c|}
\hline \multirow[b]{2}{*}{ Variable } & \multicolumn{2}{|c|}{ Univariable analysis } & \multicolumn{2}{|c|}{ Multivariable analysis } \\
\hline & $\beta(95 \% \mathrm{CI})$ & $P$ value & $\beta(95 \% \mathrm{CI})$ & $P$ value \\
\hline Age (per year) & $0.008(-0.08-0.095)$ & 0.86 & $0.026(-0.065-0.12)$ & 0.57 \\
\hline Male gender & $-0.29(-0.85-0.27)$ & 0.31 & $-0.32(-0.89-0.25)$ & 0.26 \\
\hline$B V A S$ (per point) ${ }^{1}$ & $0.076(0.027-0.13)$ & 0.002 & $0.096(0.037-0.16)$ & 0.002 \\
\hline$M P O / P-A N C A$ & $-0.45(-1.03-0.13)$ & 0.13 & $-0.072(-0.72-0.57)$ & 0.82 \\
\hline$C R P(\text { per percentile })^{2}$ & $-0.038(-0.21-0.13)$ & 0.66 & $-0.18(-0.34-0.007)$ & 0.059 \\
\hline Creatinine (per percentile) 3 & $0.023(-0.16-0.21)$ & 0.81 & $-0.068(-0.26-0.12)$ & 0.48 \\
\hline $\begin{array}{l}\text { Comorbidity score } \\
\text { (per point) }\end{array}$ & $0.19(-0.17-0.55)$ & 0.29 & $0.12(-0.24-0.48)$ & 0.52 \\
\hline $\begin{array}{l}\text { Cyclophosphamide/ } \\
\text { rituximab }\end{array}$ & $-0.82(-1.66-0.022)$ & 0.056 & $-1.16(-2.09--0.23)$ & 0.015 \\
\hline $\begin{array}{l}\text { Prednisolone dose } \\
\text { (per percentile) }\end{array}$ & $-0.002(-0.18-0.17)$ & 0.98 & $0.005(-0.19-0.20)$ & 0.96 \\
\hline $\begin{array}{l}\text { Methylprednisolone dose } \\
\text { (per } 250 \mathrm{mg} \text { ) }\end{array}$ & $-0.004(-0.11-0.11)$ & 0.95 & $0.059(-0.064-0.18)$ & 0.34 \\
\hline $\begin{array}{l}\text { Year of diagnosis } \\
\text { (per year from 1997) }\end{array}$ & $-0.09\left(-0.15^{--0.025)}\right.$ & 0.007 & $-0.046(-0.12-0.025)$ & 0.20 \\
\hline
\end{tabular}

Analysis of 108 patients with complete treatment data and data on VDI at two years. Multivariable analysis performed on 100 patients. ${ }^{1}$ Data missing for two patients; ${ }^{2}$ data missing for five patients; 3 data missing for two patients.

Treatment-related damage was seen in $26.9 \%$ of the patients alive at two years. This is lower than the frequency of $58 \%$ reported for patients aged above 65 years in a previous study with longer follow-up [178], but higher than the frequency of $15 \%$ described from the WGET trial [179]. Cumulative methylprednisolone dose during the first three months was associated with higher odds of treatment-related damage at two years (OR per $250 \mathrm{mg} 1.25$; 95\% CI 1.01-1.55; $\mathrm{P}=0.043$ ), while oral prednisolone dose and treatment with cyclophosphamide/rituximab were not. Similar results were seen at one year, both in univariable and multivariable analysis. Previous studies have found associations between long duration of glucocorticoid use, especially in higher doses, and total organ damage [24, 267]. Associations have also been reported between duration of glucocorticoids and cataract [267], and between treatment with intravenous methylprednisolone and development of diabetes mellitus [268, 269].

\section{Hospitalization}

The readmission rate was high during the first year after diagnosis; $69.1 \%$ of the patients were readmitted to hospital, and $24.2 \%$ had two or more readmissions. The total hospital stay during the first year was 31 days (IQR 17-50). This is substantially higher than the median stay of six days found in a previous study of patients hospitalized with a principal diagnosis of GPA [270]. However, the numbers are not entirely comparable since the hospitalizations recorded in Paper 
IV were of any cause and did not necessarily have AAV as the principal diagnosis. Compared to the general population in Sweden aged above 75 years, the median total hospital stay in elderly patients with AAV was almost five times higher [271].

Higher creatinine at presentation was associated with higher odds of readmission, while MPO/P-ANCA positivity was associated with lower odds. Treatment with cyclophosphamide/ rituximab or glucocorticoids was not associated with readmission to hospital during the first year after diagnosis (Table 15).

\section{Table 15. Rehospitalization during the first year after diagnosis}

\begin{tabular}{lllll}
\hline \multirow{2}{*}{ Variable } & \multicolumn{2}{l}{ Univariable analysis } & \multicolumn{2}{l}{ Multivariable analysis } \\
& OR $(95 \% \mathrm{CI})$ & P value & OR $(95 \% \mathrm{CI})$ & P value \\
\hline Age (per year) & $0.99(0.91-1.09)$ & 0.89 & $0.99(0.89-1.10)$ & 0.82 \\
\hline Male gender & $0.73(0.37-1.41)$ & 0.34 & $0.50(0.24-1.06)$ & 0.072 \\
\hline BVAS (per point) 1 & $1.05(0.98-1.11)$ & 0.16 & $1.02(0.95-1.10)$ & 0.63 \\
\hline MPO/P-ANCA & $0.56(0.27-1.16)$ & 0.12 & $0.36(0.15-0.87)$ & 0.024 \\
\hline CRP (per percentile) & $1.02(0.82-1.26)$ & 0.89 & $1.02(0.78-1.34)$ & 0.87 \\
\hline Creatinine (per percentile) 3 & $1.22(0.98-1.52)$ & 0.072 & $1.34(1.02-1.78)$ & 0.039 \\
\hline Comorbidity score (per point) & $1.18(0.78-1.80)$ & 0.43 & $1.23(0.77-1.96)$ & 0.39 \\
\hline Cyclophosphamide/rituximab & $1.83(0.82-4.09)$ & 0.14 & $2.21(0.82-5.94)$ & 0.12 \\
\hline $\begin{array}{l}\text { Prednisolone dose } \\
\text { (per percentile) }\end{array}$ & $1.05(0.86-1.29)$ & 0.62 & $0.99(0.76-1.30)$ & 0.96 \\
\hline $\begin{array}{l}\text { Methylprednisolone dose } \\
\text { (per 250 mg) }\end{array}$ & $1.07(0.93-1.23)$ & 0.37 & $1.02(0.86-1.20)$ & 0.85 \\
\hline
\end{tabular}

Analysis of 165 patients with complete treatment data and data on rehospitalization. Multivariable analysis performed on 148 patients. ${ }^{1}$ Data missing for five patients; ${ }^{2}$ data missing for five patients; 3 data missing for seven patients.

Higher creatinine was also the only significant factor associated with the length of the total hospital stay during the first year of diagnosis $(\beta 5.04 ; 95 \%$ CI $0.67-9.41, \mathrm{P}=0.024)$. Together with the association with both mortality and ESRD observed in Paper III, it is clear that renal involvement in elderly patients is of great clinical importance, and further stresses the need for early detection before advanced renal damage develops.

Information on the cause of readmission to hospital was available in 156 of the total number of 187 readmissions that occurred during the first year after diagnosis. The most common cause was infections (37.2\%), followed by dialysis-related events (11.5\%) and cardiovascular events (9.6\%). Relapse was the cause of readmission in a minority of patients, only $5.1 \%$ of the known causes were due to relapses or active vasculitis. 


\section{Cause of death}

During the two years of follow-up, 69 of 202 patients died (34.2\%). The cause of death was known in 55 of these cases, with the most common causes being infections (34.5\%), myocardial infarction (16.4\%) and active vasculitis (14.5\%). Infections have been shown to be the most common cause of death both in younger vasculitis patients $[19,163]$ and in other studies of older patients [158].

There was an association between cumulative oral prednisolone dose and death caused by infection both in univariable and multivariable Cox regression analysis (HR per percentile 1.57; 95\% CI 1.06-2.32; $\mathrm{P}=0.024)$, and the median cumulative dose of oral prednisolone during the first three months was higher in the patients who died from infections compared to those who died from other causes or survived two years $(3480 \mathrm{mg}$ versus $2280 \mathrm{mg}$ and $2290 \mathrm{mg}$ respectively; $\mathrm{P}=0.01$ ). The majority of infection-related deaths occurred after the first three months of treatment. Since we did not have data on treatment beyond three months, it is not possible to establish whether the observed association with fatal infections was due to a continued trend of higher prednisolone dose or whether higher doses during the induction phase also conferred an increased risk after the first months of treatment. It should also be noted that the number of events was rather low.

Previous studies have shown that longer use of glucocorticoids and steroid-induced diabetes are associated with increased risk of infections [269, 272]. In contrast to cyclophosphamide, in which the dose is normally adjusted for both age and renal function, glucocorticoids are generally only adjusted for body weight. The risks associated with both short- and long-term use of glucocorticoids have been increasingly acknowledged and alternatives have been suggested, including a prospective non-randomized study of rapid glucocorticoid withdrawal within two weeks [273], the low-dose glucocorticoid regimen studied in the PEXIVAS trial [137], and the C5a receptor inhibitor avacopan that has shown promising results in a phase II trial [69]. In a randomized trial of patients aged 65 years or more, lower dose of cyclophosphamide and faster tapering of glucocorticoids was found to decrease the risk of serious adverse events, while mortality, remission and relapse rates did not differ significantly [274]. The median cumulative dose of pulsed intravenous cyclophosphamide in Paper IV was $3000 \mathrm{mg}$ (IQR 2100-4500), similar to the median dose of $2688 \mathrm{mg}$ in the experimental arm in that study.

Severe infections pose a major threat to patients with AAV. Compared to population controls, the rate ratio for serious infections was 4.5 in a study from southern Sweden [275] and the risk of hospitalization due to infections was increased almost ten times in a study from Denmark [276]. Although the aim of Paper IV was not to study infections, we did find that it was the most common cause of both death and readmission, in line with the increased risk of infections in AAV, seen especially with higher age and renal impairment [269, 272, 275, 277]. 


\section{Ethical considerations}

In all observational and register-based research there are important ethical considerations. If participants are not subject to any intervention, sampling, interview or other contact with the investigator, informed consent is generally not required. However, when data are only obtained from available registries and medical records it is also important to safeguard individual privacy. This has to be balanced against the benefit that society will gain from the research conducted, and it could even be considered unethical not to carry out high quality epidemiological research [278].

This thesis is based on observational data retrieved from different registries, databases and patients' medical records. The identity of the individual participants has only been known to the researchers collecting data. Code lists have been stored at each participating centre separately from the coded material and have only been available to the local researcher designated to collect data. The data that have been shared and analysed have been completely anonymized. Since the data were anonymized and reported at group rather than individual level, it was judged that the participants would suffer no negative consequences despite not having consented to participation. 


\section{STRENGTHS AND LIMITATIONS}

\section{Paper I}

The strength of Paper I is that the incidence estimates are population-based and retrieved from two geographically defined areas in Sweden with comprehensive and well-organized followup of patients. The completeness of the retrieval of LN and AAN cases in the Skane area has been shown by capture-recapture methodology. Similar capture-recapture analysis has not been performed in the Östergötland area, but the clinical registries for SLE and AAV at the Rheumatology and Nephrology departments include all known cases in the region.

The study was limited to biopsy-proven nephritis. This ensures a correct diagnosis, but cases with clinical nephritis that are not biopsied are not included and the true incidence might be underestimated. A limitation related to this is the differences in biopsy rate, with a higher biopsy rate seen in SLE cases compared to AAV cases. However, this does not change the conclusion that AAN is more common than LN, but rather underestimate the number of AAN cases.

Another limitation of the study is that it was not possible to carry out meaningful analyses of factors associated with death and ESRD due to the low number of events among the LN patients. Although the follow-up was 6.5 years for AAN and 8.6 years for LN, with even longer follow-up outcomes in terms of death and ESRD in older patients with LN could have been analysed and compared to the outcomes in AAN.

\section{Paper II}

The large population studied is a strength compared to many other studies focusing on the geographic distribution of AAV. It is also the first study to focus on ANCA serotype instead of clinical phenotype in relation to geographical latitude, an approach that limits the risk of differences in classification and a division that is increasingly supported based on genetic susceptibility, treatment response and prediction of outcome.

Studying only renal biopsy-proven cases with a focus on serotype makes the population more homogeneous and was done with the aim to reduce differences in inclusion of patients between regions and units. However, it also limits the generalizability to patients with ANCA positive renal vasculitis and does not answer the question of whether the distribution of the different disease entities GPA and MPA vary with geographical latitude.

A limitation is that we did not have data on UV radiation from the USA. In addition, the use of latitude and mean UV radiation levels for one city in every region does not take into account the fact that there are differences in latitude and UV radiation within regions or migration from other regions. We did not have data on the distribution of genetic variants such as SERPINA1 or $H L A-D P B 1 * 0401$. Nor did we have data on vitamin D levels or dietary habits in the studied 
populations, factors that could affect vitamin $\mathrm{D}$ status in addition to the exposure to UV radiation.

\section{Papers III and IV}

The patients studied in Paper III and Paper IV are, to our knowledge, the largest cohort of patients above 75 years with AAV that has been studied to date. Patients have been included from several centres, giving this large number and reflecting real-life data on treatment and outcome of elderly patients in different parts of Europe. A limitation is the fact that some of the centres are tertiary referral centres that almost exclusively see nephrology patients, including the most severely ill patients with dialysis-dependent renal failure, and the results might not be generalizable to populations seen mainly at rheumatology units.

The main limitations are that the data are retrospective and that patients have not been randomized to the treatment given. By excluding deaths during the first month and using an intention-to-treat approach, we have tried to reduce the risk of selection by prognosis. However, despite adjusting for markers of disease severity and comorbidities, we cannot rule out the possibility that some patients were perceived to be frail and not suitable for immunosuppressive therapy or that some patients developed adverse events due to therapy and that it was thus stopped. Such patients would likely have higher risks of both death and permanent damage. It is also possible that patients with severe disease received higher doses of glucocorticoids and that the underlying more aggressive disease made them more susceptible to adverse events and development of organ damage. Another limitation is the lack of data on glucocorticoid treatment beyond three months. As a result, we cannot establish whether the danger lies in using high doses during a short time period or a long duration of glucocorticoid treatment. 


\section{CONCLUSIONS AND FUTURE PERSPECTIVES}

\section{Paper I}

The incidence of biopsy-verified AAN is about threefold higher than the incidence of LN in two geographically defined populations in Sweden. Previous studies by our group have shown that the incidence of SLE is higher than that found for AAV, and we therefore conclude that a lower occurrence of nephritis among SLE patients compared to AAV patients is the main explanation. Outcomes in terms of both patient and renal survival are considerably worse in AAN. The majority of the patients with LN had an established diagnosis of SLE at the time of the first renal flare, while none of the patients with AAN had a diagnosis of AAV before the onset of nephritis. Our data suggest that early diagnosis and treatment before the onset of nephritis is of pivotal importance for the good results seen in SLE with respect to ESRD and early deaths.

The remaining question is if similar improvement is possible to achieve in AAV and in SLE in other parts of the world. To investigate this further future studies should be aimed at studying changes in incidence of LN and AAN over time in defined areas and exploring treatment, diagnosis delay and outcome during the same time period. Since age differs substantially between patients with $\mathrm{LN}$ and patients with AAN, an interesting future project would be to calculate potential years of life lost for the two diseases, as well as for other glomerular diseases.

\section{Paper II}

There are clear differences between MPO-ANCA positive and PR3-ANCA positive biopsyproven glomerulonephritis with regard to age, gender and renal function. There are also associations between PR3-ANCA and higher latitude and lower UV radiation levels, in line with the north-south hypothesis. With these results we add to the current knowledge by focusing on ANCA serotype and by studying renal AAV. However, the geographical differences in distribution of GPA and MPA seem to be greater than the differences between renal PR3ANCA positive AAV and MPO-ANCA positive AAV. Given the loss of the associations between ANCA serotype and latitude and UV radiation level in the analysis of northern and central Europe, the contribution of genetic differences needs more attention.

To further elucidate the relative contribution of environmental and genetic factors to both serotype and phenotype it would be interesting to include centres in Norway, Sweden and Denmark, countries in which the populations have similar genetic inheritance, and to investigate differences in GPA/MPA, PR3-AAV/MPO-AAV and non-renal GPA/renal GPA in relation to different environmental exposures. 


\section{Papers III and IV}

Elderly patients with AAV often present with significant renal involvement, predominance of MPO-ANCA positivity and a clinical MPA diagnosis. Patient survival is significantly better in patients treated with adequate doses of cyclophosphamide or rituximab compared to patients who are left untreated, or are treated with alternative regimens such as azathioprine, MMF, methotrexate or glucocorticoids alone. Although elderly patients are at higher risk of adverse events, treatment with cyclophosphamide and rituximab is not associated with development of more permanent organ damage and need for hospitalization when compared with no treatment or other treatment regimens. Rather, our results suggest that adequate treatment of the elderly can halt the disease process and lower the risk of organ damage. Our results support induction treatment of elderly patients with cyclophosphamide or rituximab, but raise concerns regarding the use of high doses of glucocorticoids in the elderly.

Future randomized trials of treatment in AAV should not exclude elderly patients, especially those aiming at reducing the use of glucocorticoids. Although our results suggest that patients who are treated with rituximab do well, too few patients were treated with this agent to allow for a comparison between rituximab and cyclophosphamide. Data on the use of rituximab in elderly patients are scarce, but the increasing use during the last years could allow for comparison with cyclophosphamide with respect to remission rates, mortality and adverse events. We would like to carry out a long-term follow-up of the elderly cohort with a focus on renal and patient survival. With longer follow-up it would also be possible to include data on maintenance therapy and relapse rates. 


\section{ACKNOWLEDGEMENTS}

I would like to express my gratitude to:

Mårten Segelmark, my main supervisor. I have rarely met anyone with such an ability to guide, inspire and help in both the clinical and academic fields. I am ever so thankful to you for sharing your deep knowledge in the field of vasculitis and glomerulonephritis, for your ability to help me move forwards and put my thoughts and arguments into words, and for sharing your large network around the world.

Per Eriksson, my assistant supervisor and the founder of the vasculitis registry in Linköping. Your great knowledge and your perspectives from the rheumatologist's point of view have both broadened and deepened my understanding of the many complexities of vasculitis and its epidemiology.

Aladdin Mohammad, manager of the vasculitis registry in Lund, first author of Paper I and my co-author on the remaining papers. Thank you for all your advice and help over the years and for your very quick response to all my requests, both small and large.

Kerstin Westman, Daina Selga and Annette Bruchfeld. Thank you for the effort you put into the data collection, your valuable input in manuscript revision and your encouragement by e-mail and during meetings.

All co-authors: Vladimir Tesar, Alan Salama, Charles Pusey, Lorraine Harper, David Jayne, Zdenka Hruskova, Zdenka Chocova, Anisha Tanna, Amy Kang, Su Mein Goh, Phoebe Sharp, Rune Bjфrneklett, Knut Aasarфd, Colin Geddes, Susan Hogan, Matija Crnogorac, Duvuru Geetha, Loreto Gesualdo, Leo Sindelar, Caroline Poulton, Bruce Mackinnon, Christopher Sjöwall, Martin Johansson, Anders Bengtsson, Christina Ståhl-Hallengren, Ola Nived and Gunnar Sturfelt. Without your contributions the studies in this thesis would have been impossible to realize.

Agneta Cassel, my clinical tutor and mentor. You are a true inspiration when it comes to caring for patients. Thank you for always finding the time for me, for listening to my frustration and for guiding me to answer my own questions.

Anders Fernström, Head of the Department of Nephrology in Linköping. Thank you for encouraging me to pursue the academic path and for giving me the conditions to do so.

Olle Stål, supervisor for my degree thesis. Thank you for opening the door to my interest in research.

Fredrik Uhlin and Micael Gylling ("Forsket"). Thank you for all the fun, for encouragement and for helping me out with all sorts of paperwork and economic questions. 
Madeleine Örlin, administrator at the Division of Drug Research. For your quick help with paperwork, payment and other questions.

Daniel Appelgren, for good advice on how to finish a PhD. I am looking forward to future collaborations.

Forum Östergötland, for many hours of statistic counseling.

All my colleagues at the Department of Nephrology in Linköping. Thank you for your support, friendship and everyday encouragement, and for making up the best workplace there is!

Financial support: The Ingrid Asp Foundation and the Swedish Renal Foundation.

Sist men inte minst ni som står mig närmast:

Mina fantastiska vänner, särskilt Solveig, Hanna, Josefin, Elin, Stina, Elin och Klara. Ni gör mitt liv så mycket roligare, lättare och rikare.

Susanne och Göran. Tack för att ni öppnade upp ert hem för mig från dag ett och för att ni alltid stöttat och uppmuntrat.

Asta och Ottilia. Tänk vilken tur att just ni två blev en del av min familj.

Pappa. Du är den som har stöttat mig längst av alla. Från det lilla barnets behov av ständig närhet och kärlek, till den vuxna dotterns behov av självständighet men också uppmuntran och någon att diskutera livets stora och små händelser med.

Mamma. Du som gav mig livet, det röda håret och intresset för handarbete. Du fattas mig varje dag.

Anders och Kerstin, mina älskade syskon och mina favoritpersoner. Med er två delar jag livets finaste, roligaste och svåraste stunder. Det finns inga andra jag varig så arg och irriterad på, men heller inga andra jag har skrattat så mycket med. Vi ska alltid höra ihop.

Daniel, min stora kärlek och min absolut bästa vän. Du är den mest lojala, kärleksfulla och tålmodiga jag vet och dessutom envis som få, lugn och med en förmåga att skapa ordning i både bildligt och bokstavligt kaos. TACK FÖR ALLT.

Signe och Astrid, mina älskade barn. Kärleken till er vet inga gränser och tar aldrig slut. Ni är mina bästisar, min glädje, min trygghet och min oro. Alla ovan har lärt mig mycket, men ni två har lärt mig mer. 


\section{REFERENCES}

1. Jennette JC, Falk RJ, Bacon PA, Basu N, Cid MC, Ferrario F, et al. 2012 revised International Chapel Hill Consensus Conference Nomenclature of Vasculitides. Arthritis and rheumatism. 2013;65(1):1-11.

2. Lightfoot RW, Jr., Michel BA, Bloch DA, Hunder GG, Zvaifler NJ, McShane DJ, et al. The American College of Rheumatology 1990 criteria for the classification of polyarteritis nodosa. Arthritis and rheumatism. 1990;33(8):1088-93.

3. Leavitt RY, Fauci AS, Bloch DA, Michel BA, Hunder GG, Arend WP, et al. The American College of Rheumatology 1990 criteria for the classification of Wegener's granulomatosis. Arthritis Rheum. 1990;33(8):1101-7.

4. Calabrese LH, Michel BA, Bloch DA, Arend WP, Edworthy SM, Fauci AS, et al. The American College of Rheumatology 1990 criteria for the classification of hypersensitivity vasculitis. Arthritis and rheumatism. 1990;33(8):1108-13.

5. Mills JA, Michel BA, Bloch DA, Calabrese LH, Hunder GG, Arend WP, et al. The American College of Rheumatology 1990 criteria for the classification of Henoch-Schonlein purpura. Arthritis and rheumatism. 1990;33(8):1114-21.

6. Hunder GG, Bloch DA, Michel BA, Stevens MB, Arend WP, Calabrese LH, et al. The American College of Rheumatology 1990 criteria for the classification of giant cell arteritis. Arthritis and rheumatism. 1990;33(8):1122-8.

7. Arend WP, Michel BA, Bloch DA, Hunder GG, Calabrese LH, Edworthy SM, et al. The American College of Rheumatology 1990 criteria for the classification of Takayasu arteritis. Arthritis and rheumatism. 1990;33(8):1129-34.

8. Masi AT, Hunder GG, Lie JT, Michel BA, Bloch DA, Arend WP, et al. The American College of Rheumatology 1990 criteria for the classification of Churg-Strauss syndrome (allergic granulomatosis and angiitis). Arthritis and rheumatism. 1990;33(8):1094-100.

9. Bloch DA, Michel BA, Hunder GG, McShane DJ, Arend WP, Calabrese LH, et al. The American College of Rheumatology 1990 criteria for the classification of vasculitis. Patients and methods. Arthritis and rheumatism. 1990;33(8):1068-73.

10. Rao JK, Allen NB, Pincus T. Limitations of the 1990 American College of Rheumatology classification criteria in the diagnosis of vasculitis. Annals of internal medicine. 1998;129(5):345-52.

11. Jennette JC, Falk RJ, Andrassy K, Bacon PA, Churg J, Gross WL, et al. Nomenclature of systemic vasculitides. Proposal of an international consensus conference. Arthritis Rheum. 1994;37(2):187-92.

12. Watts R, Lane S, Hanslik T, Hauser T, Hellmich B, Koldingsnes W, et al. Development and validation of a consensus methodology for the classification of the ANCA-associated vasculitides and polyarteritis nodosa for epidemiological studies. Annals of the rheumatic diseases. 2007;66(2):222-7.

13. Lanham JG, Elkon KB, Pusey CD, Hughes GR. Systemic vasculitis with asthma and eosinophilia: a clinical approach to the Churg-Strauss syndrome. Medicine. 1984;63(2):65-81.

14. Liu LJ, Chen M, Yu F, Zhao MH, Wang HY. Evaluation of a new algorithm in classification of systemic vasculitis. Rheumatology (Oxford, England). 2008;47(5):708-12.

15. Kamali S, Artim-Esen B, Erer B, Ozdener L, Gul A, Ocal L, et al. Re-evaluation of 129 patients with systemic necrotizing vasculitides by using classification algorithm according to consensus methodology. Clinical rheumatology. 2012;31(2):325-8.

16. Abdulkader R, Lane SE, Scott DG, Watts RA. Classification of vasculitis: EMA classification using CHCC 2012 definitions. Annals of the rheumatic diseases.

2013;72(11):1888. 
17. Craven A, Robson J, Ponte C, Grayson PC, Suppiah R, Judge A, et al. ACR/EULARendorsed study to develop Diagnostic and Classification Criteria for Vasculitis (DCVAS). Clinical and experimental nephrology. 2013;17(5):619-21.

18. Hagen EC, Daha MR, Hermans J, Andrassy K, Csernok E, Gaskin G, et al. Diagnostic value of standardized assays for anti-neutrophil cytoplasmic antibodies in idiopathic systemic vasculitis. EC/BCR Project for ANCA Assay Standardization. Kidney international. 1998;53(3):743-53.

19. Flossmann O, Berden A, de Groot K, Hagen C, Harper L, Heijl C, et al. Long-term patient survival in ANCA-associated vasculitis. Annals of the rheumatic diseases. 2011;70(3):488-94.

20. Lyons PA, Rayner TF, Trivedi S, Holle JU, Watts RA, Jayne DR, et al. Genetically distinct subsets within ANCA-associated vasculitis. The New England journal of medicine. 2012;367(3):214-23.

21. Mohammad AJ, Jacobsson LT, Westman KW, Sturfelt G, Segelmark M. Incidence and survival rates in Wegener's granulomatosis, microscopic polyangiitis, Churg-Strauss syndrome and polyarteritis nodosa. Rheumatology (Oxford, England). 2009;48(12):1560-5. 22. Comarmond C, Cacoub P. Granulomatosis with polyangiitis (Wegener): clinical aspects and treatment. Autoimmunity reviews. 2014;13(11):1121-5.

23. Koldingsnes W, Nossent H. Epidemiology of Wegener's granulomatosis in northern Norway. Arthritis and rheumatism. 2000;43(11):2481-7.

24. Koldingsnes W, Nossent H. Predictors of survival and organ damage in Wegener's granulomatosis. Rheumatology (Oxford, England). 2002;41(5):572-81.

25. Eriksson P, Segelmark M, Hallbook O. Frequency, Diagnosis, Treatment, and Outcome of Gastrointestinal Disease in Granulomatosis with Polyangiitis and Microscopic Polyangiitis. The Journal of rheumatology. 2018;45(4):529-37.

26. Pagnoux C, Mahr A, Cohen P, Guillevin L. Presentation and outcome of gastrointestinal involvement in systemic necrotizing vasculitides: analysis of 62 patients with polyarteritis nodosa, microscopic polyangiitis, Wegener granulomatosis, Churg-Strauss syndrome, or rheumatoid arthritis-associated vasculitis. Medicine. 2005;84(2):115-28.

27. Mahr A, Katsahian S, Varet H, Guillevin L, Hagen EC, Hoglund P, et al. Revisiting the classification of clinical phenotypes of anti-neutrophil cytoplasmic antibody-associated vasculitis: a cluster analysis. Annals of the rheumatic diseases. 2013;72(6):1003-10.

28. Holle JU, Gross WL, Holl-Ulrich K, Ambrosch P, Noelle B, Both M, et al. Prospective long-term follow-up of patients with localised Wegener's granulomatosis: does it occur as persistent disease stage? Annals of the rheumatic diseases. 2010;69(11):1934-9.

29. Mukhtyar C, Flossmann O, Hellmich B, Bacon P, Cid M, Cohen-Tervaert JW, et al. Outcomes from studies of antineutrophil cytoplasm antibody associated vasculitis: a systematic review by the European League Against Rheumatism systemic vasculitis task force. Annals of the rheumatic diseases. 2008;67(7):1004-10.

30. Kallenberg CG. The diagnosis and classification of microscopic polyangiitis. Journal of autoimmunity. 2014;48-49:90-3.

31. Comarmond C, Crestani B, Tazi A, Hervier B, Adam-Marchand S, Nunes H, et al. Pulmonary fibrosis in antineutrophil cytoplasmic antibodies (ANCA)-associated vasculitis: a series of 49 patients and review of the literature. Medicine. 2014;93(24):340-9.

32. Guillevin L, Durand-Gasselin B, Cevallos R, Gayraud M, Lhote F, Callard P, et al. Microscopic polyangiitis: clinical and laboratory findings in eighty-five patients. Arthritis and rheumatism. 1999;42(3):421-30.

33. Harper L, Savage CO. ANCA-associated renal vasculitis at the end of the twentieth century--a disease of older patients. Rheumatology (Oxford, England). 2005;44(4):495-501. 
34. Jennette JC, Falk RJ, Bacon PA, Basu N, Cid MC, Ferrario F, et al. 2012 revised International Chapel Hill Consensus Conference Nomenclature of Vasculitides. Arthritis Rheum. 2013;65(1):1-11.

35. Sinico RA, Di Toma L, Maggiore U, Bottero P, Radice A, Tosoni C, et al. Prevalence and clinical significance of antineutrophil cytoplasmic antibodies in Churg-Strauss syndrome. Arthritis and rheumatism. 2005;52(9):2926-35.

36. Mouthon L, Dunogue B, Guillevin L. Diagnosis and classification of eosinophilic granulomatosis with polyangiitis (formerly named Churg-Strauss syndrome). J Autoimmun. 2014;48-49:99-103.

37. Wiik A. Delineation of a standard procedure for indirect immunofluorescence detection of ANCA. APMIS Supplementum. 1989;6:12-3.

38. Bossuyt X, Cohen Tervaert JW, Arimura Y, Blockmans D, Flores-Suarez LF, Guillevin L, et al. Position paper: Revised 2017 international consensus on testing of ANCAs in granulomatosis with polyangiitis and microscopic polyangiitis. Nature reviews Rheumatology. 2017;13(11):683-92.

39. Falk RJ, Jennette JC. Anti-neutrophil cytoplasmic autoantibodies with specificity for myeloperoxidase in patients with systemic vasculitis and idiopathic necrotizing and crescentic glomerulonephritis. The New England journal of medicine. 1988;318(25):1651-7.

40. Jennette JC, Hoidal JR, Falk RJ. Specificity of anti-neutrophil cytoplasmic autoantibodies for proteinase 3. Blood. 1990;75(11):2263-4.

41. Zhao MH, Jones SJ, Lockwood CM. Bactericidal/permeability-increasing protein (BPI) is an important antigen for anti-neutrophil cytoplasmic autoantibodies (ANCA) in vasculitis. Clinical and experimental immunology. 1995;99(1):49-56.

42. Tervaert JW, Mulder L, Stegeman C, Elema J, Huitema M, The H, et al. Occurrence of autoantibodies to human leucocyte elastase in Wegener's granulomatosis and other inflammatory disorders. Annals of the rheumatic diseases. 1993;52(2):115-20.

43. Coremans IE, Hagen EC, Daha MR, van der Woude FJ, van der Voort EA, Kleijburg-van der Keur C, et al. Antilactoferrin antibodies in patients with rheumatoid arthritis are associated with vasculitis. Arthritis and rheumatism. 1992;35(12):1466-75.

44. Halbwachs-Mecarelli L, Nusbaum P, Noel LH, Reumaux D, Erlinger S, Grunfeld JP, et al. Antineutrophil cytoplasmic antibodies (ANCA) directed against cathepsin G in ulcerative colitis, Crohn's disease and primary sclerosing cholangitis. Clinical and experimental immunology. 1992;90(1):79-84.

45. Jayne DR, Marshall PD, Jones SJ, Lockwood CM. Autoantibodies to GBM and neutrophil cytoplasm in rapidly progressive glomerulonephritis. Kidney international. 1990;37(3):965-70.

46. Saxon A, Shanahan F, Landers C, Ganz T, Targan S. A distinct subset of antineutrophil cytoplasmic antibodies is associated with inflammatory bowel disease. The Journal of allergy and clinical immunology. 1990;86(2):202-10.

47. Locht H, Skogh T, Wiik A. Characterisation of autoantibodies to neutrophil granule constituents among patients with reactive arthritis, rheumatoid arthritis, and ulcerative colitis. Annals of the rheumatic diseases. 2000;59(11):898-903.

48. Schnabel A, Csernok E, Isenberg DA, Mrowka C, Gross WL. Antineutrophil cytoplasmic antibodies in systemic lupus erythematosus. Prevalence, specificities, and clinical significance. Arthritis and rheumatism. 1995;38(5):633-7.

49. Mahr A, Batteux F, Tubiana S, Goulvestre C, Wolff M, Papo T, et al. Brief report: prevalence of antineutrophil cytoplasmic antibodies in infective endocarditis. Arthritis \& rheumatology (Hoboken, NJ). 2014;66(6):1672-7. 
50. Flores-Suarez LF, Cabiedes J, Villa AR, van der Woude FJ, Alcocer-Varela J. Prevalence of antineutrophil cytoplasmic autoantibodies in patients with tuberculosis. Rheumatology (Oxford, England). 2003;42(2):223-9.

51. Cornely OA, Hauschild S, Weise C, Csernok E, Gross WL, Salzberger B, et al. Seroprevalence and disease association of antineutrophil cytoplasmic autoantibodies and antigens in HIV infection. Infection. 1999;27(2):92-6.

52. Cil T, Altintas A, Isikdogan A, Batun S. Prevalence of antineutrophil cytoplasmic antibody positivity in patients with Hodgkin's and non-Hodgkin lymphoma: a single center experience. International journal of hematology. 2009;90(1):52-7.

53. Esnault VL, Jayne DR, Keogan MT, Brownlee AA, Testa A, Lecarrer D, et al. Antineutrophil cytoplasm antibodies in patients with monoclonal gammopathies. Journal of clinical \& laboratory immunology. 1990;32(4):153-9.

54. Tervaert JW, van der Woude FJ, Fauci AS, Ambrus JL, Velosa J, Keane WF, et al. Association between active Wegener's granulomatosis and anticytoplasmic antibodies. Archives of internal medicine. 1989;149(11):2461-5.

55. Morgan MD, Szeto M, Walsh M, Jayne D, Westman K, Rasmussen N, et al. Negative anti-neutrophil cytoplasm antibody at switch to maintenance therapy is associated with a reduced risk of relapse. Arthritis Res Ther. 2017;19(1):129.

56. Tomasson G, Grayson PC, Mahr AD, Lavalley M, Merkel PA. Value of ANCA measurements during remission to predict a relapse of ANCA-associated vasculitis--a metaanalysis. Rheumatology (Oxford, England). 2012;51(1):100-9.

57. Unizony S, Villarreal M, Miloslavsky EM, Lu N, Merkel PA, Spiera R, et al. Clinical outcomes of treatment of anti-neutrophil cytoplasmic antibody (ANCA)-associated vasculitis based on ANCA type. Annals of the rheumatic diseases. 2016;75(6):1166-9.

58. Mohammad AJ, Segelmark M. A population-based study showing better renal prognosis for proteinase 3 antineutrophil cytoplasmic antibody (ANCA)-associated nephritis versus myeloperoxidase ANCA-associated nephritis. The Journal of rheumatology. 2014;41(7):136673.

59. Lionaki S, Blyth ER, Hogan SL, Hu Y, Senior BA, Jennette CE, et al. Classification of antineutrophil cytoplasmic autoantibody vasculitides: the role of antineutrophil cytoplasmic autoantibody specificity for myeloperoxidase or proteinase 3 in disease recognition and prognosis. Arthritis and rheumatism. 2012;64(10):3452-62.

60. Salama AD, Little MA. Animal models of antineutrophil cytoplasm antibody-associated vasculitis. Current opinion in rheumatology. 2012;24(1):1-7.

61. Xiao H, Heeringa P, Hu P, Liu Z, Zhao M, Aratani Y, et al. Antineutrophil cytoplasmic autoantibodies specific for myeloperoxidase cause glomerulonephritis and vasculitis in mice. The Journal of clinical investigation. 2002;110(7):955-63.

62. Little MA, Al-Ani B, Ren S, Al-Nuaimi H, Leite M, Jr., Alpers CE, et al. Anti-proteinase 3 anti-neutrophil cytoplasm autoantibodies recapitulate systemic vasculitis in mice with a humanized immune system. PloS one. 2012;7(1):e28626.

63. Kallenberg CG. Pathogenesis of ANCA-associated vasculitides. Annals of the rheumatic diseases. 2011;70 Suppl 1:i59-63.

64. Falk RJ, Terrell RS, Charles LA, Jennette JC. Anti-neutrophil cytoplasmic autoantibodies induce neutrophils to degranulate and produce oxygen radicals in vitro. Proceedings of the National Academy of Sciences of the United States of America. 1990;87(11):4115-9.

65. Brooks CJ, King WJ, Radford DJ, Adu D, McGrath M, Savage CO. IL-1 beta production by human polymorphonuclear leucocytes stimulated by anti-neutrophil cytoplasmic autoantibodies: relevance to systemic vasculitis. Clinical and experimental immunology. 1996;106(2):273-9. 
66. Kessenbrock K, Krumbholz M, Schonermarck U, Back W, Gross WL, Werb Z, et al. Netting neutrophils in autoimmune small-vessel vasculitis. Nat Med. 2009;15(6):623-5. 67. Xiao H, Schreiber A, Heeringa P, Falk RJ, Jennette JC. Alternative complement pathway in the pathogenesis of disease mediated by anti-neutrophil cytoplasmic autoantibodies. Am J Pathol. 2007;170(1):52-64.

68. Ohlsson S, Holm L, Hansson C, Ohlsson SM, Gunnarsson L, Pettersson A, et al. Neutrophils from ANCA-associated vasculitis patients show an increased capacity to activate the complement system via the alternative pathway after ANCA stimulation. PloS one. 2019;14(6):e0218272.

69. Jayne DRW, Bruchfeld AN, Harper L, Schaier M, Venning MC, Hamilton P, et al. Randomized Trial of C5a Receptor Inhibitor Avacopan in ANCA-Associated Vasculitis. Journal of the American Society of Nephrology : JASN. 2017;28(9):2756-67.

70. Bekker P, Dairaghi D, Seitz L, Leleti M, Wang Y, Ertl L, et al. Characterization of Pharmacologic and Pharmacokinetic Properties of CCX168, a Potent and Selective Orally Administered Complement 5a Receptor Inhibitor, Based on Preclinical Evaluation and Randomized Phase 1 Clinical Study. PloS one. 2016;11(10):e0164646.

71. Ormerod AS, Cook MC. Epidemiology of primary systemic vasculitis in the Australian Capital Territory and south-eastern New South Wales. Internal medicine journal. 2008;38(11):816-23.

72. Berti A, Cornec D, Crowson CS, Specks U, Matteson EL. The Epidemiology of Antineutrophil Cytoplasmic Autoantibody-Associated Vasculitis in Olmsted County, Minnesota: A Twenty-Year US Population-Based Study. Arthritis \& rheumatology (Hoboken, NJ). 2017;69(12):2338-50.

73. Andrews M, Edmunds M, Campbell A, Walls J, Feehally J. Systemic vasculitis in the 1980s--is there an increasing incidence of Wegener's granulomatosis and microscopic polyarteritis? Journal of the Royal College of Physicians of London. 1990;24(4):284-8. 74. Knight A, Ekbom A, Brandt L, Askling J. Increasing incidence of Wegener's granulomatosis in Sweden, 1975-2001. The Journal of rheumatology. 2006;33(10):2060-3. 75. Reinhold-Keller E, Herlyn K, Wagner-Bastmeyer R, Gross WL. Stable incidence of primary systemic vasculitides over five years: results from the German vasculitis register. Arthritis and rheumatism. 2005;53(1):93-9.

76. Gonzalez-Gay MA, Garcia-Porrua C, Guerrero J, Rodriguez-Ledo P, Llorca J. The epidemiology of the primary systemic vasculitides in northwest Spain: implications of the Chapel Hill Consensus Conference definitions. Arthritis and rheumatism. 2003;49(3):388-93. 77. Ntatsaki E, Watts RA, Scott DG. Epidemiology of ANCA-associated vasculitis. Rheumatic diseases clinics of North America. 2010;36(3):447-61.

78. Watts RA, Al-Taiar A, Scott DG, Macgregor AJ. Prevalence and incidence of Wegener's granulomatosis in the UK general practice research database. Arthritis and rheumatism. 2009;61(10):1412-6.

79. Herlyn K, Buckert F, Gross WL, Reinhold-Keller E. Doubled prevalence rates of ANCAassociated vasculitides and giant cell arteritis between 1994 and 2006 in northern Germany. Rheumatology (Oxford, England). 2014;53(5):882-9.

80. Mohammad AJ, Jacobsson LT, Mahr AD, Sturfelt G, Segelmark M. Prevalence of Wegener's granulomatosis, microscopic polyangiitis, polyarteritis nodosa and Churg-Strauss syndrome within a defined population in southern Sweden. Rheumatology (Oxford, England). 2007;46(8):1329-37.

81. Watts RA, Mooney J, Skinner J, Scott DG, Macgregor AJ. The contrasting epidemiology of granulomatosis with polyangiitis (Wegener's) and microscopic polyangiitis. Rheumatology (Oxford, England). 2012;51(5):926-31. 
82. Mahr A, Guillevin L, Poissonnet M, Ayme S. Prevalences of polyarteritis nodosa, microscopic polyangiitis, Wegener's granulomatosis, and Churg-Strauss syndrome in a French urban multiethnic population in 2000: a capture-recapture estimate. Arthritis and rheumatism. 2004;51(1):92-9.

83. Catanoso M, Macchioni P, Boiardi L, Manenti L, Tumiati B, Cavazza A, et al. Epidemiology of granulomatosis with polyangiitis (Wegener's granulomatosis) in Northern Italy: a 15-year population-based study. Seminars in arthritis and rheumatism. 2014;44(2):202-7.

84. Gibson A, Stamp LK, Chapman PT, O'Donnell JL. The epidemiology of Wegener's granulomatosis and microscopic polyangiitis in a Southern Hemisphere region. Rheumatology (Oxford, England). 2006;45(5):624-8.

85. Fujimoto S, Uezono S, Hisanaga S, Fukudome K, Kobayashi S, Suzuki K, et al. Incidence of ANCA-associated primary renal vasculitis in the Miyazaki Prefecture: the first population-based, retrospective, epidemiologic survey in Japan. Clinical journal of the American Society of Nephrology : CJASN. 2006;1(5):1016-22.

86. Panagiotakis SH, Perysinakis GS, Kritikos H, Vassilopoulos D, Vrentzos G, Linardakis $\mathrm{M}$, et al. The epidemiology of primary systemic vasculitides involving small vessels in Crete (southern Greece): a comparison of older versus younger adult patients. Clinical and experimental rheumatology. 2009;27(3):409-15.

87. Pamuk ON, Donmez S, Calayir GB, Pamuk GE. The epidemiology of antineutrophil cytoplasmic antibody-associated vasculitis in northwestern Turkey. Clinical rheumatology. 2016;35(8):2063-71.

88. Watts RA, Lane SE, Bentham G, Scott DG. Epidemiology of systemic vasculitis: a tenyear study in the United Kingdom. Arthritis and rheumatism. 2000;43(2):414-9.

89. Fujimoto S, Watts RA, Kobayashi S, Suzuki K, Jayne DR, Scott DG, et al. Comparison of the epidemiology of anti-neutrophil cytoplasmic antibody-associated vasculitis between Japan and the U.K. Rheumatology (Oxford, England). 2011;50(10):1916-20.

90. Takala JH, Kautiainen H, Malmberg H, Leirisalo-Repo M. Incidence of Wegener's granulomatosis in Finland 1981-2000. Clinical and experimental rheumatology. 2008;26(3 Suppl 49):S81-5.

91. O'Donnell JL, Stevanovic VR, Frampton C, Stamp LK, Chapman PT. Wegener's granulomatosis in New Zealand: evidence for a latitude-dependent incidence gradient. Internal medicine journal. 2007;37(4):242-6.

92. Watts RA, Lane SE, Scott DG, Koldingsnes W, Nossent H, Gonzalez-Gay MA, et al. Epidemiology of vasculitis in Europe. Annals of the rheumatic diseases. 2001;60(12):1156-7. 93. Chen M, Yu F, Zhang Y, Zhao MH. Clinical [corrected] and pathological characteristics of Chinese patients with antineutrophil cytoplasmic autoantibody associated systemic vasculitides: a study of 426 patients from a single centre. Postgraduate medical journal. 2005;81(961):723-7.

94. Cao Y, Schmitz JL, Yang J, Hogan SL, Bunch D, Hu Y, et al. DRB1*15 allele is a risk factor for PR3-ANCA disease in African Americans. Journal of the American Society of Nephrology : JASN. 2011;22(6):1161-7.

95. Faurschou M, Helleberg M, Obel N, Baslund B. Incidence of granulomatosis with polyangiitis (Wegener's) in Greenland and the Faroe Islands: epidemiology of an ANCAassociated vasculitic syndrome in two ethnically distinct populations in the North Atlantic area. Clinical and experimental rheumatology. 2013;31(1 Suppl 75):S52-5.

96. Anderson K, Klassen J, Stewart SA, Taylor-Gjevre RM. Does geographic location affect incidence of ANCA-associated renal vasculitis in northern Saskatchewan, Canada?

Rheumatology (Oxford, England). 2013;52(10):1840-4. 
97. Tidman M, Olander R, Svalander C, Danielsson D. Patients hospitalized because of small vessel vasculitides with renal involvement in the period 1975-95: organ involvement, antineutrophil cytoplasmic antibodies patterns, seasonal attack rates and fluctuation of annual frequencies. Journal of internal medicine. 1998;244(2):133-41.

98. Raynauld JP, Bloch DA, Fries JF. Seasonal variation in the onset of Wegener's granulomatosis, polyarteritis nodosa and giant cell arteritis. The Journal of rheumatology. 1993;20(9):1524-6.

99. Mahr A, Artigues N, Coste J, Aouba A, Pagnoux C, Guillevin L. Seasonal variations in onset of Wegener's granulomatosis: increased in summer? The Journal of rheumatology. 2006;33(8):1615-22.

100. Cotch MF, Hoffman GS, Yerg DE, Kaufman GI, Targonski P, Kaslow RA. The epidemiology of Wegener's granulomatosis. Estimates of the five-year period prevalence, annual mortality, and geographic disease distribution from population-based data sources. Arthritis and rheumatism. 1996;39(1):87-92.

101. Stegeman CA, Tervaert JW, Sluiter WJ, Manson WL, de Jong PE, Kallenberg CG. Association of chronic nasal carriage of Staphylococcus aureus and higher relapse rates in Wegener granulomatosis. Annals of internal medicine. 1994;120(1):12-7.

102. Laudien M, Gadola SD, Podschun R, Hedderich J, Paulsen J, Reinhold-Keller E, et al. Nasal carriage of Staphylococcus aureus and endonasal activity in Wegener s granulomatosis as compared to rheumatoid arthritis and chronic Rhinosinusitis with nasal polyps. Clinical and experimental rheumatology. 2010;28(1 Suppl 57):51-5.

103. Stegeman CA, Tervaert JW, de Jong PE, Kallenberg CG. Trimethoprimsulfamethoxazole (co-trimoxazole) for the prevention of relapses of Wegener's granulomatosis. Dutch Co-Trimoxazole Wegener Study Group. The New England journal of medicine. 1996;335(1):16-20.

104. Popa ER, Tervaert JW. The relation between Staphylococcus aureus and Wegener's granulomatosis: current knowledge and future directions. Internal medicine (Tokyo, Japan). 2003;42(9):771-80.

105. Wichmann I, Sanchez-Roman J, Morales J, Castillo MJ, Ocana C, Nunez-Roldan A. Antimyeloperoxidase antibodies in individuals with occupational exposure to silica. Annals of the rheumatic diseases. 1996;55(3):205-7.

106. Lee S, Hayashi H, Maeda M, Chen Y, Matsuzaki H, Takei-Kumagai N, et al. Environmental factors producing autoimmune dysregulation--chronic activation of $\mathrm{T}$ cells caused by silica exposure. Immunobiology. 2012;217(7):743-8.

107. Maeda M, Nishimura Y, Kumagai N, Hayashi H, Hatayama T, Katoh M, et al. Dysregulation of the immune system caused by silica and asbestos. Journal of immunotoxicology. 2010;7(4):268-78.

108. Pfau JC, Brown JM, Holian A. Silica-exposed mice generate autoantibodies to apoptotic cells. Toxicology. 2004;195(2-3):167-76.

109. Khuder SA, Peshimam AZ, Agraharam S. Environmental risk factors for rheumatoid arthritis. Reviews on environmental health. 2002;17(4):307-15.

110. Finckh A, Cooper GS, Chibnik LB, Costenbader KH, Watts J, Pankey H, et al. Occupational silica and solvent exposures and risk of systemic lupus erythematosus in urban women. Arthritis and rheumatism. 2006;54(11):3648-54.

111. McCormic ZD, Khuder SS, Aryal BK, Ames AL, Khuder SA. Occupational silica exposure as a risk factor for scleroderma: a meta-analysis. International archives of occupational and environmental health. 2010;83(7):763-9.

112. Gomez-Puerta JA, Gedmintas L, Costenbader KH. The association between silica exposure and development of ANCA-associated vasculitis: systematic review and metaanalysis. Autoimmunity reviews. 2013;12(12):1129-35. 
113. Simpson S, Jr., Blizzard L, Otahal P, Van der Mei I, Taylor B. Latitude is significantly associated with the prevalence of multiple sclerosis: a meta-analysis. Journal of neurology, neurosurgery, and psychiatry. 2011;82(10):1132-41.

114. Beretich BD, Beretich TM. Explaining multiple sclerosis prevalence by ultraviolet exposure: a geospatial analysis. Multiple sclerosis (Houndmills, Basingstoke, England). 2009;15(8):891-8.

115. Staples JA, Ponsonby AL, Lim LL, McMichael AJ. Ecologic analysis of some immunerelated disorders, including type 1 diabetes, in Australia: latitude, regional ultraviolet radiation, and disease prevalence. Environmental health perspectives. 2003;111(4):518-23.

116. Gatenby PA, Lucas RM, Engelsen O, Ponsonby AL, Clements M. Antineutrophil cytoplasmic antibody-associated vasculitides: could geographic patterns be explained by ambient ultraviolet radiation? Arthritis and rheumatism. 2009;61(10):1417-24.

117. Webb AR, Kline L, Holick MF. Influence of season and latitude on the cutaneous synthesis of vitamin D3: exposure to winter sunlight in Boston and Edmonton will not promote vitamin D3 synthesis in human skin. The Journal of clinical endocrinology and metabolism. 1988;67(2):373-8.

118. Arnson Y, Amital H, Shoenfeld Y. Vitamin D and autoimmunity: new aetiological and therapeutic considerations. Annals of the rheumatic diseases. 2007;66(9):1137-42.

119. Kallenberg CG. Pathogenesis of PR3-ANCA associated vasculitis. Journal of autoimmunity. 2008;30(1-2):29-36.

120. de Lind van Wijngaarden RA, van Rijn L, Hagen EC, Watts RA, Gregorini G, Tervaert JW, et al. Hypotheses on the etiology of antineutrophil cytoplasmic autoantibody associated vasculitis: the cause is hidden, but the result is known. Clinical journal of the American Society of Nephrology : CJASN. 2008;3(1):237-52.

121. Muniain MA, Moreno JC, Gonzalez Campora R. Wegener's granulomatosis in two sisters. Annals of the rheumatic diseases. 1986;45(5):417-21.

122. Nowack R, Lehmann H, Flores-Suarez LF, Nanhou A, van der Woude FJ. Familial occurrence of systemic vasculitis and rapidly progressive glomerulonephritis. American journal of kidney diseases : the official journal of the National Kidney Foundation. 1999;34(2):364-73.

123. Knight A, Sandin S, Askling J. Risks and relative risks of Wegener's granulomatosis among close relatives of patients with the disease. Arthritis and rheumatism. 2008;58(1):3027.

124. Rahmattulla C, Mooyaart AL, van Hooven D, Schoones JW, Bruijn JA, Dekkers OM, et al. Genetic variants in ANCA-associated vasculitis: a meta-analysis. Annals of the rheumatic diseases. 2016;75(9):1687-92.

125. Xie G, Roshandel D, Sherva R, Monach PA, Lu EY, Kung T, et al. Association of granulomatosis with polyangiitis (Wegener's) with HLA-DPB1*04 and SEMA6A gene variants: evidence from genome-wide analysis. Arthritis and rheumatism. 2013;65(9):245768.

126. de Serres FJ, Blanco I. Prevalence of alpha1-antitrypsin deficiency alleles PI*S and $\mathrm{PI}$ *Z worldwide and effective screening for each of the five phenotypic classes PI*MS, PI*MZ, PI*SS, PI*SZ, and PI*ZZ: a comprehensive review. Therapeutic advances in respiratory disease. 2012;6(5):277-95.

127. Watts RA, MacGregor AJ, Mackie SL. HLA allele variation as a potential explanation for the geographical distribution of granulomatosis with polyangiitis. Rheumatology (Oxford, England). 2015;54(2):359-62.

128. Novack SN, Pearson CM. Cyclophosphamide therapy in Wegener's granulomatosis. The New England journal of medicine. 1971;284(17):938-42. 
129. de Groot K, Harper L, Jayne DR, Flores Suarez LF, Gregorini G, Gross WL, et al. Pulse versus daily oral cyclophosphamide for induction of remission in antineutrophil cytoplasmic antibody-associated vasculitis: a randomized trial. Annals of internal medicine. 2009;150(10):670-80.

130. Stone JH, Merkel PA, Spiera R, Seo P, Langford CA, Hoffman GS, et al. Rituximab versus cyclophosphamide for ANCA-associated vasculitis. The New England journal of medicine. 2010;363(3):221-32.

131. Geetha D, Specks U, Stone JH, Merkel PA, Seo P, Spiera R, et al. Rituximab versus cyclophosphamide for ANCA-associated vasculitis with renal involvement. Journal of the American Society of Nephrology : JASN. 2015;26(4):976-85.

132. Jones RB, Tervaert JW, Hauser T, Luqmani R, Morgan MD, Peh CA, et al. Rituximab versus cyclophosphamide in ANCA-associated renal vasculitis. The New England journal of medicine. 2010;363(3):211-20.

133. Jones RB, Furuta S, Tervaert JW, Hauser T, Luqmani R, Morgan MD, et al. Rituximab versus cyclophosphamide in ANCA-associated renal vasculitis: 2-year results of a randomised trial. Annals of the rheumatic diseases. 2015;74(6):1178-82.

134. Ntatsaki E, Carruthers D, Chakravarty K, D'Cruz D, Harper L, Jayne D, et al. BSR and BHPR guideline for the management of adults with ANCA-associated vasculitis.

Rheumatology (Oxford, England). 2014;53(12):2306-9.

135. Yates M, Watts RA, Bajema IM, Cid MC, Crestani B, Hauser T, et al. EULAR/ERAEDTA recommendations for the management of ANCA-associated vasculitis. Annals of the rheumatic diseases. 2016;75(9):1583-94.

136. Jayne DR, Gaskin G, Rasmussen N, Abramowicz D, Ferrario F, Guillevin L, et al. Randomized trial of plasma exchange or high-dosage methylprednisolone as adjunctive therapy for severe renal vasculitis. Journal of the American Society of Nephrology : JASN. 2007;18(7):2180-8.

137. Walsh M, Merkel PA, Peh CA, Szpirt W, Guillevin L, Pusey CD, et al. Plasma exchange and glucocorticoid dosing in the treatment of anti-neutrophil cytoplasm antibody associated vasculitis (PEXIVAS): protocol for a randomized controlled trial. Trials. $2013 ; 14: 73$.

138. Walsh M MP, Jayne D. The Effects of Plasma Exchange and Reduced-Dose Glucocorticoids during Remission-Induction for Treatment of Severe ANCA-Associated Vasculitis [abstract]. Arthritis \& rheumatology (Hoboken, NJ). 2018;70 (suppl 10). 139. De Groot K, Rasmussen N, Bacon PA, Tervaert JW, Feighery C, Gregorini G, et al. Randomized trial of cyclophosphamide versus methotrexate for induction of remission in early systemic antineutrophil cytoplasmic antibody-associated vasculitis. Arthritis and rheumatism. 2005;52(8):2461-9.

140. Jones RB, Hiemstra TF, Ballarin J, Blockmans DE, Brogan P, Bruchfeld A, et al. Mycophenolate mofetil versus cyclophosphamide for remission induction in ANCAassociated vasculitis: a randomised, non-inferiority trial. Annals of the rheumatic diseases. 2019;78(3):399-405.

141. Faurschou M, Westman K, Rasmussen N, de Groot K, Flossmann O, Hoglund P, et al. Brief Report: long-term outcome of a randomized clinical trial comparing methotrexate to cyclophosphamide for remission induction in early systemic antineutrophil cytoplasmic antibody-associated vasculitis. Arthritis and rheumatism. 2012;64(10):3472-7.

142. Jayne D, Rasmussen N, Andrassy K, Bacon P, Tervaert JW, Dadoniene J, et al. A randomized trial of maintenance therapy for vasculitis associated with antineutrophil cytoplasmic autoantibodies. The New England journal of medicine. 2003;349(1):36-44. 
143. Karras A, Pagnoux C, Haubitz M, Groot K, Puechal X, Tervaert JWC, et al. Randomised controlled trial of prolonged treatment in the remission phase of ANCAassociated vasculitis. Annals of the rheumatic diseases. 2017;76(10):1662-8.

144. Pagnoux C, Mahr A, Hamidou MA, Boffa JJ, Ruivard M, Ducroix JP, et al. Azathioprine or methotrexate maintenance for ANCA-associated vasculitis. The New England journal of medicine. 2008;359(26):2790-803.

145. Hiemstra TF, Walsh M, Mahr A, Savage CO, de Groot K, Harper L, et al. Mycophenolate mofetil vs azathioprine for remission maintenance in antineutrophil cytoplasmic antibody-associated vasculitis: a randomized controlled trial. Jama. 2010;304(21):2381-8.

146. Guillevin L, Pagnoux C, Karras A, Khouatra C, Aumaitre O, Cohen P, et al. Rituximab versus azathioprine for maintenance in ANCA-associated vasculitis. The New England journal of medicine. 2014;371(19):1771-80.

147. Charles P, Terrier B, Perrodeau E, Cohen P, Faguer S, Huart A, et al. Comparison of individually tailored versus fixed-schedule rituximab regimen to maintain ANCA-associated vasculitis remission: results of a multicentre, randomised controlled, phase III trial (MAINRITSAN2). Annals of the rheumatic diseases. 2018;77(8):1143-9.

148. Merkel PA, Aydin SZ, Boers M, Direskeneli H, Herlyn K, Seo P, et al. The OMERACT core set of outcome measures for use in clinical trials of ANCA-associated vasculitis. The Journal of rheumatology. 2011;38(7):1480-6.

149. Luqmani RA, Bacon PA, Moots RJ, Janssen BA, Pall A, Emery P, et al. Birmingham Vasculitis Activity Score (BVAS) in systemic necrotizing vasculitis. QJM : monthly journal of the Association of Physicians. 1994;87(11):671-8.

150. Flossmann O, Bacon P, de Groot K, Jayne D, Rasmussen N, Seo P, et al. Development of comprehensive disease assessment in systemic vasculitis. Annals of the rheumatic diseases. 2007;66(3):283-92.

151. Exley AR, Bacon PA, Luqmani RA, Kitas GD, Gordon C, Savage CO, et al. Development and initial validation of the Vasculitis Damage Index for the standardized clinical assessment of damage in the systemic vasculitides. Arthritis and rheumatism. 1997;40(2):371-80.

152. Exley AR, Bacon PA, Luqmani RA, Kitas GD, Carruthers DM, Moots R. Examination of disease severity in systemic vasculitis from the novel perspective of damage using the vasculitis damage index (VDI). British journal of rheumatology. 1998;37(1):57-63.

153. Robson J, Doll H, Suppiah R, Flossmann O, Harper L, Hoglund P, et al. Damage in the anca-associated vasculitides: long-term data from the European vasculitis study group (EUVAS) therapeutic trials. Annals of the rheumatic diseases. 2015;74(1):177-84.

154. Erwig LP, Savage CO. ANCA-associated vasculitides: advances in pathophysiology and treatment. The Netherlands journal of medicine. 2010;68(2):62-7.

155. Walton EW. Giant-cell granuloma of the respiratory tract (Wegener's granulomatosis). British medical journal. 1958;2(5091):265-70.

156. Westman KW, Selga D, Isberg PE, Bladstrom A, Olsson H. High proteinase 3-antineutrophil cytoplasmic antibody (ANCA) level measured by the capture enzyme-linked immunosorbent assay method is associated with decreased patient survival in ANCAassociated vasculitis with renal involvement. Journal of the American Society of Nephrology : JASN. 2003;14(11):2926-33.

157. Booth AD, Almond MK, Burns A, Ellis P, Gaskin G, Neild GH, et al. Outcome of ANCA-associated renal vasculitis: a 5-year retrospective study. American journal of kidney diseases : the official journal of the National Kidney Foundation. 2003;41(4):776-84.

158. Hoganson DD, From AM, Michet CJ. ANCA vasculitis in the elderly. Journal of clinical rheumatology : practical reports on rheumatic \& musculoskeletal diseases. 2008;14(2):78-81. 
159. Eriksson P, Jacobsson L, Lindell A, Nilsson JA, Skogh T. Improved outcome in Wegener's granulomatosis and microscopic polyangiitis? A retrospective analysis of 95 cases in two cohorts. Journal of internal medicine. 2009;265(4):496-506.

160. Slot MC, Tervaert JW, Franssen CF, Stegeman CA. Renal survival and prognostic factors in patients with PR3-ANCA associated vasculitis with renal involvement. Kidney international. 2003;63(2):670-7.

161. Chen M, Yu F, Zhang Y, Zhao MH. Antineutrophil cytoplasmic autoantibodyassociated vasculitis in older patients. Medicine. 2008;87(4):203-9.

162. Aasarod K, Iversen BM, Hammerstrom J, Bostad L, Vatten L, Jorstad S. Wegener's granulomatosis: clinical course in 108 patients with renal involvement. Nephrology, dialysis, transplantation : official publication of the European Dialysis and Transplant Association European Renal Association. 2000;15(5):611-8.

163. Little MA, Nightingale P, Verburgh CA, Hauser T, De Groot K, Savage C, et al. Early mortality in systemic vasculitis: relative contribution of adverse events and active vasculitis. Annals of the rheumatic diseases. 2010;69(6):1036-43.

164. Heijl C, Harper L, Flossmann O, Stucker I, Scott DG, Watts RA, et al. Incidence of malignancy in patients treated for antineutrophil cytoplasm antibody-associated vasculitis: follow-up data from European Vasculitis Study Group clinical trials. Annals of the rheumatic diseases. 2011;70(8):1415-21.

165. Faurschou M, Mellemkjaer L, Sorensen IJ, Svalgaard Thomsen B, Dreyer L, Baslund B. Increased morbidity from ischemic heart disease in patients with Wegener's granulomatosis. Arthritis and rheumatism. 2009;60(4):1187-92.

166. Faurschou M, Sorensen IJ, Mellemkjaer L, Loft AG, Thomsen BS, Tvede N, et al. Malignancies in Wegener's granulomatosis: incidence and relation to cyclophosphamide therapy in a cohort of 293 patients. The Journal of rheumatology. 2008;35(1):100-5. 167. Knight A, Askling J, Ekbom A. Cancer incidence in a population-based cohort of patients with Wegener's granulomatosis. Int J Cancer. 2002;100(1):82-5.

168. Holle JU, Gross WL, Latza U, Nolle B, Ambrosch P, Heller M, et al. Improved outcome in 445 patients with Wegener's granulomatosis in a German vasculitis center over four decades. Arthritis and rheumatism. 2011;63(1):257-66.

169. Westman K, Flossmann O, Gregorini G. The long-term outcomes of systemic vasculitis. Nephrology, dialysis, transplantation : official publication of the European Dialysis and Transplant Association - European Renal Association. 2015;30 Suppl 1:i60-6.

170. Berti A, Matteson EL, Crowson CS, Specks U, Cornec D. Risk of Cardiovascular Disease and Venous Thromboembolism Among Patients With Incident ANCA-Associated Vasculitis: A 20-Year Population-Based Cohort Study. Mayo Clin Proc. 2018;93(5):597-606. 171. Suppiah R, Judge A, Batra R, Flossmann O, Harper L, Hoglund P, et al. A model to predict cardiovascular events in patients with newly diagnosed Wegener's granulomatosis and microscopic polyangiitis. Arthritis care \& research. 2011;63(4):588-96.

172. Hogan SL, Nachman PH, Wilkman AS, Jennette JC, Falk RJ. Prognostic markers in patients with antineutrophil cytoplasmic autoantibody-associated microscopic polyangiitis and glomerulonephritis. Journal of the American Society of Nephrology : JASN. 1996;7(1):23-32. 173. de Joode AA, Sanders JS, Stegeman CA. Renal survival in proteinase 3 and myeloperoxidase ANCA-associated systemic vasculitis. Clinical journal of the American Society of Nephrology : CJASN. 2013;8(10):1709-17.

174. Franssen CF, Gans RO, Arends B, Hageluken C, ter Wee PM, Gerlag PG, et al. Differences between anti-myeloperoxidase- and anti-proteinase 3-associated renal disease. Kidney international. 1995;47(1):193-9. 
175. Hauer HA, Bajema IM, van Houwelingen HC, Ferrario F, Noel LH, Waldherr R, et al. Renal histology in ANCA-associated vasculitis: differences between diagnostic and serologic subgroups. Kidney international. 2002;61(1):80-9.

176. Weidner S, Geuss S, Hafezi-Rachti S, Wonka A, Rupprecht HD. ANCA-associated vasculitis with renal involvement: an outcome analysis. Nephrology, dialysis, transplantation : official publication of the European Dialysis and Transplant Association - European Renal Association. 2004;19(6):1403-11.

177. Lionaki S, Hogan SL, Jennette CE, Hu Y, Hamra JB, Jennette JC, et al. The clinical course of ANCA small-vessel vasculitis on chronic dialysis. Kidney international. 2009;76(6):644-51.

178. Mohammad AJ, Bakoush O, Sturfelt G, Segelmark M. The extent and pattern of organ damage in small vessel vasculitis measured by the Vasculitis Damage Index (VDI). Scandinavian journal of rheumatology. 2009;38(4):268-75.

179. Seo P, Min YI, Holbrook JT, Hoffman GS, Merkel PA, Spiera R, et al. Damage caused by Wegener's granulomatosis and its treatment: prospective data from the Wegener's Granulomatosis Etanercept Trial (WGET). Arthritis and rheumatism. 2005;52(7):2168-78. 180. Westman KW, Bygren PG, Olsson H, Ranstam J, Wieslander J. Relapse rate, renal survival, and cancer morbidity in patients with Wegener's granulomatosis or microscopic polyangiitis with renal involvement. Journal of the American Society of Nephrology : JASN. 1998;9(5):842-52.

181. Koldingsnes W, Nossent JC. Baseline features and initial treatment as predictors of remission and relapse in Wegener's granulomatosis. The Journal of rheumatology. 2003;30(1):80-8.

182. Pagnoux C, Hogan SL, Chin H, Jennette JC, Falk RJ, Guillevin L, et al. Predictors of treatment resistance and relapse in antineutrophil cytoplasmic antibody-associated smallvessel vasculitis: comparison of two independent cohorts. Arthritis and rheumatism. 2008;58(9):2908-18.

183. Sriskandarajah S, Aasarod K, Skrede S, Knoop T, Reisaeter AV, Bjorneklett R. Improved prognosis in Norwegian patients with glomerulonephritis associated with antineutrophil cytoplasmic antibodies. Nephrology, dialysis, transplantation : official publication of the European Dialysis and Transplant Association - European Renal Association. 2015;30 Suppl 1:i67-75.

184. Segelmark M, Peters, B. Svenskt njurregister årsrapport 2018.

185. Moutzouris DA, Herlitz L, Appel GB, Markowitz GS, Freudenthal B, Radhakrishnan J, et al. Renal biopsy in the very elderly. Clinical journal of the American Society of Nephrology : CJASN. 2009;4(6):1073-82.

186. Haris A, Polner K, Aranyi J, Braunitzer H, Kaszas I, Mucsi I. Clinical outcomes of ANCA-associated vasculitis in elderly patients. International urology and nephrology. 2014;46(8):1595-600.

187. Krafcik SS, Covin RB, Lynch JP, 3rd, Sitrin RG. Wegener's granulomatosis in the elderly. Chest. 1996;109(2):430-7.

188. Manno RL, Seo P, Geetha D. Older patients with ANCA-associated vasculitis and dialysis dependent renal failure: a retrospective study. BMC nephrology. 2015;16:88.

189. Judge PK, Reschen ME, Haynes R, Sharples EJ. Outcomes of Elderly Patients with Anti-Neutrophil Cytoplasmic Autoantibody-Associated Vasculitis Treated with Immunosuppressive Therapy. Nephron. 2016;133(4):223-31.

190. Titeca-Beauport D, Francois A, Lobbedez T, Guerrot D, Launay D, Vrigneaud L, et al. Early predictors of one-year mortality in patients over 65 presenting with ANCA-associated renal vasculitis: a retrospective, multicentre study. BMC nephrology. 2018;19(1):317. 
191. Valiathan R, Ashman M, Asthana D. Effects of Ageing on the Immune System: Infants to Elderly. Scand J Immunol. 2016;83(4):255-66.

192. Jacobsen S, Petersen J, Ullman S, Junker P, Voss A, Rasmussen JM, et al. A multicentre study of 513 Danish patients with systemic lupus erythematosus. I. Disease manifestations and analyses of clinical subsets. Clinical rheumatology. 1998;17(6):468-77.

193. Alonso MD, Llorca J, Martinez-Vazquez F, Miranda-Filloy JA, Diaz de Teran T, Dierssen T, et al. Systemic lupus erythematosus in northwestern Spain: a 20-year epidemiologic study. Medicine. 2011;90(5):350-8.

194. Alarcon GS, McGwin G, Jr., Petri M, Reveille JD, Ramsey-Goldman R, Kimberly RP. Baseline characteristics of a multiethnic lupus cohort: PROFILE. Lupus. 2002;11(2):95-101. 195. Reppe Moe SE, Molberg O, Strom EH, Lerang K. Assessing the relative impact of lupus nephritis on mortality in a population-based systemic lupus erythematosus cohort. Lupus. 2019;28(7):818-25.

196. Borchers AT, Naguwa SM, Shoenfeld Y, Gershwin ME. The geoepidemiology of systemic lupus erythematosus. Autoimmunity reviews. 2010;9(5):A277-87.

197. Borchers AT, Leibushor N, Naguwa SM, Cheema GS, Shoenfeld Y, Gershwin ME. Lupus nephritis: a critical review. Autoimmunity reviews. 2012;12(2):174-94.

198. Rees F, Doherty M, Grainge MJ, Lanyon P, Zhang W. The worldwide incidence and prevalence of systemic lupus erythematosus: a systematic review of epidemiological studies. Rheumatology (Oxford, England). 2017;56(11):1945-61.

199. Danchenko N, Satia JA, Anthony MS. Epidemiology of systemic lupus erythematosus: a comparison of worldwide disease burden. Lupus. 2006;15(5):308-18.

200. Izmirly PM, Wan I, Sahl S, Buyon JP, Belmont HM, Salmon JE, et al. The Incidence and Prevalence of Systemic Lupus Erythematosus in New York County (Manhattan), New York: The Manhattan Lupus Surveillance Program. Arthritis \& rheumatology (Hoboken, NJ). 2017;69(10):2006-17.

201. Bastian HM, Roseman JM, McGwin G, Jr., Alarcon GS, Friedman AW, Fessler BJ, et al. Systemic lupus erythematosus in three ethnic groups. XII. Risk factors for lupus nephritis after diagnosis. Lupus. 2002;11(3):152-60.

202. Patel M, Clarke AM, Bruce IN, Symmons DP. The prevalence and incidence of biopsyproven lupus nephritis in the UK: Evidence of an ethnic gradient. Arthritis and rheumatism. 2006;54(9):2963-9.

203. Swaminathan S, Leung N, Lager DJ, Melton LJ, 3rd, Bergstralh EJ, Rohlinger A, et al. Changing incidence of glomerular disease in Olmsted County, Minnesota: a 30-year renal biopsy study. Clinical journal of the American Society of Nephrology : CJASN. 2006;1(3):483-7.

204. Eilertsen GO, Fismen S, Hanssen TA, Nossent JC. Decreased incidence of lupus nephritis in northern Norway is linked to increased use of antihypertensive and anticoagulant therapy. Nephrology, dialysis, transplantation : official publication of the European Dialysis and Transplant Association - European Renal Association. 2011;26(2):620-7.

205. Rivera F, Lopez-Gomez JM, Perez-Garcia R. Frequency of renal pathology in Spain 1994-1999. Nephrology, dialysis, transplantation : official publication of the European Dialysis and Transplant Association - European Renal Association. 2002;17(9):1594-602. 206. Maixnerova D, Jancova E, Skibova J, Rysava R, Rychlik I, Viklicky O, et al. Nationwide biopsy survey of renal diseases in the Czech Republic during the years 19942011. J Nephrol. 2015;28(1):39-49.

207. Zink C ES, Riehl J, Helmchen U, Gröne HJ, Floege J, Schlieper G. Trends of renal diseases in Germany: review of a regional biopsy database from 1990 to 2013. Clinical Kidney Journal. 2019:1-6. 
208. Niu Z, Zhang P, Tong Y. Value of HLA-DR genotype in systemic lupus erythematosus and lupus nephritis: a meta-analysis. Int J Rheum Dis. 2015;18(1):17-28.

209. Parks CG, de Souza Espindola Santos A, Barbhaiya M, Costenbader KH. Understanding the role of environmental factors in the development of systemic lupus erythematosus. Best practice \& research Clinical rheumatology. 2017;31(3):306-20.

210. Costenbader KH, Feskanich D, Stampfer MJ, Karlson EW. Reproductive and menopausal factors and risk of systemic lupus erythematosus in women. Arthritis and rheumatism. 2007;56(4):1251-62.

211. Bernier MO, Mikaeloff Y, Hudson M, Suissa S. Combined oral contraceptive use and the risk of systemic lupus erythematosus. Arthritis and rheumatism. 2009;61(4):476-81. 212. Costenbader KH, Kim DJ, Peerzada J, Lockman S, Nobles-Knight D, Petri M, et al. Cigarette smoking and the risk of systemic lupus erythematosus: a meta-analysis. Arthritis and rheumatism. 2004;50(3):849-57.

213. Barbhaiya M, Tedeschi SK, Lu B, Malspeis S, Kreps D, Sparks JA, et al. Cigarette smoking and the risk of systemic lupus erythematosus, overall and by anti-double stranded DNA antibody subtype, in the Nurses' Health Study cohorts. Annals of the rheumatic diseases. 2018;77(2):196-202.

214. Wang J, Pan HF, Ye DQ, Su H, Li XP. Moderate alcohol drinking might be protective for systemic lupus erythematosus: a systematic review and meta-analysis. Clinical rheumatology. 2008;27(12):1557-63.

215. Barbhaiya M, Costenbader KH. Ultraviolet radiation and systemic lupus erythematosus. Lupus. 2014;23(6):588-95.

216. Fanouriakis A, Kostopoulou M, Alunno A, Aringer M, Bajema I, Boletis JN, et al. 2019 update of the EULAR recommendations for the management of systemic lupus erythematosus. Annals of the rheumatic diseases. 2019;78(6):736-45.

217. Ruiz-Irastorza G, Ramos-Casals M, Brito-Zeron P, Khamashta MA. Clinical efficacy and side effects of antimalarials in systemic lupus erythematosus: a systematic review. Annals of the rheumatic diseases. 2010;69(1):20-8.

218. Appel GB, Contreras G, Dooley MA, Ginzler EM, Isenberg D, Jayne D, et al. Mycophenolate mofetil versus cyclophosphamide for induction treatment of lupus nephritis. Journal of the American Society of Nephrology : JASN. 2009;20(5):1103-12.

219. Houssiau FA, Vasconcelos C, D'Cruz D, Sebastiani GD, Garrido Ed Ede R, Danieli MG, et al. Immunosuppressive therapy in lupus nephritis: the Euro-Lupus Nephritis Trial, a randomized trial of low-dose versus high-dose intravenous cyclophosphamide. Arthritis and rheumatism. 2002;46(8):2121-31.

220. Houssiau FA, Vasconcelos C, D'Cruz D, Sebastiani GD, de Ramon Garrido E, Danieli MG, et al. The 10-year follow-up data of the Euro-Lupus Nephritis Trial comparing low-dose and high-dose intravenous cyclophosphamide. Annals of the rheumatic diseases.

2010;69(1):61-4.

221. Dooley MA, Jayne D, Ginzler EM, Isenberg D, Olsen NJ, Wofsy D, et al. Mycophenolate versus azathioprine as maintenance therapy for lupus nephritis. The New England journal of medicine. 2011;365(20):1886-95.

222. Liu Z, Zhang H, Liu Z, Xing C, Fu P, Ni Z, et al. Multitarget therapy for induction treatment of lupus nephritis: a randomized trial. Annals of internal medicine. 2015;162(1):1826.

223. Zhang H, Liu Z, Zhou M, Liu Z, Chen J, Xing C, et al. Multitarget Therapy for Maintenance Treatment of Lupus Nephritis. Journal of the American Society of Nephrology : JASN. 2017;28(12):3671-8. 
224. Mok CC, To CH, Yu KL, Ho LY. Combined low-dose mycophenolate mofetil and tacrolimus for lupus nephritis with suboptimal response to standard therapy: a 12-month prospective study. Lupus. 2013;22(11):1135-41.

225. Kasitanon N, Boripatkosol P, Louthrenoo W. Response to combination of mycophenolate mofetil, cyclosporin A and corticosteroid treatment in lupus nephritis patients with persistent proteinuria. Int J Rheum Dis. 2018;21(1):200-7.

226. Rovin BH, Solomons N, Pendergraft WF, 3rd, Dooley MA, Tumlin J, Romero-Diaz J, et al. A randomized, controlled double-blind study comparing the efficacy and safety of doseranging voclosporin with placebo in achieving remission in patients with active lupus nephritis. Kidney international. 2019;95(1):219-31.

227. Diaz-Lagares C, Croca S, Sangle S, Vital EM, Catapano F, Martinez-Berriotxoa A, et al. Efficacy of rituximab in 164 patients with biopsy-proven lupus nephritis: pooled data from European cohorts. Autoimmunity reviews. 2012;11(5):357-64.

228. Kasitanon N, Magder LS, Petri M. Predictors of survival in systemic lupus erythematosus. Medicine. 2006;85(3):147-56.

229. Nossent J, Cikes N, Kiss E, Marchesoni A, Nassonova V, Mosca M, et al. Current causes of death in systemic lupus erythematosus in Europe, 2000--2004: relation to disease activity and damage accrual. Lupus. 2007;16(5):309-17.

230. Borchers AT, Keen CL, Shoenfeld Y, Gershwin ME. Surviving the butterfly and the wolf: mortality trends in systemic lupus erythematosus. Autoimmunity reviews.

2004;3(6):423-53.

231. Contreras G, Lenz O, Pardo V, Borja E, Cely C, Iqbal K, et al. Outcomes in African Americans and Hispanics with lupus nephritis. Kidney international. 2006;69(10):1846-51. 232. Bernatsky S, Boivin JF, Joseph L, Manzi S, Ginzler E, Gladman DD, et al. Mortality in systemic lupus erythematosus. Arthritis and rheumatism. 2006;54(8):2550-7.

233. Lerang K, Gilboe IM, Steinar Thelle D, Gran JT. Mortality and years of potential life loss in systemic lupus erythematosus: a population-based cohort study. Lupus.

2014;23(14):1546-52.

234. Garen T, Lerang K, Hoffmann-Vold AM, Andersson H, Midtvedt O, Brunborg C, et al. Mortality and causes of death across the systemic connective tissue diseases and the primary systemic vasculitides. Rheumatology (Oxford, England). 2019;58(2):313-20.

235. Faurschou M, Dreyer L, Kamper AL, Starklint H, Jacobsen S. Long-term mortality and renal outcome in a cohort of 100 patients with lupus nephritis. Arthritis care \& research. 2010;62(6):873-80.

236. Yap DY, Tang CS, Ma MK, Lam MF, Chan TM. Survival analysis and causes of mortality in patients with lupus nephritis. Nephrology, dialysis, transplantation : official publication of the European Dialysis and Transplant Association - European Renal Association. 2012;27(8):3248-54.

237. Tektonidou MG, Dasgupta A, Ward MM. Risk of End-Stage Renal Disease in Patients With Lupus Nephritis, 1971-2015: A Systematic Review and Bayesian Meta-Analysis. Arthritis \& rheumatology (Hoboken, NJ). 2016;68(6):1432-41.

238. Berden AE, Ferrario F, Hagen EC, Jayne DR, Jennette JC, Joh K, et al. Histopathologic classification of ANCA-associated glomerulonephritis. Journal of the American Society of Nephrology : JASN. 2010;21(10):1628-36.

239. Bjorneklett R, Bostad L, Fismen AS. Prognosis and Histological Classification in Elderly Patients with ANCA-Glomerulonephritis: A Registry-Based Cohort Study. Biomed Res Int. 2018;2018:7581567.

240. Devaney KO, Travis WD, Hoffman G, Leavitt R, Lebovics R, Fauci AS. Interpretation of head and neck biopsies in Wegener's granulomatosis. A pathologic study of 126 biopsies in 70 patients. Am J Surg Pathol. 1990;14(6):555-64. 
241. Jennings CR, Jones NS, Dugar J, Powell RJ, Lowe J. Wegener's granulomatosis--a review of diagnosis and treatment in 53 subjects. Rhinology. 1998;36(4):188-91.

242. Travis WD, Hoffman GS, Leavitt RY, Pass HI, Fauci AS. Surgical pathology of the lung in Wegener's granulomatosis. Review of 87 open lung biopsies from 67 patients. Am J Surg Pathol. 1991;15(4):315-33.

243. Bandari J, Fuller TW, Turner capital I UiURM, D'Agostino LA. Renal biopsy for medical renal disease: indications and contraindications. Can J Urol. 2016;23(1):8121-6. 244. Perkowska-Ptasinska A, Bartczak A, Wagrowska-Danilewicz M, Halon A, Okon K, Wozniak A, et al. Clinicopathologic correlations of renal pathology in the adult population of Poland. Nephrology, dialysis, transplantation : official publication of the European Dialysis and Transplant Association - European Renal Association. 2017;32(suppl_2):ii209-ii18. 245. Almaani S, Meara A, Rovin BH. Update on Lupus Nephritis. Clinical journal of the American Society of Nephrology : CJASN. 2017;12(5):825-35.

246. Weening JJ, D'Agati VD, Schwartz MM, Seshan SV, Alpers CE, Appel GB, et al. The classification of glomerulonephritis in systemic lupus erythematosus revisited. Journal of the American Society of Nephrology : JASN. 2004;15(2):241-50.

247. Jonsson H, Nived O, Sturfelt G, Silman A. Estimating the incidence of systemic lupus erythematosus in a defined population using multiple sources of retrieval. British journal of rheumatology. 1990;29(3):185-8.

248. Lam GK, Petri M. Assessment of systemic lupus erythematosus. Clinical and experimental rheumatology. 2005;23(5 Suppl 39):S120-32.

249. Levey AS, Bosch JP, Lewis JB, Greene T, Rogers N, Roth D. A more accurate method to estimate glomerular filtration rate from serum creatinine: a new prediction equation.

Modification of Diet in Renal Disease Study Group. Annals of internal medicine. 1999;130(6):461-70.

250. STRÅNG - a mesoscale model for solar radiation [Available from:

http://strang.smhi.se/].

251. Davies SJ, Russell L, Bryan J, Phillips L, Russell GI. Comorbidity, urea kinetics, and appetite in continuous ambulatory peritoneal dialysis patients: their interrelationship and prediction of survival. American journal of kidney diseases : the official journal of the National Kidney Foundation. 1995;26(2):353-61.

252. Tan EM, Cohen AS, Fries JF, Masi AT, McShane DJ, Rothfield NF, et al. The 1982 revised criteria for the classification of systemic lupus erythematosus. Arthritis and rheumatism. 1982;25(11):1271-7.

253. Watts RA, Scott DG, Jayne DR, Ito-Ihara T, Muso E, Fujimoto S, et al. Renal vasculitis in Japan and the UK--are there differences in epidemiology and clinical phenotype? Nephrology, dialysis, transplantation : official publication of the European Dialysis and Transplant Association - European Renal Association. 2008;23(12):3928-31.

254. Stahl-Hallengren C, Jonsen A, Nived O, Sturfelt G. Incidence studies of systemic lupus erythematosus in Southern Sweden: increasing age, decreasing frequency of renal manifestations and good prognosis. The Journal of rheumatology. 2000;27(3):685-91. 255. Singh RR, Yen EY. SLE mortality remains disproportionately high, despite improvements over the last decade. Lupus. 2018;27(10):1577-81.

256. Rihova Z, Jancova E, Merta M, Rysava R, Reiterova J, Zabka J, et al. Long-term outcome of patients with antineutrophil cytoplasmic autoantibody-associated vasculitis with renal involvement. Kidney \& blood pressure research. 2005;28(3):144-52.

257. Hedger N, Stevens J, Drey N, Walker S, Roderick P. Incidence and outcome of pauciimmune rapidly progressive glomerulonephritis in Wessex, UK: a 10-year retrospective study. Nephrology, dialysis, transplantation : official publication of the European Dialysis and Transplant Association - European Renal Association. 2000;15(10):1593-9. 
258. Rhee RL, Hogan SL, Poulton CJ, McGregor JA, Landis JR, Falk RJ, et al. Trends in Long-Term Outcomes Among Patients With Antineutrophil Cytoplasmic AntibodyAssociated Vasculitis With Renal Disease. Arthritis \& rheumatology (Hoboken, NJ). 2016;68(7):1711-20.

259. Whatmough S, Fernandez S, Sweeney N, Howell L, Dhaygude A. Comparing outcomes of biopsy-proven anti-neutrophil cytoplasmic autoantibody-associated glomerulonephritis patients treated with cyclophosphamide in the 20th and 21st centuries: a 23-year study. Clin Kidney J. 2019;12(1):42-8.

260. Stone JH. Limited versus severe Wegener's granulomatosis: baseline data on patients in the Wegener's granulomatosis etanercept trial. Arthritis and rheumatism. 2003;48(8):2299309.

261. Novembre J, Johnson T, Bryc K, Kutalik Z, Boyko AR, Auton A, et al. Genes mirror geography within Europe. Nature. 2008;456(7218):98-101.

262. Pearce FA, Craven A, Merkel PA, Luqmani RA, Watts RA. Global ethnic and geographic differences in the clinical presentations of anti-neutrophil cytoplasm antibodyassociated vasculitis. Rheumatology (Oxford, England). 2017;56(11):1962-9.

263. Sato S, Yashiro M, Matsuoka N, Asano T, Kobayashi H, Watanabe H, et al. Clinical features and outcomes in patients with elderly-onset anti-neutrophil cytoplasmic antibodyassociated vasculitis. Geriatrics \& gerontology international. 2018;18(10):1453-7.

264. Bomback AS, Appel GB, Radhakrishnan J, Shirazian S, Herlitz LC, Stokes B, et al. ANCA-associated glomerulonephritis in the very elderly. Kidney international. 2011;79(7):757-64.

265. Tan JA, Dehghan N, Chen W, Xie H, Esdaile JM, Avina-Zubieta JA. Mortality in ANCA-associated vasculitis: ameta-analysis of observational studies. Annals of the rheumatic diseases. 2017;76(9):1566-74.

266. Lee T, Gasim A, Derebail VK, Chung Y, McGregor JG, Lionaki S, et al. Predictors of treatment outcomes in ANCA-associated vasculitis with severe kidney failure. Clinical journal of the American Society of Nephrology : CJASN. 2014;9(5):905-13.

267. Robson J, Doll H, Suppiah R, Flossmann O, Harper L, Hoglund P, et al. Glucocorticoid treatment and damage in the anti-neutrophil cytoplasm antibody-associated vasculitides: longterm data from the European Vasculitis Study Group trials. Rheumatology (Oxford, England). 2015;54(3):471-81.

268. Chanouzas D, McGregor JAG, Nightingale P, Salama AD, Szpirt WM, Basu N, et al. Intravenous pulse methylprednisolone for induction of remission in severe ANCA associated Vasculitis: a multi-center retrospective cohort study. BMC nephrology. 2019;20(1):58. 269. McGregor JG, Negrete-Lopez R, Poulton CJ, Kidd JM, Katsanos SL, Goetz L, et al. Adverse events and infectious burden, microbes and temporal outline from immunosuppressive therapy in antineutrophil cytoplasmic antibody-associated vasculitis with native renal function. Nephrology, dialysis, transplantation : official publication of the European Dialysis and Transplant Association - European Renal Association. 2015;30 Suppl 1:i171-81.

270. Wallace ZS, Lu N, Miloslavsky E, Unizony S, Stone JH, Choi HK. Nationwide Trends in Hospitalizations and In-Hospital Mortality in Granulomatosis With Polyangiitis

(Wegener's). Arthritis care \& research. 2017;69(6):915-21.

271. Socialstyrelsen. Diagnoser i slutenvård 2018 [Available from:

http://www.socialstyrelsen.se/statistic/statistikdatabas].

272. Goupil R, Brachemi S, Nadeau-Fredette AC, Deziel C, Troyanov Y, Lavergne V, et al. Lymphopenia and treatment-related infectious complications in ANCA-associated vasculitis. Clinical journal of the American Society of Nephrology : CJASN. 2013;8(3):416-23. 
273. Pepper RJ, McAdoo SP, Moran SM, Kelly D, Scott J, Hamour S, et al. A novel glucocorticoid-free maintenance regimen for anti-neutrophil cytoplasm antibody-associated vasculitis. Rheumatology (Oxford, England). 2019;58(2):260-8.

274. Pagnoux C, Quemeneur T, Ninet J, Diot E, Kyndt X, de Wazieres B, et al. Treatment of systemic necrotizing vasculitides in patients aged sixty-five years or older: results of a multicenter, open-label, randomized controlled trial of corticosteroid and cyclophosphamidebased induction therapy. Arthritis \& rheumatology (Hoboken, NJ). 2015;67(4):1117-27. 275. Mohammad AJ, Segelmark M, Smith R, Englund M, Nilsson JA, Westman K, et al. Severe Infection in Antineutrophil Cytoplasmic Antibody-associated Vasculitis. The Journal of rheumatology. 2017;44(10):1468-75.

276. Faurschou M, Obel N, Baslund B. Long-term risk and outcome of infection-related hospitalization in granulomatosis with polyangiitis: a nationwide population-based cohort study. Scandinavian journal of rheumatology. 2018;47(6):475-80.

277. Yang L, Xie H, Liu Z, Chen Y, Wang J, Zhang H, et al. Risk factors for infectious complications of ANCA-associated vasculitis: a cohort study. BMC nephrology. 2018;19(1):138.

278. Eriksson S SE. Etiska aspekter att tänka på i observationsforskning. Läkartidningen. 2013;110(5):220-2. 


\section{Papers}

The papers associated with this thesis have been removed for copyright reasons. For more details about these see:

http://urn.kb.se/resolve?urn=urn:nbn:se:liu:diva-161582 


\section{FACULTY OF MEDICINE AND HEALTH SCIENCES}

Linköping University Medical Dissertation No. 1701, 2019

Department of Nephrology and Department of Medical and Health Sciences

Linköping University

SE-581 83 Linköping, Sweden

www.liu.se 